University of Michigan Law School

University of Michigan Law School Scholarship Repository

Articles

Faculty Scholarship

1984

\title{
Rethinking the Substantive Rules for Custody Disputes in Divorce
}

David L. Chambers

University of Michigan Law School, dcham@umich.edu

Available at: https://repository.law.umich.edu/articles/657

Follow this and additional works at: https://repository.law.umich.edu/articles

Cart of the Courts Commons, Family Law Commons, Judges Commons, Juvenile Law Commons, and the Law and Gender Commons

\section{Recommended Citation}

Chambers, David L. "Rethinking the Substantive Rules for Custody Disputes in Divorce." Mich. L. Rev. 83 (1984): 477-569.

This Article is brought to you for free and open access by the Faculty Scholarship at University of Michigan Law School Scholarship Repository. It has been accepted for inclusion in Articles by an authorized administrator of University of Michigan Law School Scholarship Repository. For more information, please contact mlaw.repository@umich.edu. 


\title{
RETHINKING THE SUBSTANTIVE RULES FOR CUSTODY DISPUTES IN DIVORCE
}

\author{
David L. Chambers*
}

\section{CONTENTS}

I. The Difficulties of the Best-INTERests

StANDARD ............................... 480

II. The Goals of a Custody Determination ......... 486

A. Ways of Thinking About Children's Best Interests ... 487

B. The Case for Considering the Interests of Parents .... 499

III. INFORMATION BEARING ON RULES FOR SOLE

CUSTODY................................. 503

A. What We Know About the Needs of Children ...... 503

1. Research on the Children of Divorce .......... 504

2. The Indirect Evidence from Intact Families and Other Sources.......................... 515

a. The relevance of gender ............... 515

(1) Evidence favoring mothers because they are women ...................... 515

(2) Evidence favoring matching children with the parent of the same sex ........... 524

b. The relevance of primary-caretaker status .... 527

c. A counterweight: the higher earnings of men and the relevance of resources in general ..... 538

B. What We Know About the Needs of the Parents ..... 541

IV. INFORMATION BEARING ON RULES FOR JOINT PHYSICAL Custody ................................... 549

A. What We Know About the Needs of Children ...... 550

B. What We Know About the Needs of Parents ....... 557

V. New SubSTANTIVE STANDARDS FOR THE RESOlution of CUSTOdy DisPUTES ......................... 558

* Professor, University of Michigan Law School. A.B. 1962, Princeton University; LL.B. 1965, Harvard University. - Ed.

I am grateful to many people in other fields who took the time to meet with me and to review an early draft - most especially, Michael Lamb, Neil Kaiter, and Ross Thompson, as well as to Michael Wald, Don Duquette, Rick Lempert, Martha Minow, Terry Sandalow, Carl Schneider, Heather Wishik, and Frank Zimring, friends and colleagues in law teaching, and to Nancy Polikoff and Austin Sarat, all of whom have reviewed drafts or provided ideas. For their assistance in research I am in debt to Megan Dorsey, Mary Hendrickson, Andrew McKim, Jeffrey Pickar, and Christopher Wu. 
A. $\quad$ Rules for Sole Custody ..................... 558

B. Rules for Joint Custody ...................... 565

ConCLUSION ..................................... 568

A few states, mostly in the West and South, still retain a preference in custody disputes for placing young children with their mothers. ${ }^{1}$ In most other states, legislatures or courts have replaced the maternal presumption with a rule directing courts to be guided solely by the child's "welfare" or "best interests."2 A few legislatures have created a new preference for joint custody, directing courts to consider favorably requests by a parent for such arrangements, even over the objection of the other parent. ${ }^{3}$

This Article argues that the trend away from the maternal presumption is sensible, but that the current best-interests standard is both too broad and too narrow to be acceptable. It is too broad because the current standard provides too little guidance to courts, given the resources actually available to them, to enable them to reach sensible decisions about how a child's interests will actually be best served. As a guide to more satisfactory decisions, I suggest that judges applying the current test should adopt a loose assumption that the best interests of preschool children will be fostered by placing them with the parent, if there is one, who has provided a substantial majority of the day-to-day care for the child. At least one state supreme court has already adopted a preference for such "primary caretakers," 4 recasting the old maternal preference in a sex-neutral form. On the other hand, the best-interests standard is also too narrow, because, in some circumstances, the child's interests are not the only ones worthy of recognition in a custody dispute. I thus recommend that legislatures create a formal preference for primary caretakers, to advance both the inter-

1. Freed \& Foster, Divorce in the Fifty States: An Overview as of August 1, 1981, 7 FAM. L. REP. (BNA) 4049, $4063-64$ (table VIII E(2) \& (3)) (Oct. 20, 1981).

2. See Klaff, The Tender Years Doctrine: A Defense, 70 CALIF. L. REv. 335, 335-36 (1982). States with a best-interests standard often include a list of factors to be considered, but do not identify any single parental quality or any aspect of the parent-child relationship that is to be accorded dominant weight. As of 1981, 13 states had adopted laws explicitly directing courts not to consider parental gender in reaching a decision. See Freed \& Foster, supra note 1, at 4064 (table VIII E(6)).

3. See Scott \& Derdyn, Rethinking Joint Custody, 45 OHIo ST. L.J. 455,472 n.81, 474 n.87 (1984) (listing two states as having adopted a formal preference for joint custody and twelve others as having adopted a formal policy covering joint custody, including court-imposed joint custody; most do not distinguish joint legal from joint physical custody); see also note 322 infra.

4. See Garska v. McCoy, 278 S.E.2d 357, 362 (W. Va. 1981); see also Commonwealth ex rel Jordan v. Jordan, 302 Pa. Super. 421, 425, 448 A.2d 1113, 1115 (1982) ("We hold . . . that where two parents are both fit, and the child is of tender years, the trial court must give positive consideration to the parent who has been the primary caretaker.") (citation omitted). 
ests of young children caught in these disputes and, secondarily, the legitimate interests of primary caretakers.

The movement to encourage joint physical custody is wise but the movement to permit courts to impose joint custody is not. Legislatures thus should deny courts authority to disallow joint-custody arrangements agreed to by the parties, but remove the authority of courts to impose joint custody over the objections of either parent.

My search for factors present in all or most custody disputes that might serve courts as guides for decision has grown out of an unease with statutes that direct judges to place a child where her interests or welfare will be best served without the guidance of any rule creating a presumption for, or placing a burden of proof on, either party. Such statutes place extraordinary burdens on judges, encourage costly and painful litigation by parents, and probably (though unprovably) lead in many cases to placements for children that do not in fact best serve their needs. The first part of the Article traces briefly some of the difficulties courts face in applying the current standard.

Before recommending the replacement of the current approach with a new approach directing courts to give weight to one or more specific factors, the case must be made that considering such factors will advance the purposes that states should be seeking to serve when resolving disputes. Unfortunately, while all states and nearly all writers seem to accept a view that courts should resolve these disputes in the way that best serves the child's interests, there is no consistent view on what is meant by "children's interests" or "children's best interests." The second section of this Article thus seeks to clarify this notion, offering several conceivable ways of approaching a concept of children's interests and providing guidance for choosing among them. The Article then goes on to argue that children's interests, however defined, need not be the only interests reflected in rules for resolving custody disputes and that, in cases in which the child's interests do not point toward a particular placement, it would be wise, on certain sets of facts, to recognize the strong interests of one parent. Because of the scarcity of literature on the subject, the discussion of how courts should think about children's interests, and why and when courts should consider parents' interests is of substantial length and has become nearly as central to the focus of the Article as the inquiry into the evidence supporting any particular new rules.

A broad-ranging review of the available research fills most of the rest of the Article. Over the last two decades research on the family has flowered in this country. My review includes not only research bearing on the special consideration that might be accorded a parent 
who has been a primary caretaker, but also research bearing on the relevance of a parent's gender and the relevance of a parent's shared gender with a child. On the other hand, the review excludes research on some other parental qualities of likely importance to children, such as a parent's mental health or a parent's authoritarian or passive personality. I am seeking rules that parents, lawyers, and judges can apply, and apply easily, in all or the great majority of cases.

In the end, there is a disturbing tenuousness about the recommendations I am able to make. The research points with only a quivering finger toward the rules that I recommend. Indeed, the suggested rules rest in large part not on hard evidence but on theory, clinical observation, and even hunch - an educated hunch but a hunch nonetheless. That very tenuousness - and the fact that I am unable to recommend even a weak rule of thumb for children beyond preschool age - conveys most pressingly the need for more research on the effects on children of various custodial arrangements. It also suggests the need for developing ways of resolving divorce custody disputes without trials by procedures that help parents reflect sensibly on what arrangements will best serve their children's and their own needs. ${ }^{5}$ Nothing in this Article suggests that courts, even with a new presumption, can reach wiser decisions than parents. On the other hand, any new presumptions will affect not only the decisions of judges who apply them but also the planning and negotiating of the parents who know they will be applied. One danger of adopting a preference for primary caretakers is that it will loom too large in the negotiating process and cause secondary caretakers to yield custody even in cases in which a child would be better off with that parent. The counterbalancing hope is that in as many cases or more it can help remind parents of a factor that deserves more weight than they might be inclined to give it.

\section{The Difficulties of THE Best-INTERESTS StANDARD}

Over the history of this country, legislatures and courts have relied on various preferences or presumptions in custody disputes between parents - presumptions for fathers and later presumptions for mothers, presumptions against parents who commit adultery, and so forth. ${ }^{6}$ Today, judges in most states are directed to determine what

5. See Schepard, Philbuck \& Rabino, Ground Rules for Custody Mediation and Modification, 48 ALBANY L. REv. 616 (1984). Many states are now moving to provide mediation services to parents disputing over custody.

6. See, e.g., Klaff, supra note 2, at 337-42; Lauerman, Nonmarital Sexual Conduct and Child Custody, 46 U. CIN. L. Rev. 647, 649-53 (1977); Roth, The Tender Years Presumption in Child Custody Disputes, 15 J. FAM. L. 423, 425-28 (1976-77). 
placement will serve the child's "best interests,"7 a standard that seems wonderfully simple, egalitarian, and flexible.

By not assigning fixed weight to any single factor, the current statutes offer the important virtues of flexibility and adaptability. ${ }^{8}$ They encourage judges to assign each parental act, trait, or capacity whatever weight it appears to deserve on the facts of the particular case. They also accommodate changes in knowledge. No change in legislation is needed when new research reveals that linking parents with children of the same sex or placing children with an alcoholic parent is more or less wise than previously believed. Judges can simply adjust the weight they give the factor.

Decisions reached under open and flexible standards, however, are often regarded as arbitrary or overreaching. Many people criticize judges who decide custody cases for giving inappropriate expression to personal or sexist biases. In our peculiarly American tradition, the decisions are regarded not merely as arbitrary but as discriminatory as well. The father, if he loses, will believe that the judge was prejudiced in the mother's favor just because she is a woman. ${ }^{9}$ The mother, if she loses, will believe that the judge gave inappropriate weight to the father's better financial circumstances. ${ }^{10}$ These criticisms have some merit but reflect deeper, more fundamental problems in the best-interests standard. ${ }^{11}$ For our purposes there are two critical problems. The first is that to the extent that judges are applying the wrong values, it is in large part because legislatures have failed to convey a col-

7. See Klaff, supra note 2, at 335.

8. For these reasons, such open and flexible standards are familiar in American jurisprudence. See Kennedy, Form and Substance in Private Law Adjudication, 89 HARv. L. REv. 1685, 1687-88 (1976). Legislatures commonly adopt them when they trust judges (or some other public decisionmaker) to reflect appropriate values in their decisions and believe no fixed rule will provide sensible outcomes for the varied range of cases that will present themselves. Often framed in the language of a goal or goals, such standards are common when judges or administrators must fix relationships for the future. See O. FISS \& D. RENDLEMAN, INIUNCTIONS 104 08 (2d ed. 1984). Thus, judges in criminal cases are commonly accorded broad discretion to choose among types and lengths of sentences to serve unstated or broadly stated goals. Judges in school desegregation cases must choose among a variety of equitable remedies. The Federal Communications Commission decides among competing applicants for a television license under a loose and general standard. In each context, including the custody context, the decisionmaker tries to obtain accurate information about present circumstances in order to make loose predictions about the future under the possible alternative dispositions, and then picks among the alternatives in an effort to achieve the optimal balance among the values to be advanced.

9. See R. Doyle, The RAPE of the Male (1976); M. FranK, WinNing Custody (1983).

10. See, eg., Polikoff, Why Mothers Are Losing: A Brief Analysis of Criteria Used in Child Custody Determinations, 7 WoMEN's RTS. L. REP. 235, $237-39$ (1982); Uviller, Father's Rights and Feminism: The Maternal Presumption Revisited, 1 HARV. WOMEN's L.J. 107, 108-09 (1978).

11. The best single article on the difficulties of custody decisions in general and the bestinterests standard in particular is Mnookin, Child-Custody Adjudication: Judicial Functions in the Face of Indeterminacy, 39 LAW \& CONTEMP. PROBS., Summer 1975, at 226. 
lective social judgment about the right values. That is the subject of the next section, in which I try to suggest ways of giving content to a notion of children's interests in a democratic society. The other difficulty, and the one addressed here, is more mundane but no less serious. Regardless of what values judges apply, they do not obtain, and perhaps can never routinely obtain, reliable information about the child and the parents, and thus they cannot make sensible predictions or choices.

To be sure, some cases are easily decided: one parent is severely withdrawn and rarely speaks to his or her child or one parent has been seriously abusive. It appears, however, that in a large proportion of families the differences between the two parents in the quality of their relationships to their children and in their childrearing skills are more subtle, ${ }^{12}$ under any view of children's interests. If the trend toward fathers taking an increased role in childtending continues, ${ }^{13}$ it is probable that the incidence of cases in which the differences are subtle will grow.

Those who favor the current system believe that, even in these cases, courts can make the necessary assessments if aided by skilled mental health professionals who interview family members and observe each parent with the child. ${ }^{14}$ Yet, sadly, American courts rarely have available to them thorough examinations by mental health professionals of the sort that those professionals themselves recommend. ${ }^{15}$ In many places, including some large metropolitan areas, mental health professionals of any sort are only infrequently retained by either party or the court: the government does not provide them and only the well-heeled can afford them. ${ }^{16}$ In these cases, the judge has to rely

12. See notes 211-27 infra and accompanying text.

13. See Hoffman, Increased Fathering: Effects on the Mother, in FATHERHOOD AND FAMILY Policy 167 (M. Lamb \& E. Sagi eds. 1983).

14. See, e.g., 10 COMmittee on the Family, Group for the AdVANCEMENT of PSYChIATRY, PUB. No. 106, DivorCE, Child Custody aND THE FAMILY (1980) [hereinafter cited as COMMITTEE ON THE FAMILY]. The Uniform Marriage and Divorce Act [hereinafter cited as UMDA] provides for investigations and reports by a court social service agency in contested cases, on the ground that "[i]t is obvious that custody investigations . . . can be useful aids to the court." UMDA, supra, at § 405 commissioner's note, 9A U.L.A. 205 (1979).

15. See COMMITTEE ON THE FAMILY, supra note 14, at 915. Such standards may be unattainable in the real world. For example, psychiatrist Richard Gardner, in a recent book on custody evaluations, sets forth his view of the elements of a good examination and then provides two case studies that he suggests are representative. In one case he spent 18 hours with members of the family, in the other 19 hours - not counting, in either case, the time to prepare a written report or to prepare (or actually present) testimony in court. R. GARDNER, FAMILY EvALUATION IN CHILD CUSTODY LITIGATION apps. V-VI (1982). Gardner generally charges more than $\$ 2,000$ for his examinations.

16. Interviews with judges and staff of Friend of the Court, Detroit, Wayne County, Michigan, January 1981. 
on what she hears or observes in court. She almost never personally observes either parent with the child and usually hears testimony only from the parties and from partisan lay witnesses. ${ }^{17}$

Some courts do have staff workers who make recommendations regarding custody, but such workers often have only minimal training in child development and labor under caseloads that permit them to see the parents and children on only one or two brief occasions. States might, of course, seek to remedy the inadequacy of examinations by committing more public funds to providing skilled advisors to courts, ${ }^{18}$ but for the foreseeable future it seems highly unlikely that states, strapped for funds, will in fact make a greater commitment. For now, it seems more sensible for rules of custody to be based on a premise that modest resources, at best, will be available to the decisionmaker. As the West Virginia Supreme Court recently commented in the course of announcing a preference for primary caretakers in custody disputes, "[in] the average divorce proceeding intelligent determination of relative degrees of fitness requires a degree of precision of measurement which is not possible given the tools available to judges."19

Even if more resources for advisors could be made available, a more fundamental question persists. That question is whether it is possible for anyone to make reliable observations of parent-child relationships during the divorce period. ${ }^{20}$ The period shortly after separa-

17. Many of us have an image of custody litigation with high-paid counsel and batteries of psychiatrists battling for weeks on end - in its extreme form, the fights of the Pulitzers and the Vanderbilts. While there is little statistical information about those who fight, what little there is and my own observations in Michigan suggest that most of the cases involve middle-income couples who may be as angry as the rich, but whose hearings last only a few hours. See $\mathbf{K}$. Gersick, Fathers by Choice: Characteristics of Men Who Do and Do Not Seek Custody of Their Children Following Divorce 114 (Sept. 1975) (unpublished dissertation, Harvard University); see also Pearson \& Ring, Judicial Decision-Making in Contested Custody Cases, 21 J. FAM. L. 703, 712 (1983) (mean income of families in Colorado who contested custody between $\$ 1260$ and $\$ 1919$ per month). A review by the author in January, 1981, of a sample of reports by referees in custody disputes in Detroit indicates that the parties only infrequently hired experts.

18. The state of Colorado has, for example, established a Children's Diagnostic Center at the University of Colorado Medical Center in Denver. The Center, founded in 1955, performs examinations in divorce custody disputes. On average, each case requires 19 hours of contact with family members and case conferences among professionals. Jackson, Warner, Hormbein, Nelson \& Fortescue, Beyond the Best Interests of the Child Revisited: An Approach to Custody Evaluations, 3 J. Divorce 207, 208, 212 (1980).

19. Garska v. McCoy, 278 S.E.2d 357, 361 (W. Va. 1981).

20. Some critics believe that psychological testimony is rarely helpful. Others believe courts should rely on it heavily. Compare, e.g., Okpaku, Psychology: Impediment or Aid in Child Custody Cases?, 29 RuTGERS L. REV. 1117 (1976) (concluding that psychologists and psychiatrists are rarely useful), and Litwak, Gerber \& Fenster, The Proper Role of Psychology in Child Custody Disputes, 18 J. FAM. L. 269 (1979-80) (defending a narrow role), with Benedek \& Benedek, Participating in Child Custody Cases, in CHILd PsychiatRy AND THE LAW (P. Schetky \& E. Benedek eds. 1980), R. GaRdner, supra note 15, and Watson, Child Custody Problems, During Divorce, Weekly Psychiatry Update Series, Lesson 2, Vol. 2 (1977) (advocating very active roles). 
tion, when most struggles over custody occur, is abnormally stressful. ${ }^{21}$ During this period, the behavior of children and adults toward each other may bear little resemblance to the past or the future. As we will see, many mothers report that their nurturing qualities, the qualities we may most want to observe, seem to them dramatically impaired during the post-separation period when they are often absorbed by their own emotional needs. ${ }^{22}$ Children often respond to divorce with fear, anger, loneliness, or guilt. ${ }^{23}$ Even an expert who recognizes the problem of stress may not be able to determine how the children or adults would behave in its absence. ${ }^{24}$

There is, in addition, some evidence that the very process of separation and divorce can alter the quality of the relationship of a child to each of her parents in enduring ways that probably cannot be predicted at the time of separation. ${ }^{25}$ These short- and long-term reactions to the divorce period compound the difficulties of making reliable observations even under the best of circumstances. ${ }^{26}$ The fear I would

The issue here, however, is not whether psychologists or psychiatrists can do a better job than judges in making observations, but rather whether any of them can do an adequate job, given the stresses family members experience during the divorcing period.

21. See J. Wallerstein \& J. Kelly, SuRviving tHe BreaK-UP: How Children and PARENTS COPE WITH DIVORCE (1980), and the research of Hetherington, Cox, and Cox, both discussed extensively in the text at notes 91-107 infra.

22. Cf. J. WALLERSTEIN \& J. KeLLY, supra note 21 , at 31 (reporting $30 \%$ of mothers and fathers in a sample volunteering for counseling severely depressed after separation), 36.38 (discussing parents' diminished capacity to "parent" at the time of divorce).

23. See notes 94-105 infra and accompanying text.

24. I worry that experts do not sufficiently consider the effects of the divorcing period on the parent-child relationship. For example, Richard Gardner, a psychiatrist and author of a book about custody observations, see note 15 supra, recognizes in an earlier essay that "[c]ustody litigation is generally even fiercer and more psychologically devastating than traditional marital conflict." Gardner, The Psychiatrist as Impartial Expert in Custody Litigation, in ADvocATiNG FOR CHILDREN IN THE COURTS 455, 466 (A.B.A. National Institute 1979). Yet he makes dubious claims like the following about clinical observations of parents and children during the litigation period:

The child will put his or her head in the lap of the preferred parent when sitting between the parents in the family interview. The child will snuggle up to the warmer parent when shy and embarrassed in front of the stranger called a psychiatrist. These are the kinds of observations that provide the evaluation with its most convincing data.

Id. at 463 . It seems to me that there are many explanations other than the one Gardner offers for the child's behavior during the tense period of a divorce-custody struggle.

25. J. WALleRsTein \& J. Kelly, supra note 21, at 99-107. There are, of course, other events, unpredictable in the individual case at the time of separation, that are likely to affect the quality of the child's relationship to each parent. Most prominent among these is either parent's remarriage. See, e.g., Clingempeel \& Reppucci, Joint Custody After Divorce: Major Issues and Goals for Research, 91 Psychological BuLl. 102 (1982) (theorizing that the remarriage of either parent is likely to affect the success of joint-custody arrangements more than almost any other factor); J. WAILERSTEIN \& J. KeLLY, supra note 21, at 285-301.

26. For example, studies of young children's attachment to their parents conducted under "normal" circumstances have often found, to the researchers' chagrin, that a child who appears in a laboratory setting to have a warm and secure, or a poor and insecure, relationship with his mother or father on one occasion often looks very different to the same researchers later. See 
have is that, in the frequent cases in which there were not gross discrepancies in the quality of the relationships of the two parents to the child, the recommendation of the expert or the observations of the judge would be unduly colored by the stresses of the divorce process - by the parents' depression, anxiety, anger, and confusion and the child's reactions to it.

It is for these reasons that this Article seeks to explore the justifiability of new rules for decision that depend less on case-by-case inquiries. One approach, discussed at least half-seriously by more than one scholar, would be for courts to flip a coin in cases in which neither parent was obviously unfit. ${ }^{27}$ Most people, even parents who lose in court, would probably find such an approach callous, an evasion of responsibilities both to children and to "justice."28 The less radical approach of this Article is to explore the feasibility of a statutory preference based on some parental quality or characteristic that is readily identifiable, that is present in most or all cases, and that would suggest the placement in which a child would, on average, be better off under some acceptable view of children's interests. The most obvious characteristics to consider, because of their universality and ready identification, are parents' genders or shared gender with their child and, perhaps most promising, though sometimes less easy to determine, their role as a primary caretaker of the child.

Such new general rules should also rest ultimately on observations of children and their parents and thus the problems of making case-bycase decisions may arise in attempting to design such rules. Yet sometimes general rules framed in terms of some factor can be justified when case-by-case decisions based on the same factor would be impractical or impossible to make. Furthermore, a general rule based upon a factor of demonstrated importance may be desirable not merely because of the difficulties of individual assessments, but also because the relevance of a factor to the individual case may never be brought to the attention of the judge in a persuasive manner. During a typical trial with lay witnesses, a judge is unlikely to learn the weight that a parent's gender or primary-caretaker status deserves. Even judges who begin with a background sense that, for example, young children and primary caretakers have a special relationship, may find

Lamb, Thompson, Gardner, Charnov \& Estes, Security of Infantile Attachment as Assessed in the "Strange Situation": Its Study and Biological Interpretation, 7 BEHAVIORAL \& BRAIN SCIENCES 127 (1984).

27. See, e.g., J. GoldsteIn, A. FReud \& A. Solnit, BEyond THE BEST INTERESTS Of THE CHILd 153 n.12 (1973); Mnookin, supra note 11, at 289-91.

28. Mnookin, supra note 11 , at 290. 
their attention to that factor inappropriately deflected by mid-trial by a parent's unpleasant courtroom demeanor or by information about that parent's sexual activities. ${ }^{29}$

\section{The Goals of a Custody Determination}

When parents fight over custody during divorce, at least three sets of interests might be served by rules to resolve the dispute: the child's interest in being in the "better" setting, however that is defined; each parent's interests in maintaining contact with the child and in guiding the child's development; and society's interests in preventing the child from becoming seriously antisocial and, more debatably, in encouraging the development of the child into a "good citizen." 30 Current state statutes typically direct courts to consider only the interests of the child. ${ }^{31}$ The parents' separate interests are excluded from consideration, probably because they are assumed to be equal and thus to cancel each other out or because the interest of any one parent is considered insignificant when compared with the child's interest. The state's interests are ignored, at least overtly, probably in the belief that those interests can be adequately served by focusing on the child's needs alone. ${ }^{32}$ As we shall see however, because the "best interests of the

29. The high percentage of victories by secondary-caretaking fathers in some states in litigated cases, see, e.g., Weitzman \& Dixon, Child Custody Awards: Legal Standards and Empirical Patterns for Child Custody, Support and Visitation After Divorce, 12 U.C.D. L. REV. 471, 503-04 (1979), may be due in part to the fact that at trial, in the deluge of evidence of misconduct, something subtle and invisible like a special emotional tie between a primary caretaker and a child tends to be overlooked.

Legislatures that list factors that judges are to consider in resolving custody disputes commonly list first the quality of the child's emotional ties or relationship with each parent, see, e.g., UMDA, supra note 14 , at $\S 402$, but, at least in the judicial opinions I am able to find, few judges rest their decisions on a finding that the child has in fact a closer relationship to one parent than the other, or that one is a better parent. I am uncertain why this should be so, but there are at least three possibilities.

The first is that some judges may not believe that emotional ties are important. If legislatures do believe them important, a generalized rule resting on evidence about emotional ties might encourage or compel judges to bend to the legislature's will. The second is that most judges care about emotional ties, but simply cannot discern in most cases which parent has the closer tic with the child. If this is the case, a general rule grounded in empirical evidence should produce better decisions. The final explanation is that judges typically do have a hunch about the child's stronger ties to one parent, but are reluctant to reveal their hunch because of the wound it could infict on the other parent. In such cases, judges may rest their stated conclusions on some other ground that played less of a role or no role in their decisions, such as the comparative financial positions of the parents. If this is the case, a general rule, adequately grounded, should at least do no harm, though it may cause pain for the judges who must reveal more about their grounds for decision in cases in which their hunches run in the opposite direction of the preference.

30. See notes 49-51 infra and accompanying text.

31. See note 2 supra.

32. However, trial judges sometimes allude to the extra welfare costs that placement with the mother would entail as a reason for placement with the father, without discussing at all how the child's interests would be adversely affected. See, e.g., Saunders v. Saunders, No. V-65-76 (N.Y. 
child" are difficult to define, judges may in practice often think they are being guided by a child's needs when in fact they are affected by the needs or goals of the state (much like judges in juvenile courts who, as they send the teenage mugger to an institution, tell him that it is being done "for his own good").

There are good reasons for according the needs of children the dominant place in custody determinations. Divorce greatly disrupts the lives of children, causing deep and often lasting distress. ${ }^{33}$ For young children, the entire course of their development seems at issue. Moreover, of all family members, children are the ones least able to protect their own interests.

In this Section, I have set out to accomplish two tasks. The first is to develop some coherent views of "children's best interests" as a predicate for appraising factors that might be given weight in a custody dispute. The second is to make a case for openly taking parents' interests into account to a limited degree in framing custody rules.

\section{A. Ways of Thinking About Children's Best Interests}

In trying to determine a child's "best interests" in a custody dispute, what weight should a court accord to the fact that one of the parents has been the child's primary caretaker or is of the same sex as the child? Or to the fact that one parent is particularly warm and attentive to the child? It is not possible to prescribe how to take into account any parental quality until we come to grips with what it means for a child's life to be "better" in one setting than another. We must identify and prepare to defend some settings or outcomes for the child that are in some sense "better" than others.

Few writers or appellate courts have tried to define what makes some settings for a child "better" than others and, of those who have tried, few have explained why their "better" is better than others. In a nation tolerant of diverse approaches to childrearing, without a single national orthodoxy about what sorts of adults children should grow into, such an omission is understandable. Many state statutes duck the problem of definition and simply direct their courts to serve the child's "best interests" or "welfare" without providing any further guidance. Some statutes list factors to consider, such as the child's "relationship" with each parent, which sound helpful but do not reveal the goals the state is seeking to serve. ${ }^{34}$ All parents in custody

Fam. Ct., July 8, 1977), revd. on other grounds, 60 A.D.2d 701, 400 N.Y.S.2d 588 (1977) (mem.), discussed in Uviller, supra note 10, at 122.

33. See text at notes 91-102 infra.

34. Many states have adopted some version of $\S 402$ of the Uniform Marriage and Divorce 
disputes have had "relationships" with their children. What makes one relationship better than another?

The writings of most legal scholars and mental health professionals are also unhelpful. Some advocate careful inquiries by courts into the parent-child relationship, but, perhaps because they are writing for others with similar beliefs, either fail to make clear what the court is to look for or, if they do prescribe some particular factor that they consider especially important, fail to explain why that factor is more worthy of weight than others. ${ }^{35} \mathrm{~A}$ few writers, more reflective about the jurisprudential problems presented, point out the absence of a public consensus about childrearing and suggest that the absence of consensus makes it difficult or impossible to define "best interests" beyond some minimum of abuse. ${ }^{36}$ Robert Mnookin, for example, summed up with pained eloquence the difficulty of prescribing standards in custody disputes: "Deciding what is best for the child poses a question no less ultimate than the purposes and values of life itself. . . . [W]here is the judge to look for the set of values that should inform the choice of what is best . . .?"37 He has no answer to the question he poses and reluctantly endorses the current standard without adding more content to it.

The task of prescribing where the judge is to look for a set of values to guide decisions is indeed difficult, but it is not impossible. The first and critical task is to identify the appropriate source of values to guide decisions - to decide whose values are to guide decisions. I believe that can be done.

The concept of "children's best interests," unlike such concepts as distance or mass, has no objective content. Whenever the word "best" is used, one must always ask "according to whom?" The state, the parents, and the child might all be sources of views, worthy of consideration, about the child's interests and how best to serve them. The child's view might take either of two forms - the child's stated preference as to custody or a view of what we would expect this child, or

Act, which provides that the court shall consider "the interaction and interrelationship of the child with his parent or parents." UMDA, supra note 14 , at $\$ 402$.

35. See, e.g., COMMrTTEE ON THE FAMILY, supra note 14, which discusses at length the problems of custody decisionmaking, the steps that should be taken in an examination, and some factors that should be taken into account, but never discusses exactly what values the court should seek to advance or why those values, whatever they are, are more appropriate to consider than other values. See especially the discussion of five "broad guidelines that should be recognized and carefully weighed." Id. at 880-92; see also R. GARDNER, supra note 15, at 212-30; Benedek \& Benedek, New Child Custody Laws: Making Them Do What They Say, 42 AM. J. ORTHOPSYCHIATRY 825 (1972).

36. See, e.g., Mnookin, supra note 11, at 229, 260-61; Okpaku, supra note 20, at 1152-53.

37. See Mnookin, supra note 11 , at 260. 
children in general, to choose for themselves either now or from the hindsight of their own adulthood. The latter view, through the child's expected experience, needs more explanation and will be elaborated later. ${ }^{38}$ It is this view that I recommend adopting.

Outside of the context of custody disputes, it is the parents' view of a child's interests that normally controls in our society. Parents have the authority (shared inevitably with the child as she grows) to make the important decisions about their child's upbringing, including the decision about where the child should live. ${ }^{39}$ The United States Constitution has been read to protect the parents' authority to make such decisions for their children ${ }^{40}$ and might be read to require deference to divorcing parents' agreements to place custody with one of them. ${ }^{41}$ But when parents disagree about custody and fail to resolve their dispute between themselves, the state and its judges can no longer defer. ${ }^{42}$ Judges, in rare cases, may find that they can draw upon some shared views of the child's needs revealed by the parents' conduct during the marriage, ${ }^{43}$ but, in most cases, the judge will have to look beyond the warring parents for a source of values to resolve the dispute.

38. See notes 52-58 infra and accompanying text.

39. That parents need no one's consent to take their child with them when they move from one house to another is so clear in this country that no statutes are needed to confirm their authority. Rules to cover some unusual situations do exist, such as those that permit parents to designate by will the custodian for their child or to designate the guardian for their child when they face prolonged hospitalization.

40. See, e.g., Parham v. J.R., 442 U.S. 584, 602-04, 607 (1979) (upholding a state statute permitting parents to commit their children to mental hospitals with the concurrence of a physician, over the child's objections and without a court hearing); Pierce v. Society of Sisters, 268 U.S. 510, 534-35 (1925), and Meyer v. Nebraska, 262 U.S. 390, 401 (1923) (striking laws infringing on parents' decisions regarding education). To be sure, the Supreme Court's decisions are not always consistent and do not always place parental control above other social values. For an especially perceptive discussion of these cases, see Burt, The Constitution of the Family, 1979 SuP. CT. REV. 329; see also Hafen, The Constitutional Status of Marriage, Kinship, and Sexual Privacy - Balancing the Individual and Social Interests, 81 MicH. L. REV. 463 (1983); Developments in the Law - The Constitution and the Family, 93 HARV. L. REV. 1156, 1313-15 (1980) [hereinafter cited as Developments].

41. See Developments, supra note 40, at 1323-26.

42. States can try to force parents to agree by requiring that disputing parents mediate. See, e.g., CAL. Civ. CodE $\$ 4607$ (West Supp. 1985).

43. Imagine a case in which the parents had agreed before separating that their four-year-old child should be raised in the Greek Orthodox faith and had begun taking the child to religious services shortly before their separation. Now, at divorce, both parents plan to move, one to an urban center with a substantial Greek Orthodox community, the other to a small town with no Greek Orthodox church within a hundred miles. I believe it would be appropriate for a court to consider with favor the parent planning to move to the urban center because that parent would carry forward the parents' previously shared view of what will be best for the child and for the "family." The state has no appropriate view about religious training. The child might be perfectly happy not going to church or going to a church of another denomination. It is the parents' own view here that would be given independent weight. $C f$. T. v. H., 102 N.J. Super. 38, 40, 245 A.2d 221, 222 (Ch. Div. 1968), affd. per curiam on other grounds, 110 N.J. Super. 8, 264 A.2d 244 (App. Div. 1970). 
The second approach - through the child's stated view of her own interests - relies upon the child as her own source of values for decision. It can be defended on several grounds as the appropriate basis for resolving disputes over custody. First, it treats children more nearly as full citizens entitled, like other citizens, to control the decisions, or at least to influence the decisions, that affect their lives.44 Second, to the extent we wish to keep the state out of the business of defining the "good" family, it leaves the judgment in private hands. 45 Third, it recognizes that, in most cases, children are likely to do at least as good a job as judges in divining their interests. ${ }^{46}$ For all these reasons, a good case can be made for permitting an adolescent to resolve a custody dispute between her parents, except in unusual circumstances. ${ }^{47} \mathrm{~A}$ few states already have rules giving formal weight to the older child's preference. ${ }^{48}$ On the other hand, some children are too young to be able to express a preference. Others who are able to express a view may lack the capacity to understand their own needs to

44. The Supreme Court itself has recognized a constitutional right of minors, or at least "mature" minors, to make decisions on their own in some circumstances. See, e.g., Bellotti v. Baird, 443 U.S. 622 (1979) (statute requiring a minor to seek parental consent before a judicial authorization for an abortion could be granted held unconstitutional when the minor is "mature and fully competent"); Tinker v. Des Moines Indep. Comm. School Dist., 393 U.S. 503 (1969) (public school regulation forbidding students to wear armbands protesting the Vietnam war unconstitutional under the first amendment). Much has been written in the last two decades on the extent to which children should be treated as autonomous individuals entitled to make decisions. For a particularly strident defense of the position that children should have essentially the same rights as adults, including the right to choose where they live, see J. HoLT, EsCAPE FROM CHILdHOOD (1974). For a contrasting view, see Hafen, Children's Liberation and the New Egalitarianism: Some Reservations About Abandoning Youths to Their Rights, 1976 B.Y.U. L. REv. 605,651 . For a fine analysis and synthesis, see F. ZIMRING, THE CHANGING LEGAL World of ADOLESCENCE (1982).

45. See text at notes $49-52$ infra.

46. See the discussion above in Section I of the difficulties for judges in learning enough about a child's relationships and parents' capacities to make sensible choices. There is, on the other hand, a growing literature on the capacity of children to make reasoned decisions for themselves. For a helpful review see Ramsey, Representation of the Child in Protection Proceedings: The Determination of Decision-Making Capacity, 17 FAM. L.Q. 287, 309-20 (1983).

47. I have not tried to make that case in this Article. For the elements on which such a case can be built on the basis of children's capacities to make decisions, see E. Greenberg, An Empiri. cal Determination of the Competence of Children to Participate in Child Custody DecisionMaking (unpublished doctoral thesis, University of Illinois, Champaign-Urbana 1983); see also note 46 supra. Adolescent children often control their placement after a court order has been entered by simply moving to the home of the noncustodial parent and expressing a strong preference to stay there.

48. See Moskowitz, Divorce-Custody Dispositions: The Child's Wishes in Perspective, 18 Santa Clara L. Rev. 427, $431-34$ (1978) (discussing laws in Georgia, Ohio, and Utah); Siegel \& Hurley, The Role of the Child's Preference in Custody Proceedings, 11 FAM. L.Q. 1 (1977). Most other states permit or require the trial judge to consider the child's preference. See, e.g., UMDA, supra note 14 , at $\$ 402$ (2). In most such statutes, including the UMDA, it is unclear whether the child's wish is to be accorded weight because of the child's interest in making her own decision or merely because of the indirect evidence it provides of the child's interests as the court determines them. 
such a degree that the state believes judges can make a wiser choice for them. States may also prefer to have judges make the determination, even in cases of more mature children, out of a humane desire to spare them the pain of publicly rejecting one parent and the pain, in many cases, of being subjected to unpleasant threats or cajolery by one or both parents.

The third approach, through a state-prescribed view of children's interests, has strong appeal, but fails for different reasons. Judges in custody cases today may typically see themselves as giving voice to a state view of what is "better" or "worse" for children. What they are doing when giving expression to such a view is hard to say. Judges often conclude that one setting is better for children than another without explaining why. Some may see themselves as bluntly imposing what they believe that a majority of people in the community would say was better or worse for children, without forcing themselves to inquire why a child is better or worse off with such a parent. If that is all they are doing, we should find their conduct troubling in a nation with an ostensible commitment to cultural and ethnic diversity and to parental freedom to raise children in diverse ways. ${ }^{49}$ Across a very broad range, our nation has maintained a healthy agnosticism about "good" childrearing and "good" outcomes of childhood. To be sure, judges in custody cases are forced by circumstances to make choices, but, unless no other approach to decisionmaking is possible, we ought to ask of the state that it justify its choices between parents by more than a simple reference to majority preferences. ${ }^{50}$

Most judges probably believe that they are doing more. Yet is it possible to develop a state-prescribed view of children's interests that does not mindlessly refer to the majority's (or the judge's) preferences? My own belief is that any attempt to do so will end up speaking either in terms of placements that serve the state's own needs or interests

49. See, e.g., Moore v. City of East Cleveland, 431 U.S. 494, 506 (1977) (At issue was a zoning ordinance that blocked certain forms of extended family arrangements. The Court said, "the Constitution prevents East Cleveland from standardizing its children - and its adults - by forcing all to live in certain narrowly defined family patterns."); Pierce v. Society of Sisters, 268 U.S. 510, 535 (1925) (At issue was the authority of Oregon to compel all children to attend public schools. The Court said, "[t]he fundamental theory of liberty upon which all governments in this Union repose excludes any general power of the State to standardize its children by forcing them to accept instruction from public teachers only.").

50. In one sense, I may be exaggerating the degree to which decisions by individual judges in custody cases mark a significant state pronouncement on childrearing practices. After all, the individual judges' opinions, which often contain only skimpy statements of their reasons for reaching their results, are hardly major public pronouncements of state standards for childrearing. Moreover, the judge is not imposing an absolute state standard, but is merely choosing which of two parents the state prefers. The modestness of the state intrusion, however, does not in any way alter the conceptual difficulty for the conscientious judge. 
(not the child's) or in terms of placements that the child herself will find satisfying day by day or in the future.

Consider any quality of a parent or of a parent-child relationship that might be at issue in a custody case - one parent's tenderness or coldness or promiscuity or a child's particularly joyful or fearful relationship with one parent. Talk with someone about the reasons why the state might prefer, for the child's sake, a placement that provides the child access to or protection from such a quality. You might, for example, believe that such a quality will have an effect on the child's experience or character (either as an adult or child), such as making the child feel secure or depressed, or helping the child to become selfreliant or dependent. Whatever effect you foresee, ask yourself why you consider the effect good or bad for the child. I think you will discover that you talk either in terms of what that quality is likely to mean to the child as the child experiences it in the short- or long-term or in terms of how that quality may affect some asserted interest of the state itself. You will not find another coherent way for the state to talk about what is "good" for the child or what the child's "interests" are. In our system, the state, unlike parents, cannot turn to religious doctrine for guidance. If it turns to mental health professionals, it will find that they, in turn, ultimately rely either on a view of society's needs or, more likely, on their views of the child's expected experiences as a child or as an adult.

There are thus these two approaches: the state can openly define rules of custody to serve its own needs or it can turn to the child's expected experience. Regarding its own interests, the state might, for example, desire children who, as adults, will be self-sufficient, respectful of authority, cooperative, dependable, patriotic, and resistant to extramarital sex and consequently prefer the parent who best promotes those ends. I believe, however, that most Americans would be repulsed by a statute that abandoned a concern for the child's interests and baldly provided for the resolution of their custody in the manner that served the "best interests of the state." And well they should. Shaping children for the state's own ends is a common goal of collectivist societies, but our society is much more ambivalent about such a goal. With few exceptions, we are committed to leaving to parents the task of choosing and shaping children's values and personal qualities. $^{51}$ In a custody dispute, when we can no longer turn to the par-

51. There can be little doubt that the state has an interest in preventing children from becoming delinquents. As a practical matter, however, it is difficult to bring that interest to bear in resolving custody disputes because of the impossibility of accurately forecasting delinquency as a consequence of any particular placement. Whether or not the state has a legitimate interest in creating "good citizens" through custody placements is more controversial. In this country, at- 
ents, most of us would still feel uncomfortable recruiting the child for the goals of the state. Most of us would feel comfortable preferring the parent who would help the child become self-reliant or cooperative only to the extent that we can make a case for the value of those qualities as they are experienced by the child herself.

We are left then, I believe, with defining children's interests through the child's own expected experience. Under this approach, in those cases in which the court cannot rely, or chooses not to rely, on the child's stated preference, the question the court would ask is not what the state has defined as "good" in the abstract. Rather, it would ask one of two other questions. In the case of a child who has demonstrated clear patterns of preferences and patterns of relationships with her parents, the question for the judge is which placement will this child experience most positively, both on a day-to-day basis while growing up, and from the vantage of her own adulthood. Much of this approach has been adopted in recent writing about paternalistic decisions for adults who are, for example, in comas or severely mentally ill, 52 and has sometimes been referred to by courts as a doctrine of "substituted judgment."53

tempts to instill patriotism or respect for authority would be seen by many as an illegitimate attempt to sustain the current government in power or an inappropriate attempt to instill particular moral beliefs. See generally M. YUDOF, WHEN GovernMENT SPEAKs (1983) (examining the legitimacy of government expression in a democracy); see also Justice Powell's opinion in Belloti v. Baird, 443 U.S. 622, 638 (1979) ("[A]ffirmative sponsorship of particular ethical, religious, or political beliefs is something we expect the State not to attempt in a society constitutionally committed to the ideal of individual liberty and freedom of choice.") (emphasis in original).

On the other hand, through public schools, the state inevitably seeks to instill values and promote certain individual qualities, partially to serve its own ends. Most of us accept this attribute of public education as an unavoidable by-product of a system that is valuable for the child's own sake. Virtually no one, however, would argue that it would be appropriate for governments to invoke child neglect statutes to remove the children from intact families solely because the parents were doing an inadequate job of instilling some value, such as cooperativeness or politeness, that the state would promote through the public schools for its own ends. A custody dispute in which one parent is seen as more likely than the other to instill such a quality in a child falls somewhere in the middle. There is not the same degree of intrusion on family privacy and autonomy because the parents have turned to the government for a resolution of the problem and because the court will be placing the child with one of her parents. At the same time, the state that asserts its own interests in a custody decision does so at the price of devaluing the needs of a child at risk who deserves to have her concerns given high priority.

52. See J. RAwls, A Theory of Justice $248-49$ (1971); Dworkin, Paternalism in MoralITY AND THE LAW 107 (R. Wasserstrom ed. 1971); Dworkin, Paternalism: Some Second Thoughts, in Paternalism 105 (R. Sartorius ed. 1983); Hodson, The Principles of Paternalism, 14 AM. PHIL. Q. 61, 65 (1977); see also Developments in the Law - Civil Commitment of the Mentally Ill, 87 HARV. L. REV. 1190, 1220-22 (1974).

53. See, e.g., Superintendent of Belchertown State School v. Saikewicz, 373 Mass. 728, 370 N.E.2d 417 (1977) (applying substituted judgment doctrine to uphold lower court's decision not to administer certain kinds of painful treatment that had serious side-effects to an aging, severely retarded man dying of cancer). In its pure form, the notion of "substituted judgment" is intended to protect the now-disabled person's right of self-determination - a coherent though troublesome notion even when the now disabled person, before becoming disabled, had expressed what he wanted done for him when he became disabled. In the Saikewicz case, in which the dying 
In most cases, however, the court will probably have insufficient information to predict confidently the particular child's responses to the possible alternative placements. In these cases, the question for the judge is which placement would most children in comparable positions experience more positively, now and in hindsight. In such a case the court would be applying a reasonable person - or "reasonable child" - standard, ${ }^{54}$ drawing on as many characteristics of the particular child as it can. This approach recognizes that each child has a unique set of preferences and possibilities that are not fully knowable, but tries nonetheless to lure the judge into looking at the possible placements through the eyes of a child. In many cases, judges will have to ask both sorts of questions - confident about some aspects of the particular child's responses, less confident about others.

This Article is not the place for a full elaboration and appraisal of this "child's experience" perspective. For our purposes, a few points need be made. First, there may be real differences in outcomes when using this approach in place of one that relies on developing a stateprescribed or majoritarian view of children's interests. This is true even though, at first blush, this slightly odd point of view - through the child's eyes, not out of the child's mouth - may appear to be merely a tortured way of describing a state-declared view of what is best for the child: we might presume that most children would want for themselves what most adults would want for children, and it is "most adults" who, through their representatives, would define a state view. But there are some qualities that most adults might want in children and believe were in children's best interests but that children themselves, even from the hindsight of their own adulthood, might believe less important or even irrelevant. Thus, most adults in this country might say it is "good" for children to grow up very respectful of adults or "bad" for children to grow up in a home with a parent who cohabits outside of wedlock or "good" for children to grow up

man had an IQ of 10 and had never been rational, the best that the court could do was to try to appraise the choices in terms of Saikewicz's apparent capacities, which seemed to be limited to comprehending present pleasure and present pain. In cases like Saikewicz, the task of the court is like the task described in the text for children about whose individual preferences and reactions the court believes it knows too little to make predictions. For critical analyses of Saikewicz and the difficulties of making these decisions, see Buchanan, The Limits of Proxy Decision-Making, in Paternalism 153 (R. Sartorius ed. 1983) and R. Burt, Taking Care OF Strangers 144-73 (1978). For the problems of applying this doctrine to young children facing decisions about major medical procedures, see WHo SPEAks for THE ChILD: THE PROBLEMS OF PROXY CoNSENT (W. Gaylin \& R. Macklin eds. 1982) (especially chapter 4 by A. Capron, chapter 6 by J. Dworkin, and chapter 9 by R. Macklin).

54. Cf. Buchanan, supra note 53, at 157 (arguing that a reasonable person standard should be used in determining whether to require continued medical treatment of a terminally ill person when no information exists to show the patient's preference). 
free of sexist stereotypes, but most children, so long as they had the benefit of other qualities such as love and physical security, might well be indifferent to these qualities as a child and feel no worse off as an adult for not having had them. ${ }^{55}$

The second point to be made is that there are positive, practical virtues to this approach. It is not just the least objectionable among several objectional possibilities. It places our focus squarely on the expected subjective sense of well-being of the person who has to live for the rest of her life with the choice the judge makes. It affirms that we care about how this person feels both now and later. In addition, it offers two advantages to judges. During custody hearings, it gives judges an understandable, if difficult, question to pose to themselves as they listen to the claims and accusations of the parties: not "is this parental trait or conduct that I'm hearing about 'good' for the child or "bad" for the child?" but "what is this trait or conduct likely to mean to the child as she experiences it?" Similarly, at the end of the proceeding, it offers judges a reasonably coherent point of view that can permit them, at least in theory, to make defensible choices between parents even in those cases in which both parents would be considered wholly "fit."s6

For all its advantages, however, this approach has many difficulties. It is usually difficult, even in the case of a disabled adult, to answer what a person would have wanted now or in hindsight if she had been in a position to choose. This question is especially problematic in the case of small children, who have little history of expressed or demonstrated preferences and for whom any choice that is made now will affect how they will look back on their childhood from the vantage of their adulthood. 57

In fact, in the many custody cases in which judges have little infor-

55. Some qualities might also be viewed as positive by both "most adults" and "most children," but not in the same way. In a case with an only child in which one parent planned remarriage to a person with children, most adults might believe it would be good for the child to have other siblings because it would keep her from becoming "too spoiled," whereas the child might value the step-siblings for their companionship.

56. Mnookin seems to conclude that there are no principled bases under a best-interests standard for making decisions in custody disputes except in cases in which one parent would neglect or abuse the child. See Mnookin, supra note 11, at 261-62. For the reasons stated in the text, I disagree. In my view, even cases involving direct state intervention for neglect or abuse can be better rationalized through the child's-experience point of view described here than through a theory of a state view of minimally acceptable parenting that Mnookin contemplates. Or, put another way, the state view of minimum parenting is best defined through a view of the "child's expected experience" in living in an "abusive" situation; rules about state intervention would rest on a balance of the child's interests so defined against other interests, such as parental autonomy.

57. Who Speaxs for the Child: The Problems of Proxy Consent, supra note 53, is a rare volume that addresses the question of paternalistic decisions made for children. In it, a group of lawyers, physicians, and philosophers discuss the standards that parents and courts 
mation about a particular child's special characteristics, judges may transform the elusive question about this child's likely reaction to the different custodial settings into the easier question of which parent the judge herself would prefer to live with. This transformation should not be regarded with great concern as long as the judge is striving to look at the world through a child's eyes, but the judge's vision can easily become blurred by adult moral judgments about what is "good" or "bad." This is admittedly a problem, but it nonetheless seems less likely that judges will impose their own values (or their perceptions of community values) under a standard that urges them to appraise the proposed custodial settings through the perspective of the children's subjective experience than under the typical statute today that gives them no guidance about how to think about children's interests. Moreover, what my approach asks the judge to do is psychologically tenable: it is possible to concentrate on understanding what it is likely to mean to this child to live with a strict (or a lax) disciplinarian rather than on asking what sort of disciplinarian do people believe it "best" for a child to have.

There are other problems as well, 58 but two that need emphasis are problems that apply almost equally to the other approaches. Whenever courts or legislatures try to serve a child's interests through a custody decision, they are almost inevitably concerned with the shortand long-term consequences of the possible placements. The "child"s

should apply in making decisions about risky medical procedures (such as transplanting an organ from one sibling to another or permitting a child to be a subject of medical experimentation).

Little of the other writing that I can find by philosophers focuses on decisions made on behalf of children. For example, a recent volume of essays entitled PATERNALISM (R. Sartorius ed. 1983) contains many general discussions of paternalism as well as whole chapters on the retarded and on voluntary civil commitment of the mentally ill, but, except for references to the parentchild relationship as metaphor in other discussions, the volume contains only a few scattered, brief discussions of the special issues raised by decisions made on behalf of children.

58. Consider two. First, some would condemn approaching custody decisions through the child's expected experience as hedonistic and amoral. The standard offers no conception of the good other than that which children, while children or later, experience as positive in their own terms. In one sense, this objection seems ill-considered. A court could find that a child experiences positively the instilling of some reasonably coherent moral code, see generally E. MACcoby, Social Development: Psychological Growth and the Parent-Child RELATIONSHIP 295-364 (1980) (tracing the development of a child's morality through the general process of growing and through discipline and reward), and thus prefer a parent who would provide moral guidance. The approach would limit severely the courts' freedom to prefer one parent's code over the other's.

Second, if one is genuinely committed to asking what this child would prefer both today and in hindsight, the approach may on occasion lead to results that many people, even people largely sympathetic to the approach, would consider unjustifiable. Consider, for example, the case of two parents, each reasonably strict in disciplining, but one of whom frequently gives the child expensive gifts. Or consider the case of a particular disturbed child who seems to experience positively a parental behavior such as severe beatings, that nearly everyone would say was not in her interest. We can even imagine this particular child as an adult looking back on the parent's behavior with masochistic pleasure and approval. 
eye view," like a state view of children's interests, leaves the court with the same difficult task, discussed in the preceding section, of learning enough about the child's current relationships with his parents and about the parents' other qualities to make forecasts of the consequences to the child of the alternative placements. Moreover, under this approach as under a state view, there will be many cases in which, having made rough forecasts, the judge will be unable to say that, from the child's perspective, one future seems preferable to the other. They will just seem different. There may in fact be even more such cases under this approach than under approaches in which the state is openly prescriptive about what is good for children; if so, this approach might be viewed as unhelpful by judges who are trying to reach decisions, but may in the end serve the value of prodding states toward other techniques (such as mediation) for resolving disputes without a state-imposed outcome or toward new general rules (such as a primary-caretaker preference) that are believed likely to produce better outcomes in most cases.

The second problem is that if one is trying, as I am, to devise new general rules or preferences based on this "child's experience" view, one must attempt in some systematic way to define some elemental qualities of life or personal characteristics that most children would want for themselves as they grow up and after they have grown. This is an exceedingly difficult task, but I believe it is possible to identify a few such qualities. In another context, John Rawls has attempted to define the qualities that a hypothetical person who did not know what place he would have in the world would wish from the state in which he was going to live - certain "primary goods" that the person would want whatever else he might want. 59

What a child would want from her parents is not the same as what a citizen would want from her state, but a comparable notion of certain "primary goods" within a family may be possible to develop. What, that is, are the essential qualities of a parent or a parent-child relationship that are necessary in order for a child to feel a sense of well-being during childhood and to become an adult with a sense of well-being? The starting point is a stark biological fact. Children are helpless at birth and cannot survive without the care of others. As infants, they need both dependable care and, for a sense of well-being,

59. See Rawls, supra note 52, at 90-95. Rawls in fact argues that in making paternalistic decisions on behalf of a child or other person whose preferences are unknown, we should be guided by a theory of "primary goods," "act[ing] for him as we would act for ourselves from the standpoint of the original position. We try to get for him the things he presumably wants whatever else he wants." Id. at 249. 
a sense that they are loved, valued, and protected by those who take care of them. ${ }^{60}$ As the child grows, the same qualities retain importance (though in differing degrees) and are joined by other qualities also essential to a sense of well-being. Most globally, the need is for a growing sense of competence - competence within the world around the child, competence (in the child's own view) to relate successfully to other people and competence (again, in the child's own view) to function as a productive member of the society. ${ }^{61}$ Throughout the period from infancy to adulthood, children's relationships with their parents and parental traits and conduct need to be thought of not merely as instruments for the child's future ("What will this help the child become?"), but also as important contemporaneously ("Will this be experienced positively at the time?"). And, although there may well be tension between what a child will experience as positive at the moment and what the same child will look back upon positively later - a tension between immediate gratification and growth - both perspectives need to be kept in mind.

These qualities, which I would identify as important in a child'sexperience perspective, may sound suspiciously like qualities that a majority of citizens would say were "good" for the child and that the state would want a child to have to serve its own ends. I believe, however, that at this elemental level, though only at this elemental level, the various perspectives on children's interests are likely to coincide. Though the state might regard some other qualities as nearly as important for the child, ${ }^{62}$ it would probably include these qualities of childhood and adulthood high on the list.

Thus, as we move on in this Article to appraise a preference in

60. Michael Wald has tried to identify such elemental qualities from the writings in child psychology, child development, and child placement in divorce. The list includes the following: the need to sustain a secure relationship with a parent figure, to feel valued by the parent figure, to enjoy his childhood day by day, and to develop a range of capacities to function as an adult, most particularly, to be able to love, to have a sense of self-worth, and to have a sense of control over his life. The child of divorce who has known both parents will also want the opportunity for regular contact with both parents in a conflict-free setting. The writers upon whom he draws are not self-consciously building a theory of "primary goods," but the qualities listed are remarkably consistent with the child's eye perspective argued for in this Article. (Conversations with Wald, 1984-85.).

61. See the writings of Erik Erikson, such as CHILDHOOD AND SOCIETY (1950). See also Freud's view of the mentally healthy person as someone who is able to love and to work. Others have expanded Freud's notion of the capacity to love and to work into a notion of a capacity for both "work and enjoyment," with enjoyment including not only satisfying interaction with others, but also pleasure in one's own achievements. See O. FANISHEL, THE PsYchoANALYTIC THEORY OF NEUROSIS 581 (1945).

62. Under a state-defined view of children's needs, some other qualities, such as the child's adherence to some set of conventional moral norms, might be considered especially important, but they are unlikely to be considered more important than these qualities that relate so centrally to people's capacities to live day by day without debilitating anxiety or depression. 
custody disputes for placement with mothers, primary caretakers, and the parent of the same sex as the child and for placement in joint custody, we will be asking whether these placements will advance one or more of these identified qualities - of feeling loved, secure, and valued; of developing the capacity to function productively as an adult; and so forth - and leave to another day a fuller defense and elaboration of the child's experience perspective.

\section{B. The Case for Considering the Interests of Parents}

The struggle in the preceding section to define a perspective through which to view children's interests reflects the belief that children's interests are of paramount importance in resolving issues of custody. As stated above, all states expect courts to make the children's interests the sole focus of their attention. The parents' interests are to be ignored. ${ }^{63}$ Yet adult interests need not be ignored as a matter of first principle and probably should not be as a matter of sensible policy so long as they can be kept subordinate to the interests of children.

Today, states take into account the interests of parents in framing standards for custody disputes in settings other than divorce. When, for example, a biological parent contests custody with a third party such as a grandparent or a foster parent, most states retain a presumption in favor of the biological parent. ${ }^{64}$ Why they retain such a presumption is rarely made clear. Legislators may believe in a mysterious bond between children and their biological parents that will serve the child's interests. At bottom, however, the presumption probably rests on an unexpressed but wholly defensible desire to protect the interests of adult citizens in bearing and raising their own children. ${ }^{65}$ Even in divorce cases, many states recognize the needs of the noncustodial parent in fixing standards for visitation; ${ }^{66}$ and courts have similarly begun

63. Courts rarely have occasion to reject explicitly any concern about parents. But see, e.g., In re Marriage of Tweeten, 172 Mont. 404, 407, 563 P.2d 1141, 1143 (1977) ("[1]t is important to remember the best interest of the parent, or detriment to the parent, is not the test."), overruled by Markegard v. Markegard, 616 P.2d 323 (Mont. 1980) (overruled only insofar as Tweeten supported the "tender years presumption").

64. See H. Clark, The LAw OF Domestic Relations IN THE UNITED States $\$ 17.5$ (1968); Note, Psychological Parents vs. Biological Parents: The Courts' Response to New Directions in Child Custody Dispute Resolutions, 17 J. FAM. L. 545 (1977).

65. See Richards, The Individual, the Family, and the Constitution: A Jurisprudential Perspective, 55 N.Y.U. L. REv. 1, 28 (1980) ("[P]arents also have rights of their own that, insofar as they do not impinge on the rights of children, deserve recognition. Child-rearing is one of the ways in which many people fulfill and express their deepest values about how life is to be lived.").

66. For example, $\$ 407$ (a) of the Uniform Marriage and Divorce Act, adopted in nine states as of 1984, frames the standard for visitation with a noncustodial parent not in terms of the "child's best interests," but rather as something to which the noncustodial parent is "entitled," unless "visitation would endanger seriously the child's physical, mental, moral or emotional health." UMDA, supra note 14 , at $\S 407$ (a). For an argument that post-divorce visitation is the 
to consider the needs of custodial parents when reviewing a custodial parent's request to move with the child to another state. ${ }^{67}$

In a custody proceeding during divorce, both parents face a loss of daily contact with their child that may be equal as measured in hours. Yet it does not follow that their interests are identical and cancel each other out. As an initial matter, the interests of each parent might be combined in support of rules favoring joint custody under certain circumstances. ${ }^{68}$ Moreover, even when single custody is at issue, the parents' interests may be of differing strength.

Consider your own reaction to a reasonably common case. A father who has been an involved but secondary caretaker plans to remarry immediately after the divorce becomes final. During a dispute over custody, he argues that he can provide the child, now two years old, with a two-parent home that includes a warm stepmother, who will serve as a full-time caretaker. On the other hand, he continues, the mother, who had been a full-time caretaker, has recently begun working at a job that pays much less than his job and relies on a daycare center to take care of their youngster. If we use the expected experience of the child as the test of the child's best interests, the father's arguments have considerable force: life might well be more pleasurable for the child in the father's home. (According to one observer, many judges accept such claims today in awarding custody to fathers. ${ }^{69}$ ) Yet many of us, if in the role of judge, would be likely to be affected by our sympathy for the devoted mother: We may believe that it is not fair to penalize her for her disadvantaged economic position $^{70}$ and sense a special loss for her if denied the intimate daily interaction with her child.

Part of this Article argues that, if certain facts can be shown, a

noncustodial parent's constitutional right, see Novinson, Post-Divorce Visitation: Untying the Triangular Knot, 1983 U. ILL. L. REv. 121, 124-39.

67. See Note, The Judicial Role in Post-Divorce Relocation Controversies, 35 STAN. L. REV. 949 (1983) (reporting conflicting positions among courts but taking a strong stand for letting the custodial parent decide when to move); see also D'Onofrio v. D'Onofrio, 144 N.J. Super. 200, 206, 365 A.2d 27, 30 (Ch. Div.) (considering, on deciding whether or not to allow a custodial parent to move, "the prospective advantages of the move in terms of its likely capacity for improving the general quality of life for both the custodial parent and the child"), affd. mem., 144 N.J. Super. 352, 365 A.2d 716 (App. Div. 1976).

68. See Developments, supra note 40 , at 1329 (arguing that a presumption for joint custody is constitutionally required to protect the interests of each parent in continuing contact with the child).

69. Polikoff, Gender and Child-Custody Determinations: Exploding the Myths, in FAMILIES, Polmics AND PUBLIC Policy 183, 190 (I. Diamond ed. 1983) [hereinafter cited as Polikof, Exploding the Myths]; Polikoff, supra note 10.

70. See text at notes 231-43 infra (discussing the relevance of men's more favorable economic position in the labor force). 
preference for primary caretakers would be justified to meet the needs of preschool children. ${ }^{71}$ The converse argument made here is that a preference for primary caretakers might also be wise for the sake of the primary caretaker. ${ }^{72}$ Two different sorts of principled arguments can be made for such a preference. The first is that primary caretakers deserve custody as a form of compensation for their years of providing care. ${ }^{73} \mathrm{It}$ is an argument with strong initial appeal ${ }^{74}$ - taking care of children requires great effort, persistence, and the subordination of personal needs - but it is, in the end, unpersuasive. As a broad moral principle, we should be reluctant to use children as "rewards" under any circumstances. ${ }^{75}$

Furthermore, it is not at all clear, even in the context of a traditional marriage, that the primary caretaker should be considered to have "earned" the child any more than the other parent. The other parent, usually today the father, has typically supported the family by working in the labor force. His earnings paid for the food the mother cooked and the clothes she washed. If the primary caretaker "deserves" the child because of her contributions as childraiser, then the other parent "deserves" to keep all stock and other assets held in his name, because they were acquired from his labors. ${ }^{76}$ Neither is a result

71. See Section III infra.

72. So far as I can find, no state has adopted the position argued for here. There are a couple of interesting, unusual appellate decisions in California that involved custody disputes in which one of the parents was physically disabled and in which the court, in part because of state statutes to protect the handicapped, openly took into account the handicapped parent's interest in having an opportunity to raise a child. In re Marriage of Carney, 24 Cal. 3d 725, 740-41, 598 P.2d 36, 44-45, 157 Cal. Rptr. 383, 391-92 (1979); In re Marriage of Levin, 102 Cal. App. 3d 981, 986-88, 162 Cal. Rptr. 757, 760-61 (1980).

73. See Polikoff, Exploding the Myths, supra note 69, at 196 (primary-caretaker mother deserves custody "because she has earned it by providing years of primary child care"); Uviller, supra note 10, at 129-30 (a preference for primary caretakers to compensate for economic discrimination). Uviller and Polikoff are concerned about judges who discriminate against mothers by assigning what the authors regard as unfair weight to men's economic advantages. See Polikoff, Exploding the Myths, supra note 69, at 189-90; Uviller, supra note 10, at 122-23.

74. The law of contribution, for example, forms a significant part of the law of restitution. See 1 G. Palmer, The LaW of Restitution $\$ 1.5(d)(1978)$.

75. Very similar reasoning has been used by courts to justify granting custody to a parent as a trophy for virtue when the other parent has committed a marital sin such as adultery. See, for example, the British case of $R e$ L., [1962] 3 All E.R. 1, 4 (C.A.), in which the mother had committed adultery. Lord Denning awarded custody to the father, saying, "It is a matter of simple justice between them that [the father] should have care and control. Whilst the welfare of the children is the first and paramount consideration, the claims of justice cannot be overlooked."

76. Of course, a primary-caretaking mother may not be in a position to bear more children, while the secondary caretaker is often in a position to start over in developing assets. Despite this, the secondary-caretaking father may still claim that his efforts as wage-earner directly benefited the child and that he "deserves" the child as much as the mother.

There is a related claim that applies only to primary-caretaking mothers. It is that women experience both public and private pressures, including pressures from their own husbands, to devote much of their lives to the raising of children and that it is unfair to place them in this role, 
that should be found very satisfying as a way of thinking about the breakup of the traditional "partnership" marriage. 7

A second argument for a preference for primary caretakers seems more persuasive. It starts with the assumption that what each parent has done is of equal "value" for the child and predicates a rule favoring primary caretakers on the notion that primary caretakers, regardless of gender, ${ }^{78}$ will in general be substantially more distressed by the loss of custody than will the other parent. Such a basis may seem patronizing and soft-headed - we prefer primary caretakers not because they deserve more but because we do not want to hurt them but it is in fact more justifiable. A rule would rest not on a dubious value judgment about contribution but rather on a desire to inflict the least total emotional harm on all the members of a family, in a context in which some emotional harm is inevitable under any resolution.

Before any special rule based on the needs of parents can be recommended, however, two issues need to be faced. First, the factual premises supporting such a rule need to be tested: Will primary caretakers in fact be more anguished by the loss of custody than secondary caretakers? An attempt to answer this question is one of the aims of the research review that follows.

The other issue is whether or not there are countervailing dangers in adopting rules for custody that take into account the needs of parents, even if a principled case can be made for doing so. There is a danger that, once courts or legislatures are unleashed to consider adult needs even secondarily, adult needs will eventually become primary. The fear is not idle. Today, adult groups frequently invoke the needs of children in behalf of new rules bearing on children, when the groups are in fact largely motivated by their own interests. Consider, for example, efforts by senior citizens' groups in support of laws that authorize courts to order grandparent visitation ${ }^{79}$ or efforts by some men's groups in support of laws that authorize courts to impose joint cus-

curtailing other opportunities, and then to take the children away from them upon divorce. Men can make a comparable argument about the pressures on them to be money makers.

77. The newly drafted Uniform Marital Property Act proposes that all states adopt laws very close to community property laws, providing that all assets acquired during the marriage be owned in equal shares by the parties. See UNIF. Marital ProperTY Act $\S 4$ (draft 1983).

78. Polikoff and Uviller both have argued for a preference based on parents' interests. Uviller argues for a maternal preference and Polikoff argues for a primary-caretaker preference regardless of gender. See notes 69, 73 supra.

79. After a flood of legislation in the 1960's and 1970's, at least 42 states now permit courts to order grandparent visitation in certain circumstances. See Freed \& Foster, Family Law in the Fifty States: An Overview, 16 FAM. L.Q. 289, 353-54 (1983). 
tody. ${ }^{80}$ While legitimating rules for custody that openly take into account adult needs may have the valuable effect of creating more honest and open legislative debate on the separate interests of adults and children, it also runs the risk, in a world ruled by adults, that legislatures will forget that children, not adults, are the most vulnerable participants in the divorce process. Once forgotten, the danger is the revival of rules permitting courts to use custody orders to reward the public virtue of one of the parents (such as one parent's marital fidelity). ${ }^{81}$ There is also the danger that states will openly assert some of their own crasser interests in the placement decision. It would, for example, be unfortunate if the development of a presumption for primary caretakers to benefit primary caretakers were seen as freeing the state to develop a presumption against the placement of a child with a parent already receiving or likely to receive public assistance simply to protect the interest of the state in saving money.

I regard these risks as serious. Adults cannot be trusted to keep their own needs in check. ${ }^{82}$ We live in a particularly self-indulgent era. At the same time, I continue to believe that, if primary caretakers do in fact typically suffer more than secondary caretakers upon loss of custody, their claims are compelling enough to justify the risks. We must hope that legislators will decide that giving weight to the emotional loss of primary caretakers is more important than giving weight to the financial loss to the taxpayers that occasionally comes from a decision placing children with a parent receiving welfare.

\section{Information BeARING ON RULES For SOle Custody}

\section{A. What We Know About the Needs of Children}

A predisposition toward placing children after divorce with their mothers, with primary caretakers, or with the parent of the same sex may be justified by a belief that children in such settings will receive more nurturing, feel more loved or secure, or, in the long term, be more competent and effective as adults. In this section, I appraise whether or not existing research provides any substantial support for such beliefs. I begin with research that directly studies children of

80. See Schulman \& Pitt, Second Thoughts on Joint Child Custody: Analysis of Legislation and its Implication for Women and Children, 12 GoldEN GATE L. REV. 538, 570-71 (1982).

81. See note 75 supra.

82. As Goldstein, Freud, and Solnit have argued, "Adults have deeply ingrained irrational reservations about the primacy of children's needs." J. GolDSTEIN, A. FrEUD \& A. SOLNIT, BEYOND THE BEST INTERESTS OF THE CHILD 106 (rev. ed. 1979) [hereinafter cited as BEYOND THE BEST INTERESTS]. I, like they, would accord children's needs the highest priority in decisions about custody in divorce. 
divorce in various settings and move to the more indirect evidence provided by research on the responsiveness of men and women in general to children and on the relation of children to each parent in intact families. ${ }^{83}$

\section{Research on the Children of Divorce}

In 1969, Phoebe Ellsworth and Robert Levy, in the course of the development of the Uniform Marriage and Divorce Act, reviewed at length the available research on divorced families and on children living in other than two-parent settings to "determine what was empirically known about the effects of various custodial awards and arrangements on the child's development." 84 They were disappointed. They did not find studies comparing children in different custodial settings after divorce. In fact, they could not find any studies of children with fathers after divorce or any studies of children living after divorce with mothers who had not been primary caretakers before divorce.

What they did find were studies of children who lived in institutions or other settings without either parent and studies of children living with primary-caretaker mothers with fathers absent. The studies of children raised in institutions reported deeply troubled children, but such studies had only the most oblique relevance to questions of divorce custody. The studies of children with their mothers alone found these children also, on average, more troubled and more troubling than children in two parent homes. Children, and especially boys, raised alone with mothers were reported to be more likely than children raised in two-parent families to have problems of cognitive development, sex role identification, and delinquency. ${ }^{85}$ But, as Ellsworth and Levy recognized, the question posed at divorce is not whether the children would be better off in a two-parent home but rather which of two single-parent homes would be better. Nothing in this early re-

83. Throughout this section, I am deeply indebted to Michael Lamb and Ross Thompson for directing me to relevant research. The discussions among the three of us led Thompson to write his own review of the same literature bearing on children's interests. It is more detailed in many respects than the review here and should be read by anyone with a serious interest in the subject. See Thompson, The Father's Case in Child Custody Disputes: The Contributions of Psychological Research, in FATHERHOOd AND FAMILY Policy 53 (M. Lamb \& A. Sagi eds. 1983). I am also indebted to Jeffrey Pickar, graduate student in the Department of Psychology, University of Michigan, for his review of my references and for his many helpful comments on an earlier draft.

84. Ellsworth \& Levy, Legislative Reform of Child Custody Adjudication: An Effort to Rely on Social Science Data in Formulating Legal Policies, 4 LAW \& SocY. REv. 167, 169 (1969).

85. There are many reviews of the "father-absent" literature. Among the most recent is Blechman, Are Children with One Parent at Psychological Risk? A Methodological Review, $44 \mathrm{~J}$. MARRIAGE \& FAM. 179 (1982). Among the best regarded reviews are M. RUTTER, THE QUALITY OF MOTHERING: MATERNAL Deprivation ReAsSEsSed (1974); Rutter, Maternal Deprivation, 1972-1978: New Findings, New Concepts, New Approaches, 50 CHILD DEv. 283 (1979). 
search could answer whether these children living with their mothers would have been any better off living with their fathers alone. Moreover, both before and after Ellsworth and Levy's review, researchers have questioned the soundness of the conclusion that the problems of children raised by one parent alone are attributable to the absence of the other parent, pointing to many methodological failings in the research. ${ }^{86}$ In the end, Ellsworth and Levy concluded that "social scientists have not yet provided very much useful information even about the central issue for most custody decisionmaking - how children are likely to fare under alternative custodial arrangements." 87 At best, the research suggested the questions to ask when research was later conducted on children in other settings.

In the fifteen years since Ellsworth and Levy wrote, the quantity of research on divorced families and children of divorce has multiplied several-fold. ${ }^{88}$ Although we are still far from learning all that we need to know, there is, today, a richer, more textured body of literature addressing the experience of children of divorce living with their mothers and a separate, far weaker but slowly growing body of research addressing the experience of children living with their fathers. The recent research moves us somewhat closer to answers to the questions posed in this Article, but also demonstrates again the need for more research in the future and the need, for present recommendations regarding policies, to rely as much or more on indirect evidence from research on children and their parents in intact families.

Of the recent research on children living after divorce with their mothers, most continues to be based on observations, questionnaires, or testing conducted at one point in time and most focuses on one or only a few dimensions of the experience of the mother and children. The tone of the research, however, has changed since the review by Levy and Ellsworth fifteen years ago. As social attitudes toward divorce have altered, researchers have concentrated less on searching for

86. For our purposes, two of the most important criticisms of this research are, first, that much of it lumps together children of divorce both with children whose parents never lived together and with children whose father died without looking for differences among them and, second, that much of it fails to control for the separate effects of income and class. See reviews by Blechman and Rutter, supra note 85 .

87. Ellsworth \& Levy, supra note 84, at 215.

88. For useful recent reviews and bibliographies, see Lamb, The Effects of Divorce on Children's Personal Development, 1 J. DivoRCE 163 (1977); Hetherington, Divorce: A Child's Perspective, 34 AM. Psychologist 851 (1979); Levitin, Children of Divorce: An Introduction, J. SOC. IsSUES, Fall 1979, at 1; Longfellow, Divorce in Context: Its Impact on Children, in DIVoRCE AND Separation: CONTEXT, Causes AND Consequences 287 (G. Levinger \& 0. Moles eds. 1979); Magrab, For the Sake of the Children: A Review of the Psychological Effects of Divorce, 1 J. Divorce 233 (1978). The founding in 1977 of the Journal of Divorce, solely devoted to research on divorce, attests to the growth of scholarly interest in the subject. 
pathology. Some have even identified positive aspects of divorce for children, such as an especially close relation with one parent and closer relationships with siblings, ${ }^{89}$ and more ambiguous aspects, such as "growing up a little faster." 90

Two recent studies have been particularly celebrated because the authors followed families over a period of years and sought to develop a comprehensive understanding of the lives of the children and the parents. The first, by Mavis Hetherington, Martha Cox, and Roger Cox, followed seventy-two nursery-school-age children in forty-eight families over a two-year period after divorce. ${ }^{91}$ The second, by Judith Wallerstein and Joan Kelly, followed 131 children of all ages from sixty families over a five-year period after separation. ${ }^{92}$ (For simplicity, I will refer to the studies as "Hetherington" or "Wallerstein.") Each has done further follow-ups of the same families that await publication. For our purposes, these studies are in one sense simply a more probing version of the old father-absence research, subject to the same limitation of providing no direct information on the probable consequences of placements with fathers or secondary caretakers. Moreover, neither set of researchers drew on a random sample of divorced families and the samples of both were of somewhat higher social status on average than the divorcing population in general. Wallerstein's group almost certainly included a disproportionate number of troubled families, because she obtained her sample by soliciting volunteers for short-term counseling. ${ }^{93}$

Nonetheless, because the two studies drew on extensive interviews with all family members and because they offered a more detailed view of the lives of divorcing families than had been previously available,

89. Schlesinger, Children's Viewpoints of Living in a One-Parent Family, 5 J. DivorCE 1 (1982).

90. Weiss, Growing Up a Little Faster: The Experience of Growing Up in a Single-Parent Household, J. Soc. IssuES, Fall 1979, at 97.

91. The Hetherington, Cox, and Cox research has not yet appeared in book form. Parts have appeared in many places. See, e.g., Hetherington, Cox \& Cox, Effects of Divorce on Parents and Children, in Nontraditional Families: Parenting and Child Development 233 (M. Lamb ed. 1982); Hetherington, Cox \& Cox, The Aftermath of Divorce, in MoTHER/CHILD, FATHER/CHILD RELATIONSHIPS 149 (J. Stevens \& M. Mathews eds. 1978) [hereinafter cited as The Aftermath of Divorce]; Hetherington, Cox \& Cox, Stress and Coping in Divorce: $A$ Focus on Women, in PSYchology AND WOMEN: IN TRANSITION 95 (J. Gullahorn ed. 1979) [hereinafter cited as Stress and Coping]; Hetherington, $\operatorname{Cox} \& \operatorname{Cox}$, Play and Social Interaction in Children Following Divorce, J. Soc. IssuEs, Fall 1979, at 26; Hetherington, Cox \& Cox, Divorced Fathers, 25 FaM. CoORdinator 417 (1976) [hereinafter cited as Divorced Fathers].

92. J. Wallerstein \& J. Kelly, SuRViving THE BREaK-UP: How ChIldREN AND PaRENTS COPE WITH DIVORCE (1980)

93. A discussion of the methodological problems in J. WALLERSTEIN \& J. KELLY, supra note 92, can be found in Bruch, Parenting at and After Divorce: $A$ Search for New Models (Book Review), 79 Mich. L. Rev. 708 (1981). 
their findings have been widely discussed and their broad outlines widely accepted. ${ }^{94}$ Part of their acceptance probably flows from the fact that their findings are generally consistent with one another, although Wallerstein's are somewhat bleaker than Hetherington's.

What the authors report is that for most children, custodial mothers, and noncustodial fathers, the period immediately after separation is a period of stress and anxiety. Each person is affected by the absence of a person (or persons) who had been central to their lives. Each person is forced to adjust to a substantially altered living situation at a time when each is least well-armed psychologically to cope with it. Custodial mothers must cope with all the old tasks of childcare while shaping a new role as the sole decisionmaker, disciplinarian, and principal or sole breadwinner. Children's basic physical needs are met during this period, but nearly all children experience severe emotional distress and grieve for the absent father, particularly if he does not visit regularly. Many feel unhappy and disoriented for long periods after the divorce for reasons that appear to relate to the breakup of the family. ${ }^{95}$ According to Hetherington, young children cry more, whine more, and throw more temper tantrums than children in two-parent families. Wallerstein reports that children of all ages have problems, although the reactions and problems vary depending upon the age of the child at the time of the breakup. ${ }^{96}$

During the year or so after separation, many mothers report the temporary loss of traits they most prized as personal qualities in themselves, traits that many writers associate with primary-caretaking mothers and that might incline us toward preferring placement with them. Thus, mothers report feeling less able to reach out to their children, less able to be sympathetic and compassionate or to control their own tempers, and more likely to use negative sanctions. ${ }^{97}$ In a large proportion of families, the worst point in mother-child relations is not reached until a full year after divorce when mothers describe their re-

94. Many recent writers have placed heavy reliance on their research. See, e.g., L. FraNCKE, GrowiNg UP DivorCED (1983); Clingempeel \& Reppucci, supra note 25; Cochran \& Vitz, Child Protective Divorce Laws: $A$ Response to the Effects of Parental Separation on Children, 17 FAM. L.Q. 327, 328-35, 338-43 (1983); Thompson, supra note 83; COMMTTTEE ON THE FAMILY, supra note 14.

95. J. WALLERSTEIN \& J. KELLY, supra note 92, at 13; see also Hetherington, supra note 88, at $877-78$ (reviewing the writings of others).

96. Wallerstein and Kelly found different patterns of reactions among children aged 3-5, 6-8, 9-12, and 13-18. See J. WALlerstein \& J. KelLY, supra note 92, at 55-95.

97. See J. WALlERSTEIN \& J. Kelly, supra note 92, at 108-20; Stress and Coping, supra note 91; The Aftermath of Divorce, supra note 91 . The parents' difficulties during this period have an important bearing on the capacity of courts to assess the quality of a child's relations to her parents in the course of trying to make a decision about custody. See text at notes 20-24 supra. 
lationships with their children as "declared war," "the old Chinese water torture," and "like being bitten to death by ducks."98 Mothers report particular difficulties in their relationships with their sons, and more sons than daughters seemed troubled. ${ }^{99}$ Mothers also report less satisfaction with their own performance of many of the day-to-day household tasks. ${ }^{100}$ They also report experiencing severe financial distress that exacerbated the other problems they faced. ${ }^{101}$ According to Wallerstein and Kelly, as long as three to five years after divorce, a significant minority of the mothers still report major difficulties in their relationships with their children that they and the authors attribute at least in part to their divorce. ${ }^{102}$

During the early part of this period, the noncustodial fathers report no greater satisfaction with their lives. Feeling rootless, they find painful the visitation relationship and many, though by no means all, find it difficult to maintain or build a satisfying relationship with their children. ${ }^{103}$

Both studies report that within a few years after the divorce, most families appear to have restabilized and the children's problematic behavior had subsided from its peak at approximately one year after the divorce. ${ }^{104}$ Nevertheless, both boys and girls are reported to be functioning somewhat less well than their peers from intact homes and boys continue to be comparatively more unhappy and pose more problems of discipline. ${ }^{105}$

98. See Hetherington, Cox \& Cox, Divorced Fathers, 25 FAM. COORDINATOR 417, 424-25 (1976) (comparing mothers and fathers); see also R. Weiss, MARITAL SEPARATION 176-80 (1975) (discussing the problems of the single-parent mother).

99. J. WALLERSTEIN \& J. KeLLY, supra note 92, at 165-67.

100. Id. at 36.

101. Id. at 22-24, 150-51; cf. Wallerstein \& Huntington, Bread and Roses: Nonfinancial Issues Related to Fathers' Economic Support of Their Children Following Divorce, in THE PARENTAL CHILd-Support Obligation 135 (J. Cassetty ed. 1983) (examining the convergence of economic and psychological factors in the financial support provided by the father).

102. J. Wallerstein \& J. Kelly, supra note 92, at 225.

103. Id. at 121-31; see Wallerstein \& Kelly, Effects of Divorce on the Visiting Father-Child Relationship, 137 AM. J. Psychiatry 1534 (1980); see also Jacobs, Treatment of Divorcing Fathers: Social and Psychotherapeutic Considerations, 140 AM. J. PsychiaTRY 1294 (1983). Another study has found that most children of divorce see their father at least once a month in the first two years after their parents' separation but that by five years after separation, $64 \%$ have not seen their father in over a year. See Furstenberg, Nord, Peterson \& Zill, The Life Course of Children of Divorce: Marital Disruption and Parental Contact, 48 AM. Soc. Rev. 656, 665 (table 7) [hereinafter cited as Life Course].

104. J. WALLERSTEIN \& J. Kelly, supra note 92, at 161-78, 304-05.

105. Id. at $165-67$. Elsewhere, Hetherington bas suggested that the effects on girls may be as substantial but merely delayed until adolescence. See Hetherington, Effects of Father Absence on Personality Development in Adolescent Daughters, 7 Developmental Psychology 313 (1972). Cochran and Vitz, in a recent article, consider the findings of Wallerstein and Hetherington sufficiently alarming that they recommend that states discourage divorce by requiring, for 
One limit of the Wallerstein and Hetherington works, even as studies of children in maternal custody, is that, though longitudinal and thorough, they have not yet followed the children up to adulthood. No study has done so. Oddly, it is also the case that there are few retrospective studies of adults whose parents were divorced when they were young to learn whether they report suffering or appear to suffer more problems than persons whose parents remained married throughout their childhood. One study, analyzing data from two broad national surveys of the self-reported life satisfaction of Americans, found very few differences between persons whose parents had and had not divorced, and no differences in reported current life satisfaction, but did find that more children of divorce looked back on childhood as the least happy time of their lives. ${ }^{106}$ Although the study did not analyze separately children raised by their fathers, the vast majority of the respondents to the study whose parents had been divorced had almost certainly lived with their mothers. ${ }^{107}$

Although this study, like those of Wallerstein and Hetherington, has troubling findings, it cannot inform us directly about the expected life experience of children raised by their fathers (or previous secondary caretakers). The research of Wallerstein and Hetherington is not, however, without value for our purposes. It sets the stage well for rich comparisons with the experience of children living in other settings, as research on those other settings is conducted.

About a dozen smaller-scale studies reporting on families headed by fathers have now in fact been published. ${ }^{108}$ Nearly all were written

couples with minor children, a one-year waiting period after separation before a divorce can become final. See Cochran \& Vitz, supra note 94, at 344-49.

106. Kulka \& Weingarten, The Long-Term Effects of Parental Divorce in Childhood on Adult Adjustment, J. Soc. IssuEs, Fall 1979, at 50.

107. Only about $10 \%$ of children living with a divorced parent live with their father. Glick, Children of Divorced Parents in Demographic Perspective, J. Soc. IsSUES, Fall 1979, at 170, 177.

108. See D. Luepnitz, Child Custody: A STUdy of FAMILIES AFter DIVORCE (1982); Ambert, Differences in Children's Behaviors Toward Custodial Mothers and Custodial Fathers, J. MARRIAGe \& FAM., Feb. 1972, at 73; Bartz \& Witcher, When Father Gets Custody, CHILDREN ToDAy, Sept.-Oct. 1978, at 2; Chang \& Deinard, Single-Father Caretakers: Demographic Characteristics and Adjustment Processes, 52 AM. J. ORTHOPSYCHIATRY 236 (1982); Defrain \& Eirick, Coping as Divorced Single Parents: A Comparative Study of Fathers and Mothers, 30 FAM. REL. 265 (1981); Fulton, Parental Reports of Children's Post-Divorce Adjustment, J. Soc. Issues, Fall 1979, at 126; Gasser \& Taylor, Role Adjustment of Single Parent Fathers with Dependent Children, 25 FAM. CoORdINATOR 397 (1976); Hipgrave, Child Rearing by Lone Fathers, in Changing Patterns of Child Bearing and Child Rearing 149 (R. Cheaster, P. Diggony \& M. Sutherland eds. 1982); Keshet \& Rosenthal, Single Parent Fathers: A New Study, CHILDREN TODAY, May 1978, at 13; Mendes, Single Fatherhood, 21 Soc. WoRK 308 (1976); Santrock \& Warshak, Father Custody and Social Development in Boys and Girls. J. Soc. Issues, Fall 1979, at 112; Orthner, Brown \& Ferguson, Single-Parent Fatherhood: An Emerging Family Life Style, 25 Fam. COORdinator 429 (1976); Smith \& Smith, Childrearing and Single-Parent Fathers, 30 FAM. REL. 411 (1981). The one study reporting unhappy fathers and children is Canadian. Schlesinger \& Todres, Motherless Families: An Increasing Societal Pattern, CHILd Welfare, 
within the last decade and in all the mothers of the children studied had been the primary caretakers of the children before the father assumed custody. These studies help us begin to understand both the experiences of children raised by men and the experiences of children whose care is taken over by secondary caretakers.

Sad to say, although they seem directly responsive to the questions posed in this Article, the studies of children with fathers cannot provide the answers we need. One inherent limit is that because fathercustody is still relatively unusual in our society, even a study of a random sample of fathers with custody today might tell us only a limited amount about what children's experiences are likely to be if far more fathers became custodians. ${ }^{109}$ In fact, the studies so far conducted are not based on random samples. They nearly all rely on samples of volunteers obtained through divorce support groups or advertisements. Most mix children whose parents divorced with children whose mothers have died. 110

In addition, few of the children were infants and none of the studies reports at any length on fathers caring for infants. Most involve interviews conducted several years after the father had assumed custody and thus after the point at which Wallerstein and Hetherington report children living with mothers suffering the greatest difficulties. Most describe only how fathers viewed their own situations or at most how the fathers believed their children were faring; only a few include direct observations and interviews with the children comparable to those conducted by Hetherington and by Wallerstein. ${ }^{111}$ One would be inclined not to report their findings at all except that they share a remarkable surface similarity.

The surface similarity is the positive tone of their findings. They report an expectable difficult time of transition: like mothers, fathers with custody report loneliness, frustration, and a sense of inade-

Sept.-Oct. 1976, at 533. Though bleak in tone, the experience of these Canadian fathers seemed nonetheless closely comparable to those reported for single-parent mothers in Wallerstein and Kelly. Two British studies of fathers with custody of children mix children of divorce with other children, V. GeORGE \& P. Wilding, Motherless FAMILIES (1972); Ferri, Characteristics of Motherless Families, 3 BRIT. J. Soc. WORK 91 (1973); see also O'Brien, Lone Fathers: Transition from Married to Separated State, J. CoMP. FAM. STUD., Winter 1980, at 115.

109. Fathers who seek custody today stress that they viewed themselves as the better parent than the mother and tend to have slightly higher levels of education and income than the average noncustodial father. Chang \& Deinard, supra note 108, at 238.

110. Even those with samples limited to divorced families do not separately identify children who are in the custody of fathers after a custody dispute with the mother. For our purposes at least, it would be valuable to know whether or not the experiences of such children are different from those of children who were placed in the custody of their father without dispute.

111. The most notable exception is Santrock \& Warshak, supra note 108. 
quacy. ${ }^{112}$ They faced the difficult task of mastering new skills of caregiving while trying to handle their former jobs. Because the new tasks the father was fumbling to learn involved more intimate contact with the children than the new tasks of the mother and because the children were facing adjustment to a new primary caretaker, one might expect the immediate post-separation period to be even more stressful than that depicted for mothers by Hetherington or Wallerstein. Unfortunately, with two exceptions, ${ }^{113}$ none of the studies compared the situations of custodial fathers and mothers, and few report at all on the period of adjustment as experienced by the child.

In any event, all the studies report that fathers appear to attain rapidly the housetending and childtending skills they previously lacked. More basically, not one of the studies reports father-headed families in chronic disarray, with fathers unable to cope and children either physically or emotionally neglected. Interviewers found the men knowledgeable about their children and highly motivated to meet their needs. They report that the fathers believed that their children were generally in good emotional condition, though some fathers worried that they lacked a "mother's touch."114

The few studies in which the researchers directly observed the children report complementary findings regarding the children's conditions. A study of thirty-three preschool children being raised by fathers, which the author himself treats as merely "exploratory," found no abnormal behavioral problems and reports that the children were generally well-adjusted and capable of a high degree of independent functioning for their age. ${ }^{115}$ Another small study of boys aged nine to fourteen, some raised by fathers, some by mothers, found no significant differences between the groups. ${ }^{116}$ One very recent study does report that children of divorcing parents seem to be better off with the parent of the same sex, but found no evidence whatever of overall inadequacies of custodial fathers who had previously been sec-

112. See, e.g., Chang \& Deinard, supra note 108, at 239-40; Hipgrave, supra note 108, at 15561; Schlesinger \& Todres, supra note 108, at 356-57.

113. See D. LuEPNITZ, supra note 108 , at $99-110$ (an interview study reporting few differences; mothers too had to learn new domestic skills such as appliance repair and minor plumbing); Santrock \& Warshak, studies listed in note 117 infra (studies focus on the link between gender of parent and gender of child, not on the differing experiences of mothers and fathers per se).

114. See, e.g., Hipgrave, supra note 108 , at 159 (noting that single fathers particularly fear that they are depriving their children emotionally because they cannot supply "motherly love").

115. T. Hipgrave, When the Mother is Gone: Profile Studies of Sixteen Lone Fathers with Pre-School Children (1978) (unpublished M.A. Thesis, Child Development Research Unit, Nottingham University), cited in Hipgrave, supra note 108, at 149, 165.

116. Lowenstein \& Koopman, A Comparison of the Self-Esteem Between Boys Living with Single-Parent Mothers and Single-Parent Fathers, 2 J. Divorce 195 (1978). 
ondary caretakers in comparison with custodial mothers who had been primary caretakers all along. ${ }^{117}$

That study, the results of which are still being analyzed, merits discussion at somewhat greater length because it is nearly unique in including samples of father-headed, mother-headed, and two-parent families and because its findings bear so directly on the questions posed in this Article. The authors, John Santrock and Richard Warshak of the University of Texas at Dallas, located samples of roughly twenty children each in father custody, mother custody, and intact two-parent custody and relied upon psychological tests, laboratory observations of the custodial parent with their children, and structured interviews with the children. At the time of the study, all the children were between six and eleven, and the parents in the divorced families had been separated an average of slightly over three years. The authors' principal purpose was to test whether or not the gender of the parent with whom a child lived seemed to make a difference in the child's condition or development after divorce. The authors' early findings are expressed in forceful terms: they found that, in general, the children within their sample who lived with parents of the same sex were less anxious, less demanding, and less angry; were warmer and more honest; and displayed higher levels of maturity, self-esteem, and social conformity than the children living with parents of the opposite sex. Although some of their measures may not be relevant for our purposes, ${ }^{118}$ the sum of their findings suggests that, within their sample, children with the same-sex parent felt on the whole happier and more secure, a relevant consideration in deciding custody under almost any test.

The Santrock and Warshak findings are provocative, especially because they suggest an easily applied rule of decision for judges, at least in cases in which the children involved are in the range of ages that the authors studied and all the children in the family are of the same sex. As the authors acknowledge in part, however, there are many reasons

117. See Santrock \& Warshak, supra note 108; Santrock, Warshak \& Elliott, Social Development and Parent-Child Interaction in Father Custody and Stepmother Families, in NONTRAD1tional Families Parenting and Child Development 289 (M. Lamb ed. 1982) [hereinafter cited as Social Development and Parent-Child Interaction]; Warshak \& Santrock, Children of Divorce: Impact of Custody Disposition on Social Development, in LIFE-SPAN DEVELOPMENTAL PsychologY: NonNoRMative LifE Events 241 (E. Callahan \& K. McCluskey eds. 1980) [hereinafter cited as Children of Divorce].

118. The fact that a child is "demanding" or displays less "social conformity" would not necessarily be negative qualities as experienced by the child. Thus here is one of the few places within this Article that a factor might have different weight under different views of the "bestinterests" test. See the discussion of defining children's "best interests" at notes 34-62 supra and accompanying text. 
to be cautious about their findings, cautious to the point of waiting for further research before using them in making recommendations for rules of custody.

Santrock and Warshak's use of matched samples and a diverse range of tests and observations are exemplary and their findings were "robust" in the sense that they were consistent across many different sorts of observations. Unfortunately, however, their samples were very small - only about ten each of mother-custody sons, mothercustody daughters, father-custody sons, and father-custody daughters. ${ }^{119}$ They are also nonrandom. Because of the rarity of fathercustody families in their area, the authors, much like others who have studied custodial fathers, located their sample of father-custody families through suggestions from their students, public agencies, and a support group for single parents called Parents Without.Partners, ${ }^{120}$ a form of sampling likely to produce a disproportionate number of families in which the fathers who volunteered to cooperate believed their children were faring reasonably well. Moreover, in few of these father-custody cases had there been a fight over custody. It is thus possible that the comparative difficulties for many girls living with their fathers, for all of whom their mothers had been the primary caretaker before separation, derived not so much from their situation after divorce as it did from some aspect of the mother-daughter relationship before separation. ${ }^{121}$ It hardly follows, and the authors do not claim, that these particular girls would have been happier or more secure if placed in the custody of their mothers. It is also possible that the parents themselves were in some way affected in their voluntary decisions about placement by the gender of the children and that whatever factors guided their decision continued to affect the children's experiences.

These criticisms do not prove that Santrock and Warshak's conclusions are wrong. They simply suggest that their proposition, though tantalizing, and though consistent with some evidence from studies of intact families reviewed below, remains unproven one way or the other. ${ }^{122}$

119. Social Development and Parent-Child Interaction, supra note 117, at 294.

120. Id. at 291.

121. Perhaps in some cases the daugher had lived until the parents' separation with a samesex primary caretaker who was more ambivalent than usual about devoting her life to children.

122. The one other study I can find that specifically compares boys in mother-custody with boys in father-custody found no significant differences in terms of boys' self-esteem. See Lowenstein \& Koopman, supra note 116. Santrock and Warshak themselves recommend against the adoption of any rule that establishes placement by sex-matching, preferring individualized decisions that take into account other factors such as the parents' childrearing methods. See Social Development and Parent-Child Interaction, supra note 117, at 302-03. 
We have now reviewed the research on children in various settings after divorce that has been conducted in the fifteen years since Ellsworth and Levy's review of the literature. They found the writing largely barren of reliable guidance for legislatures in framing rules for custody disputes between parents. In the years since, the ideal study of custody arrangements still has not been done, but it cannot be done: to their credit, Americans would never tolerate randomly assigning children at divorce to fathers, mothers, secondary caretakers, or joint custody, simply for the sake of advancing knowledge. On the other hand, it would be feasible (though very expensive) to follow a very large random sample of families from the point of the parents filing for divorce in the expectation that such a sample would produce a large enough number of father-custody and joint-custody families to compare over a long period of time with mother-custody families. This study too still waits to be done. ${ }^{123}$

As we have seen, however, the past fifteen years have not been wholly unproductive. Researchers have increased our knowledge of children in the custody of mothers and offered the first view of children in the custody of fathers. For our purposes, however, the recent research provides little more basis for rules than did the research available to Ellsworth and Levy. There is even a danger that the recent research could deceive us into inappropriate conclusions. The measured, sober tones of Hetherington and of Wallerstein in their studies of children with mothers, when compared with the generally optimistic tone of the studies of children placed with fathers might lead one to believe that children, and especially boys, are in general likely to be at least as well off with their secondary-caretaking fathers. This, of course, would be a wholly unjustified conclusion.

We have pointed out many of the shortcomings of the research on children with fathers, including the nearly complete absence of information about fathers with infants, the group for whom there might be the greatest concern and about whom there is some evidence that men are less likely to be responsive than women. Even as to older children, we must remember that some of the studies of fathers with custody were conducted by persons who seemed predisposed toward fathers,

123. Two studies are in progress that will meet part of this need. One is being conducted by Eleanor Maccoby, Robert Mnookin, and Charlene Depner at Stanford University and will follow children in such settings for two years, interviewing the parents and children, but not employing psychological testing devises. The other, on a smaller scale, by Pat Walsh and Neil Kalter at the University of Michigan, will interview children in such settings on only one occasion but will use a variety of psychological testing measures. A primary virtue of both studies is their attempt to rely on random samples drawn from court records. 
and all of the studies may have stressed the most positive findings because surprising findings arouse the most interest.

Moreover, even if the father-custody studies could have determined that the children studied were happier and more secure than Wallerstein's or Hetherington's children with their mothers, there would be many possible explanations for the differences other than that father custody is beneficial. The studies reported in this section all suffer sampling problems, but they are problems of differing sorts. Wallerstein, because her sample came from volunteers for counselling, seems highly likely to have studied a disproportionate number of families in which the custodial mothers felt their children were troubled while the father-custody studies were likely to have included a disproportionate number of cases in which the fathers who volunteered to participate did so because they thought they were doing well and could foresee that they were going to be compared to custodial mothers.

In the end, the only safe conclusion to be drawn from the current research on children living with fathers who had been secondary caretakers is that substantial numbers of individual children are reported to be faring well on a day-to-day basis. ${ }^{124}$ That isn't much. The limits on our knowledge make clear why as much or more reliance needs to be placed on the growing body of research about men and women in general in relation to children and about mothers and fathers in relation to their children in intact families.

\section{The Indirect Evidence from Intact Families and Other Sources}

a. The relevance of gender. (1) Evidence favoring mothers because they are women. Are women substantially more likely than men to possess traits such as patience or warmth or attentiveness to children's physical or emotional needs? Under any definition of children's best interests, such traits would probably be considered important to children's, especially young children's, well-being. ${ }^{125}$

Until the recent past, most states applied formal statutory or judicially created evidentiary presumptions in favor of mothers in custody disputes involving young children, children of "tender years."126

124. Tony Hipgrave, a professor of social work, after reviewing most of the above research, found "very little evidence that lone fathers are not perfectly capable of raising well-adjusted children." Hipgrave, supra note 108, at 149.

125. See Section II A supra.

126. See, e.g., Klaff, supra note 6, at 337-42; Roth, supra note 6, at 432-38. Before the midnineteenth century, however, many courts, including British courts, applied an almost irrebutable presumption for the father based on formalistic notions of the husband as head of the family. Klaff, supra note 2, at 337; Roth, supra note 6, at 425-28. 
Most states have now eliminated any formal preference, ${ }^{127}$ but even within the last decade, some state supreme courts have defended the continued use of the presumption. ${ }^{128}$ Even without statutory or appellate-court authorization, many trial judges believe that young children generally belong with mothers and tend to place children with them, ${ }^{129}$ though the judges' bias has almost certainly displayed itself primarily in the context of cases in which the mother has also been the primary caretaker, a separable factor the significance of which I consider in a later section. ${ }^{130}$

In America today, many people would be as hostile to suggestions that women are especially suited to raise children as they would be to suggestions that men are especially suited to run nations. And yet, although I will ultimately conclude that no preference based on gender is justifiable, the evidence bearing on such a preference is somewhat more equivocal than might be guessed.

It is not judges alone who believe that women have special gifts as caretakers of children. The sociologist Alice Rossi has, for example, argued that women have a predisposition toward childcare that is, at least in part, genetically transmitted. ${ }^{131}$ Erik Erikson also claimed that women have a "biological, psychological, and ethical commitment to take care of human infancy."132 Freud had similar beliefs. ${ }^{133}$ Conversely, speaking of men, Bruno Bettelheim once argued that "[M]ale physiology and that part of his psychology based on it are not geared

127. Freed \& Foster, supra note 63 , at 351 (table VIIIE).

128. See Gordon v. Gordon, 577 P.2d 1271, 1276-77 (Okla.), cert. denied, 439 U.S. 863 (1978); Cox v. Cox, 532 P.2d 994, 996 (Utah 1975) (upholding a preference for mothers despite a state equal rights amendment on the ground that the law need not "blindly ignore obvious and essential biological differences"); see also Grubbs v. Grubbs, 5 Kan. App. 2d 694, 623 P.2d 546 (1981) (upholding maternal presumption despite the repeal of a sex-based preference by the legislature).

129. See Johnson, Divorce, Alimony, Support and Custody: A Survey of Judges' Attitudes in One State, 3 FAM. L. REP. (BNA) 4001 (Nov. 9, 1976) (Illinois); Pearson \& Ring, Judicial Decison-Making in Contest Custody Cases, 21 J. FaM. L. 703, 716 (1983) (reporting on Denver, Colo.); Weitzman \& Dixon, supra note 29, at 506 (California).

130. See notes 183-230 infra and accompanying text.

131. See Rossi, Gender and Parenthood, 49 AM. Soc. Rev. 1 (1984); Rossi, A Biosocial Perspective on Parenting, 106 Daedalus 1 (1977); $c f$. N. CHOdorow, THE Reproduction of MOTHERING (1978) (finding a biological explanation unnecessary but developing a thesis that tendencies toward nurturing capacities have deep and strong social origins not easily altered); $D$. DinNerstein, The Mermaid and the Minotaur: Sexual ARrangements and Human MALAISE (1976) (concluding that biology explains only a small part of gender roles and that changes are possible and, indeed, necessary).

132. See Erikson, Inner and Outer Space: Reflections on Womanhood, 93 Daedalus 582, 586 (1964); see also Tucker, John Bowlby on Latchkey Kids, PsYchologY TODAY, issue 11, 1976, at 41 (quoting Bowlby as saying "mothers are specially prepared biologically; if mothers don't look after babies, then babies are not going to prosper.").

133. See, e.g., S. Freud, Civilization and Its Discontents 73 (1930). 
to infant care. . . . [T] he relationship between father and child never was and cannot now be built principally around child-caring experiences. It is built around a man's function in society: moral, economic, political." 134

Rossi, Erikson, Freud, and Bettelheim have some obvious evidence that can be adduced in their support. Only women can bear children and only women can nurse. Over the whole history of humankind, childrearing has been a central role for women, a secondary role for men. ${ }^{135}$ In America today, ${ }^{136}$ as in all other countries of the world, ${ }^{137}$ it is women who perform most of the holding, feeding, and consoling of young children.

Women are also widely perceived as possessing particular character and behavioral traits that especially suit them for the care of young children. One common characterization is that women are "expressive," while men are "instrumental." 138 Women are thought to be more open in displaying affection; to have a greater capacity for gentleness, empathy, and compassion; and to possess a greater solicitousness for the needs of others. ${ }^{139}$ These qualities when lavished on a young child may convert mere impersonal task-performing into true "nurturing." Men, by contrast, are perceived as finding satisfaction in activities that garner power or prestige rather than from activities that provide private satisfactions. ${ }^{140}$ They are viewed as more likely to be competitive, self-reliant, and aggressive and more concerned about the family's relationship to the outside world. These qualities, though probably important over time in the child's development, may be thought less central to a young child's well-being than those associated

134. Bettelheim, Fathers Shouldn't Try to Be Mothers, 31 Parents' Magazine \& FaM. Home Guide 125-26, quoted in J. LeVINE, Who WILl RAISE THE CHILDREN?: New OPTIONS FOR FATHERS (AND MOTHERS) 22 (1976).

135. See Maccoby, Woman's Sociobiological Heritage: Destiny or Free Choice?, in PsychoLOGY AND WOMEN: IN TRANSITION 147, 155 (J. Gullahorn ed. 1979).

136. See, e.g., K. Walker \& M. Woods, Time Use: A MEasure of Household ProDUCTION OF FAMILY GoODS AND SERVICES (1976); Pleck, The Work-Family Role Systems, 24 SOC. PROBS. 417, 419-20 (1977).

137. E. MACCOBY, supra note 58, at 217.

138. Talcot Parsons was among the first to so describe men and women. See Parsons, Family Structure and the Socialization of the Child, in FAMILY, SOCIALIZATIONS AND INTERACTION Process 151 (T. Parsons \& R. Bales eds. 1955).

139. See Nash \& Feldman, Sex Role and Sex-Related Attributions: Constancy and Change Across the Family Life Cycle, in 1 Advances in Developmental Psychology 1 (M. Lamb \& A. Brown eds. 1981); Broverman, Vogel, Broverman, Clarkson \& Rosenkrantz, Sex Role Stereotypes: A Current Appraisal, J. Soc. Issues, Spring 1972, at 59; Herman, Women, Divorce, and Suicide, 1 J. DrVORCE 107, 110-11 (1977). For a summary of research on children displaying these characteristics in play with others of their own age, see E. MACCOBY, supra note 58, at 21617.

140. See note 139 supra; see also Fasteau, The Male Machine (1974). 
with the mothers. Whatever role biology plays in shaping these general characteristics, it is plainly the case that from early childhood on, most boys and girls in the United States are taught that certain traits are desirable for boys and different traits, including nurturing traits, are desirable for girls. ${ }^{141}$

For our purposes, however, the issue is not quite so global as whether, in general, women are better suited to be childtenders than men. Custody disputes arise between two people who are each the parent of the child at issue and who have each indicated a willingness to be the child's caretaker. A review of the available research suggests, although less clearly than those who claim that there are no differences between the sexes might wish, that gender alone provides little useful information for making decisions between contending parents. A review also helps separate those issues that distinctly relate to the parents' gender from those that relate to a parent's status as primary caretaker, a cifficult task in a world in which the overwhelming majority of primary caretakers are women.

The broad generalizations about the personalities and behavioral traits of men and women hold up rather poorly when individual adults are studied. ${ }^{142}$ While researchers do report some persistent, sex-linked differences in the psychological responses of men and women in general, ${ }^{143}$ they also find that large numbers of individual men display traits stereotypically associated with women. The more specific research examining males and females in their interest in children, attentiveness to them, and capacity to understand and respond to their needs - what might be collectively termed their "responsiveness" to children - is especially inconclusive.

Phyllis Berman recently published a helpful review of nearly sixty studies conducted within the last twenty years that have sought to measure differences in males' and females' responsiveness to young

141. From an early age, most boys learn that playing dolls or playing house is frowned upon. By five or six, most boys have quite rigid notions of what is acceptable behavior for boys and girls. They will ridicule another boy who engages in what they consider to be "girl's" play. See E. MACcoBY, supra note 58, at 234-38; see also Barry, Bacon \& Child, $A$ Cross-Cultural Survey of Some Sex Differences in Socialization, 55 J. ABNoRmaL \& Soc. Psychology 327, 328-29 (1957) (Using ethonographic reports, the authors found that in over four-fifths of societies studied, girls received more training than boys in the care of younger siblings and other dependent persons.).

142. See J. Nicholson, MEN AND Women: How Different ARE TheY? 17 (1984) ("There is far more variety of behaviour amongst babies of the same sex than there is between a 'typical' boy and a 'typical' girl — an observation which applies to virtually every sex 'difference' between adult men and women."); see also E. MACCOBY \& C. JACKLIN, The Psychology of SEX DIFFERENCES 247 (1974) (One example: "[I]n almost every group that has been observed there are several women who are fully as aggressive as the men.").

143. E. MACCOBY \& C. JACKLIN, supra note 142. (Most of the book is devoted to a review of research exploring differences, in general, between men and women along various dimensions.) 
children. ${ }^{144}$ The findings of the studies Berman reviewed are not wholly consistent, but it is possible to discern some broad patterns. Few studies found men more responsive to children than women regardless of the measure used. A great many found women in general more responsive than men and many others reported no differences. The studies that most consistently found women more responsive were those that involved self-reported responses to photographs and drawings. These studies seem to provide the least reliable measures of how people would respond to real children, in part because respondents are likely to slant their answers toward those they believe will be socially acceptable. On the other hand, the tests that relied on physiological responses - for example, on changes in pulse rates - and are less susceptible to respondent manipulation, were least likely to report differences between men and women.

Similarly, of twenty-seven studies drawing on observations of actual interactions of males and females with children, most found no differences and only three found persistent differences between men and women in several age groups. In large part, differences when found were greatest at ages when women are expected in our society to be especially responsive to children or men are expected to be especially concerned with other roles.

In the context of custody disputes, the issue of special nurturing traits associated with one sex is posed most purely in cases involving newborns when neither parent has become the primary caretaker for the child and in cases involving preschool children when parents have shared in roughly equal measure the caregiving responsibilities. Hence, the most relevant studies to us among those Berman reviewed are those seeking to compare the responsiveness of mothers and fathers of young children. Here the findings are complex and somewhat mixed. Some studies have reported that women already serving as the primary caretaker of a young child are more responsive than their husbands to the young children of others, for example, when observed in a waiting room. ${ }^{145}$ On the other hand, when fathers and mothers are

144. Berman, Are Women More Responsive Than Men to the Young? A Review of Developmental and Situational Variables, 88 Psychological Bull. 668 (1980). As she reports, the research on men and women in relation to children has assumed many forms. Some researchers try to measure pulse rate and other physiological responses of males and females to pictures or audiotapes of infants, some ask respondents to state preferences between pictures of adults and children or to rate varying pictures on degree of attractiveness, and others, fortunately the largest in number, have observed males and females actually interacting with infants and young children and looked for signs of interest, attentiveness, or capacity to respond to the child's apparent needs. The male and female subjects of the studies have varied widely as well - boys and girls, single men and women, married but childless men and women, parents observed with children other than their own, and parents observed with their own newborns.

145. Feldman \& Nash, Interest in Babies During Young Adulthood, 49 CHILD DEv. 617 
observed with their own newborns before either has assumed differing caretaking roles, fathers are in general as likely to hold them closely, rock them, talk to them, and look directly at them. ${ }^{146}$ New fathers seem as skilled and gentle as mothers with their own children. Observers in the home at later stages, even after differing roles have been assumed, have found that although fathers interact with young children differently than mothers do, with more physical and less patterned, rhythmic play, ${ }^{147}$ there still seem to be few differences in the degree of parents' interests in their children or in their capacities to respond to their infant's signals. ${ }^{148}$

Not reviewed by Berman are a few puzzling studies of men and women actually performing the primary-caretaking role for an infant within a two-parent family. Two studies have been conducted in the United States, ${ }^{149}$ one in Sweden. ${ }^{150}$ The findings of the three studies differ somewhat, although all three found a pattern of males engaging in proportionately more physical interaction and less cuddling. In the Swedish study, the researchers found that after a period of at least a month as primary caretaker, the seventeen fathers as a group still interacted with their children far more like secondary-caretaking fathers than like primary-caretaking mothers. In comparison to the mothers, both sorts of fathers much less frequently displayed affection; smiled at, held, or spoke to their children; or initiated caretaking actions. The authors of the Swedish study read their results as suggesting that Swedish men's and women's styles of interacting with young children are either biological in origin or instilled in early social learning.

In mild contrast, in the first American study, ${ }^{151}$ primary-caretaking fathers seemed on many, but not all, measures to behave more like

(1978). This study leaves uncertain whether the differences between men and women, if real, were related to gender, primary-caretaker status, or both.

146. See Parke \& Sawin, The Father's Role in Infancy: A Re-evaluation, 25 FAM. CoordNATOR 365 (1976). This article is not cited in Berman. It is a synthesis and reappraisal of several earlier articles, by Parke and others, to which Berman refers.

147. See, e.g., Lamb, Interactions Between Eight-Month-Old Children and Their Fathers and Mothers, in The Role of THE Father IN Child Development 307 (M. Lamb ed. 1976); Yogman, Development of the Father-Infant Relationship, in 1 THEORY AND RESEARCH IN BEhavioral Pediatrics (H. Fitzgerald, B. Lester \& M. Yogman eds. 1982).

148. See E. MACCOBY, supra note 58, at 220.

149. Field, Interaction Behaviors of Primary Versus Secondary Caretaker Fathers, 14 DEV. Psychology 183 (1978); Pruett, Infants of Primary Nurturing Fathers, in 38 PsYchoANALYTIC STUDY OF THE CHILD 257 (1983).

150. Lamb, Frodi, Hwang \& Frodi, Varying Degrees of Paternal Involvement in Infant Care: Attitudinal and Behavioral Correlates, in NonTRAdITIONAL FAMILIES: PARENTING AND ChILD Development 117 (M. Lamb ed. 1982); Lamb, Frodi, Hwang \& Frodi, Effects of Paternal Involvement on Infant Preferences for Mothers and Fathers, 54 CHILD DEV. 450 (1983) [hereinafter cited as Infant Preferences].

151. Field, supra note 149. 
primary-caretaking mothers than like secondary-caretaking fathers. For example, primary-caretaking mothers and fathers both imitated sounds of their infants in a responsive, interactive way to a substantially greater extent than secondary-caretaking fathers. The author of the first American study believed that primary caretakers of both sexes learn how responsive infants are to such imitative cooing. The other American study, of seventeen infants with fathers serving as primary caretakers for extended periods, was conducted by a psychiatrist and did not draw comparisons with a sample of primary-caretaking mothers. It found, at two different examinations, that the infants were "vigorous, competent and thriving" and that their fathers had been fully capable of forming the "intense reciprocal nurturing attachments" so critical in early life. ${ }^{152}$ The Swedish and American studies are intriguing, but all involved small samples and, for differing methodological reasons, are difficult to generalize to the issues posed in custody disputes. ${ }^{153}$

The mixed evidence of the Swedish and American studies needs to be seen against the background of more general evidence about the adaptability of human beings of both sexes to new roles, including childtending roles. Although men and women are commonly assigned different tasks in our society, they have capabilities many other animals lack to adapt fairly swiftly to new ones. ${ }^{154}$ Unflattering to either sex is the evidence that Western European women of the middle and upper classes for several centuries before the nineteenth century typically displayed few nurturing qualities toward their children; parents farmed infants out to wet-nurses for several of their early years. ${ }^{155}$ On the other hand, in some agricultural societies, in which both men and women participate in food production, both are reported to display nurturing qualities, and men typically perform a more active role in

152. Pruett, supra note 149.

153. The Swedish men studied may not have been eager to play the caretaker role, but rather were pressured into it by economic circumstances. Whether or not this would be a common context for father-custody in divorce is hard to surmise. Moreover, the study suggests that there may be important cultural differences between Swedish and American men and differences in their interaction with children; American fathers often engage in more active play with their children than their wives do, whereas Swedish men apparently do not. See Infant Preferences, supra note 150, at 455-57. Field's study involved one brief, filmed observation. Pruett's involved observations of the parent and child on more than one occasion and is impressively rich in its observations, but, as with the others, his sample is small and nonrandom.

154. See Abrahams, Feldman \& Nash, Sex Role Self-Concept and Sex Role Attitudes: Enduring Personality Characteristics or Adaptations to Changing Life Situations?, 14 DEVELOPMENTAL Psychology 393 (1978); Kurdek \& Siesky, Sex Role Self-Concepts of Single Divorced Parents and Their Children, 3 J. DivorCE 249, 257 (1980); see also Berman, supra note 144, at $682,684,685$.

155. P. ARies, Centuries of Childhood: A Social History of Family Life $374-75$ (1962); E. Shorter, The MAKing of THE MODERN FAMILy 175-90 (1977). 
childtending than they do in societies in which men work outside the home. ${ }^{156}$

What then is the lesson, for our purposes, of the research on gender-related traits? The perplexing question is not whether men are able to perform various childrearing tasks. No one has doubted their physical ability to do so. The issues are whether or not fathers (1) are as capable as mothers of reading their children's signals regarding various needs, (2) have the patience and dedication to apply themselves to responding to those needs over time and, (3) have the capacity and motivation to accompany the provision of care with whatever emotional qualities are needed by a child to feel loved, respected, and secure. The studies reviewed by Berman leave some doubt about whether or not, in general, men are as capable of reading children's signals as women, though the concern about men's capacities in this respect probably does not extend to children after they become old enough to verbalize most of their needs. Few studies shed much light on the second question of whether or not men are as likely as women to apply themselves adequately over time to the provision of care to young children. The impressionistic studies of children in father-custody reviewed earlier and the few American and Swedish studies of primary-caretaker fathers in intact families indicate that some fathers are doing so, but these fathers may not be representative of fathers in general or even of the sorts of fathers who will volunteer for custody. ${ }^{157}$ Furthermore, if men receive little reinforcement from employers and peers for serving in a caretaking role, it will be harder for them than for women to sustain their efforts, even if they begin with equal motivation to succeed.

The third question, whether or not fathers in general can infuse caregiving with the appropriate emotional qualities, is especially difficult to answer. We have seen that men, even men who are primary caretakers of children, may typically behave toward children somewhat differently than women do. From this alone, of course, it does not follow that women's behavior better serves children's needs. For our purposes, the issue is not whether "father's touch" is identical to "mother's touch" but whether "father's touch," whatever it is like, is likely to lead to a less desirable quality of life or less desirable outcome

156. West \& Konner, The Role of the Father: An Anthropological Perspective, in THE RoLE of THE FATHER IN CHild DeVElopMent 185, 202-05 (M. Lamb ed. 1976).

157. See, e.g., Mendes, supra note 108, at 309 (fathers interviewed in one study who sought custody had strongly positive sentiments toward parenting); see also K. Gersick, supra note 17, at 157-64 (finding that one distinguishing characteristic of those who did seek custody of their children after divorce was a resentment of the small role their own fathers had played in their caretaking). 
for the child in either the short or long term. In this regard, the Swedish study and American studies of primary-caretaking fathers provide no clear answers and some mixed signals. ${ }^{158}$

The conclusions to be drawn on the basis of all that is now known about the differences between men and women are not obvious. It is not possible to say that there are no sex-linked differences between men and women that bear on childtending. In fact, while no evidence points toward a conclusion that men are more responsive to children than women, some evidence points in the opposite direction. Given the roles that men and women have performed over millenia and the ambiguous messages from the research on sex differences, a risk-averse legislator or judge might be inclined to retain or revive old preferences for women based simply on their gender. ${ }^{159}$ They might be especially inclined to do so, if they believe that judges in any given dispute will have grave difficulties determining the responsiveness and attentiveness of the men and women before them to their children.

Despite judges' compelling need for guidance, however, the inclination toward a maternal preference should probably be resisted for at least two reasons. The first is political. We live in an era in which there are grave suspicions of generalizations based on sex, particularly generalizations hardened into legal rules. A loose preference for women, regardless of the actual role they have played in a child's upbringing, flies in the face of efforts to equalize opportunities and responsibilities for men as childraisers. Even if a preference for women would produce slightly better dispositions for children across the generality of cases today and even if it turned out that some parenting propensities were genetically transmitted and hence unalterable, gender-based rules might transmit a harmful message to both men and women about appropriate spheres of responsibility. The harm from such a message might well be thought to outweigh the value to children to be obtained from a general rule.

The second reason for resisting a general rule is that it is probably

158. The lower level of interaction between the primary-caretaking fathers and their children could indicate less warmth and less stimulation for the child in the custody of her father. The authors of the Swedish study, see note 150 supra, made no judgments about the children's emotional development nor even any statements about whether or not the children seemed less happy or secure, but their evidence is at least disturbing. The American studies of primary-caretaking fathers, particularly the one by Pruett, see note 149 supra, found children to be "thriving" but noted that the fine condition of the children might be due in part to the fact that their mothers, though secondary caretakers, were more actively involved in their care than most secondarycaretaking fathers.

159. See Campbell, On the Conflicts Between Biological and Social Evolution and Between Psychology and Moral Tradition, 30 AM. Psychologist 1103 (1975) (warning against lightly throwing over what Campbell regards as the ancient lessons of biology). 
unnecessary or factually inappropriate in the cases that will actually come before courts, even acknowledging the difficulty courts have in making case-by-case appraisals. Consider the patterns of cases that actually arise. In cases involving young children, for whom the generalized characteristics associated with women are thought most important, there is usually one parent who has been the primary caretaker. If it is the father who has performed that role, that is itself likely to suggest that he has a high commitment to childcare and may suggest personal characteristics far from the stereotype. ${ }^{160}$ If it is the mother who is the primary caretaker, the bond she has formed with the child as primary caretaker is probably a better, even if weak, basis for a preference than her gender alone. ${ }^{161}$ If neither parent has been the primary caretaker because they have shared childcare equally, that again suggests a father who is likely to possess the desired nurturing traits. If the child is older, the nurturing characteristics peculiarly associated with women become less pressing among the values that one would want to serve through a custody decision. In the end it is only as to the newborn for whom neither parent has yet become a primary caretaker that a preference based on women's gender alone seems conceivably justified, and even here the evidence is unclear. ${ }^{162}$

(2) Evidence favoring matching children with the parent of the same sex. In the section describing current research on children of divorce in various settings, I described a recent study by Santrock and Warshak that concluded that, by several different measures, children aged six to eleven placed after divorce with a parent of the same sex seemed "better adjusted" than children of the same age in the custody of a parent of the opposite sex. ${ }^{163} \mathrm{I}$ also reported, however, that for many reasons, Santrock and Warshak's research should be regarded as exploratory. ${ }^{164}$ There is nonetheless psychological theory and some research to support a view that children have a special affinity for the parent of the same sex and special difficulties in their relations with the parent of the opposite sex.

Freudian psychological theory has long suggested an especially

160. See the study by Pruett, supra note 149.

161. See the discussion of the relevance of primary-caretaker status, text at notes $183-230$ infra.

162. See Parke \& Sawin, supra note 146. Parke and Sawin observed parents on a single occasion and found no differences between mothers and fathers. Their findings about the father's responsiveness on that occasion can tell us nothing about whether or not the fathers would show the necessary perseverance over time. Alice Rossi believes that women may have a biologically based predisposition toward long-term nurturing of newborns and infants that men lack. Rossi, Gender and Parenthood, supra note 131, at 5-9.

163. See note 117 supra (articles by Santrock \& Warshak).

164. See text following note 119 supra. 
strong identification by children with the parent of the same sex. ${ }^{165}$ Social learning theory suggests much the same conclusion, focusing on the way children learn by observing and interacting with the parent of the same sex. ${ }^{166}$ Moreover, in a society in which men and women still are encouraged toward different activities on the basis "of their sex, a child is simply more likely to enjoy participating in (and receive peer approbation for participating in) the activities of the same-sex parent. As a guide through the perils of growing up, a same-sex parent is likely to be more able to remember comparable moments in his or her own childhood and thus understand better the problems that the child encounters.

Studies of intact families provide some support for these hypotheses. In the next section I will discuss the strong bonds that seem to develop between children and both of their parents, but, as recently reviewed by Ross Thompson, ${ }^{167}$ some evidence points to especially strong relationships by sex, especially between boys and fathers. From infancy on, as Thompson summarizes, fathers in general take more interest in their sons than daughters. In observation-based studies, they typically touch and talk more to their infant sons, a pattern that continues through infancy. ${ }^{168} \mathrm{~A}$ comparable but milder preference has been found of mothers for daughters. ${ }^{169}$ In turn, children seem to respond preferentially to the parent of the same sex. At least after the first year, researchers find that young children, especially boys, seek out more contact with the parent of the same sex than the parent of the opposite sex. ${ }^{170}$

The studies of children of divorce to which I have already alluded also suggest some special problems for children, or at least for boys, separated from parents of the same sex. Studies of boys raised by single mothers have suggested that such boys more frequently experienced problems of sex-role identification and self-control than did the boys in two-parent families. ${ }^{171}$ Hetherington, Cox, and Cox found that mothers, in general, reported more difficulties in handling their

165. See summary in Santrock \& Warshak, supra note 108, at 115.

166. Id.

167. See Thompson, supra note 83 , at $72-73$ (1983).

168. Id. at 72 .

169. Id. at 73.

170. Id.

171. See note 85 supra; see also M. LAMB, THE Role of THE FATHER IN CHILd DevelopMENT 27 (1981) (lists of studies); Children of Divorce, supra note 117, at 246 (brief review of research). The studies of fatherless boys have been criticized for failing to control for the effects of economic deprivation typically faced by single-parent mothers. See Blechman, supra note 85, at 180 . 
sons than in handling their daughters. ${ }^{172}$ They relate a pattern, particularly common with boys, of mothers caught in a vicious cycle with a problem child in which the relationship steadily worsened and the mother felt more and more powerless, angry, and depressed. ${ }^{173}$

Similarly, Wallerstein and Kelly found that some mothers were especially harsh on their sons after separation, in part because the boys reminded them of their ex-husbands. ${ }^{174}$ At eighteen months after the divorce, more boys than girls longed for their fathers, more boys than girls were depressed, and only half as many boys had improved in their overall adjustment since separation. ${ }^{175}$ It is possible, however, that whatever problems boys face (or pose to their mothers) in mother-custody homes would be nearly as likely to arise in fathercustody homes and are traceable either to problems the boys faced before divorce or to special problems for boys of living in any singleparent situation. ${ }^{176}$ Furthermore, the Wallerstein study was of families in which the custodial mother believed she needed help, ${ }^{177}$ and it may be that the problems of boys in mother-custody simply display themselves earlier than the problems of girls. Hetherington in an earlier writing suggested that the problems for girls in homes without their fathers are most likely to show up in adolescence in the form of greater difficulties in relating to boys. ${ }^{178}$

In sum, the current body of research provides strong hints that many children will be happier when placed with the same-sex parent. Andrew Watson, for example, has recommended that girls be placed with their mothers. ${ }^{179}$ To my reading, more research is needed before recommending any sort of preference based on shared gender.

172. See The AfTermath of Divorce, supra note 91, at 162-73.

173. Id. at $169-70$.

174. J. WALLERSTEIN \& J. KelLY, supra note 21, at 108-13.

175. Id. at $165-68,170-72$.

176. For example, in comparison to girls, boys cause more disciplinary problems and are less responsive to parental efforts at correction in two parent-homes. See E. MACCOBY, supra note 58, at 221-23. On the other hand, at least one study conducted in the early 1960's reported a lower incidence of delinquency among boys raised by fathers than among boys raised by mothers. Gregory, Anterospective Data Following Childhood Loss of a Parent, I: Delinquency and HighSchool Dropout, 13 ARChives Gen. PsychiATRY 99 (1965).

177. J. WALLERSTEIN \& J. KELLY, supra note 21 , at 7-8. One additional puzzling aspect of Wallerstein's research is that women conducted all the interviews of children. If boys had more difficulties than girls relating to female interviewers, it could have affected the interviewers' findings.

178. See Hetherington, supra note 105 , at 313,324 (girls of divorced parents likely to be unusually apprehensive in relations with boys); see also Jacobson \& Ryder, Parental Loss and Some Characteristics of the Early Marriage Relationship, 39 AM. J. ORTHOPSYCHIATRY 779 (1969).

179. Watson, Children of Armageddon: Problems of Custody Following Divorce, 21 SyRACUSE L. REV. 55, 82 (1969). 
Although there is an abundance of research on boys in mother-headed homes, there is very little research, apart from the work of Santrock and Warshak, comparing boys in father-headed families with boys in mother-headed families or discussing girls in single-parent homes headed by fathers. Even in Santrock and Warshak's study, the youngest of the boys and girls studied were at least six years old at the time they were observed. ${ }^{180}$ None of the other impressionistic studies described earlier of families headed by single-parent fathers ${ }^{181}$ has reported substantial differences between the experiences or adjustments of girls and boys, neither remarking on boys looking especially well or girls looking comparatively poorly, although, with perhaps one exception, ${ }^{182}$ none of these studies appear to have looked for such differences.

b. The relevance of primary-caretaker status. Women have no attributes that so especially suit them for childrearing that they merit a preference in custody disputes simply because of their gender. ${ }^{183}$ On the other hand, men and women involved in custody disputes during divorce do not simply possess parenting or nurturing qualities in the abstract. They have each had a relationship with the particular child over whom they are fighting. One of them, more commonly the woman, has typically spent far more time giving care to the child than the other parent. When there is such a person within the family, I will call him or her the "primary caretaker."184

Three arguments can be advanced for preferring placement with parents who have been the primary caretaker: they know more about the particular child; they have demonstrated a dedication to meeting the child's needs; and they have built an emotional bond with the child that may be more important for the child to sustain on a daily basis than whatever bond the child has with the other parent. Of the three arguments, the last is the one most commonly advanced in favor of the primary caretaker. I will focus principally on this claim of the impor-

180. See Santrok \& Warshak, supra note 108 , at 116.

181. See note 108 supra.

182. D. LUEPNITZ, supra note 108, at 11 , describes Santrock and Warshak's research and thus seems to have been alerted to sex-linked differences. She did not report such differences in the body of her report. A few of the other father-custody studies cited at note 108 supra do relate anecdotes of particular problems fathers had with daughters (for example, feeling awkward in taking the daughter to buy clothes), but greater systematic difficulties are not discussed.

183. See notes 125-62 supra and accompanying text.

184. The term "primary caretaker" is not a precise term of art. For our purposes, we should be seeking to define the term functionally: to identify whether or not evidence suggests that a parent who performs many more of certain tasks with a child or has many more of certain sorts of contacts with the child can be predicted to serve the child's needs better. Unfortunately, we will find that such precision eludes us. 
tance of sustaining a special emotional bond between the child and the primary caretaker. The other two arguments will be taken up along the way. ${ }^{185}$

Unlike the arguments in the preceding section, the arguments for the primary caretaker can be framed without reference to the gender of the parent for whom they are being advanced. On the other hand, it is extremely difficult to discuss the arguments in any detail without alluding to gender, for, with a few exceptions, all the writing about children and their primary caretakers has relied on observations of children being raised by primary caretakers who were women. Indeed, much of this writing uses the terms "mother" and "primary caretaker" interchangeably. ${ }^{186}$ In the section that follows, the term "primary caretaker" will be used without reference to gender in discussions of theory or general propositions but the term "primary-caretaking mothers" will be used in discussions of specific research based on observations of mothers.

Here then is an attempt to state the strongest case that can be made for placing children with primary caretakers. Remember as you read that this is the partisan's brief for primary over secondary caretakers. After the case is set forth, the several ways in which it is not fully persuasive will be examined.

One of the central tenets of modern psychoanalytic and social learning theory is that the intimate interaction of a caretaker with an infant produces a bond between them, generally referred to as an "attachment."187 Young children can, and typically do, form attachments to more than one adult, including secondary-caretaking fathers, ${ }^{188}$ but the tie between a child and a primary-caretaking mother is generally depicted as stronger and more salient to the child than the tie with the father. "[M]ost theorists," says psychologist Michael Lamb, "whatever their orientation, have assumed that the

185. However, for discussions of secondary-caretaking fathers who quickly learn to meet their children's needs, see the earlier discussion of research on children in the custody of fathers, text at notes 108-16 supra.

186. An example obvious from its title is S. FralBerg, EVERY ChILD'S BIRTHRIGHT: IN DEFENSE OF MOTHERING (1977). The book is not a defense of caretaking by women but a defense of caretaking by primary caretakers, urging caution in placing children in day care and foster care. Bowlby also uses the terms interchangeably. See, e.g., J. BowLBY, ATTACHMENT (2d ed. 1982).

187. See, e.g., J. BowLBY, supra note 186; E. MAccoBX, supra note 58; see also M. RUTTER, supra note 85; Ainsworth, The Development of Infant-Mother Attachment, in 3 REVIEW op Child Development Research 1 (B. Caldwell \& H. Ricciuti eds. 1973). "Attachment" is a technical term in the field of child development. We will use it broadly, as most writers about child development seem to use it, to mean any "relatively enduring emotional tie [by one person] to a specific other person." E. MACCOBY, supra note 58, at 53 (emphasis omitted).

188. See text at notes 211-21 infra. 
mother-infant relationship is unique and vastly more important than any contemporaneous, or indeed any subsequent, relationships." 189

In the early months of a child's life, a primary-caretaker mother typically touches, caresses, and holds her child many times every day and feeds her several times a day. Within a few months, the child can typically identify her, has positive feelings toward her, and can tell her apart from others. By some point between around six months and a year, the child begins to display what is commonly called "attachment behavior": seeking to be near her, becoming distressed on separation from her, showing pleasure or relief on reunion with her, and orienting herself to her even when not in physical contact (listening for her voice, checking to make certain that she is not too far away). 190

Before becoming fully verbal, children and their primary caretakers develop elaborate and personal rituals of communication that apply to feeding, diaper-changing, responses to small injuries, and most of a child's other repeated events. Through these rituals, a high level of communication takes place in a "language" that no one else knows fully how to "speak."191 The mother assumes a place in her infant's psyche that others cannot replace by performing the same services.

Many writers about child development believe that the importance to the child of the psychological bond that develops between the child and primary caretaker in this early period stretches well beyond what might be inferred from these visible small events and interactions. They consider attachment to a primary caretaker the essential cornerstone for a child's healthy emotional development. At the earliest stage, it is critical to the child's learning to place trust in others and to have confidence in her own capacities. ${ }^{192}$ Later, it plays a central role in the child's capacity to establish emotional bonds with other persons. ${ }^{193}$ The sense of trust in others and in self that the attachment

189. Lamb, The Role of the Father: An Overview, in ThE Role of THE FATHER IN CHILD DEVELopMENT 2 (M. Lamb ed. 1976) (citation omitted). Lamb refers to several prominent theorists including Freud, Bowlby, Kohlberg, Maccoby, Parsons, and Sears.

190. See E. MACCOBY, supra note 58, at 46-54, 61; Rutter, supra note 85, at 285.

191. See E. MACCOBY, supra note 58, at 66-67, 76.

192. See, e.g., E. ERIKSON, ChILDHoOd AND SOCIETY 248-49 (2d ed. 1963).

193. As Freud put it, "the mother-infant relationship is unique, without parallel, established unalterably as the prototype of all later love relations." S. FREUD, AN OUILINE OF PSYCHOANALYSIS 45 (1948), quoted in M. Lamb, The Father's Role in the Infant's Social World, in Mother/Child, FATHer/Child Relationships 87, 88 (J. Stevens \& M. Mathews eds. 1978); see also S. FRAIBERG, supra note 186, at 4, 32. Marshall Klaus and John Kennell have stated the claim more broadly and, if possible, even more stridently:

This original mother-infant bond is the wellspring for all the infant's subsequent attachments and is the formative relationship in the course of which the child develops a sense of himself. Throughout his lifetime the strength and character of this attachment will influence the quality of all future bonds to other individuals.

M. Klaus \& J. KenNell, Maternal-INfant Bonding 1-2 (1976). 
provides may also affect the child's development of intellectual and social skills. ${ }^{194}$ The growing child passes through many developmental stages, each requiring her to acquire critical skills and capacities. At one stage, a child needs to learn how to interact successfully with other children, at another to begin to master the skills (reading, hunting, weaving, or whatever) needed to become a productive member of the larger society. The original bond of the child with the primary caretaker is believed to have an important continuing effect on the child's ability to pass through each stage with success. ${ }^{195}$

What harms are likely to befall a child who is separated from her primary caretaker at divorce and placed with the other parent? ${ }^{196}$ The greatest concern is likely to be expressed for preschool children. Unfortunately, as related in the preceding section, there are only a few studies of children of any age placed with secondary caretakers after divorce and none focusing on preschool children placed with secondary caretakers. The research that has been conducted on children separated from their parents that provides analogies to the divorce setting is primarily of two sorts. One is studies of children raised in orphanages or other institutions who never developed strong attachments as infants to any consistent caretakers. Such children, by the time they reach school age, often become withdrawn and restless and suffer severe problems in relating to others, even when adopted by loving parents in their late preschool years. ${ }^{197}$ The other relevant research is on young children who have formed attachments but are separated from both parents for periods of a few days to a week. James

194. See Ashton, The Role of the Attachment Bond in Effective Parenting, in MoTHER/ Child, Father/Child Relations, 31, 31-32 (J. Stevens \& M. Mathews eds. 1978).

195. See, e.g., BEYOND THE BEST INTERESTS, supra note 27, at 31-34.

196. In recent years, such questions about the consequences of disrupting children's relations with primary caretakers have been posed with concern in many settings - not only in the context of custody disputes after divorce, but also, for example, in the context of debates over public policies regarding the removal of children from parents thought to be neglectful or abusive, see Wald, State Intervention on Behalf of "Neglected" Children: A Search for Realistic Standards, 27 STAN. L. REV. 985 (1975); the placement of infants and toddlers in day-care programs, compare S. FRAIBERG, supra note 186, at 78-84 (raising doubts about the wisdom of day care for young children), with J. KAGAN, THE GROwTH OF THE CHILD: REFLECTIONS ON HUMAN DEVELOPMENT 74-100 (reporting on a study of day care and defending well-designed infant day-care programs); and even hospital practices that separate mothers from their newborns in the first minutes after birth, compare M. KLAUS \& J. KENNELI, supra note 193, at 88-98 (strongly urging policies to permit immediate mother-child contact), with Chess \& Thommas, Infant Bonding: Mystique and Reality, 52 AM. J. ORTHOPSYCHIATRY 213, 216-19 (1982) (raising doubts about Klaus \& Kennell's research).

197. See review of recent literature in Rutter, supra note 85 , at $287,288-89$. For research on institutionalized children, see J. BOWLBY, SEPARATION: ANXIETY AND ANGER 215-20 (1973); S. Provence \& R. LiPTON, INFANTS IN INSTITUTIONS (1962); Spitz, Hospitalism: An Inquiry into the Genesis of Psychiatric Conditions in Early Childhood, 1 Psychoanalytic Study or THE CHILD 53 (1945). 
and Joyce Robertson, for example, conducted a study and produced a series of films of young children whose mothers were briefly hospitalized and who were taken care of by strangers. Within as short a time as four days, the children suffered substantial distress and displayed withdrawal, loss of appetite, prolonged crying, and difficulty in sleeping. ${ }^{198}$

On the basis of this evidence and the general theory of attachment, both short- and long-term fears might be expressed for a child placed with a secondary caretaker, at least so long as it is assumed that the child's relationship to the secondary caretaker is not nearly as central to her sense of well-being as her relationship to the primary caretaker is. If placed with a secondary caretaker, the child might thus find the period immediately following separation especially stressful. Her needs will not be met in the way she has come to expect. Whether or not objectively cared for as well as before, the young child, and perhaps even the older child, is likely to feel anxious, sad, and less secure. Over the months that follow, the child may fail to master, or even regress in mastering, developmental tasks on which she is currently working.

The expectable long-term consequences of separation from the primary caretaker are less certain. Bowlby, however, has expressed the belief that the child who is separated from a primary caretaker early in life is more likely than other children to develop into an adult less capable than others of forming and maintaining emotional ties ${ }^{199}$ and to be subject to sudden depressions and to periods of acute anxiety. ${ }^{200}$

Although psychologists might worry about children separated from primary caretakers at all ages up to adolescence, the younger the child at separation (except for those under a few months of age), the greater the expected disruption of development. The strongest concern would probably be for children separated from their caretaker between the ages of five or six months and roughly three years. During these years many children show greater adverse reactions than at any later point to even relatively brief separations from their caretaker. ${ }^{201}$ At this early age, the child is incapable of understanding a

198. See Robertson \& Robertson, Young Children in Brief Separation: A Fresh Look, 26 Psychoanalytic Study OF THE ChILd 264 (1971).

199. See J. Bowlby, Child CARE AND the Growth of LOVE, at 215-19 (2d ed. 1965) (in these writings, Bowlby was not focusing on custody placement during divorce); $c f$. BEYOND THE BEST INTERESTS, supra note 27, at 32-33 (1973) (regarding consequences of separating children from "psychological parents," but considering both parents as likely "psychological parents").

200. See J. BowLBY, supra note 197, at 4-5.

201. See Robertson \& Robertson, supra note 198; see also Kagan, Emergent Themes in Human Development, 64 AM. SCIENTIST 186 (1976). 
primary caretaker's extended absence. Thus, in the context of divorce, even if the former primary caretaker visited frequently, the child might experience each leave-taking as permanent and as a rejection. Theory also suggests that during these early years the child is still building the strong ties to her caretaker from which healthy emotional development grows and that the primary caretaker's displacement will disrupt this process.

Some mental health professionals would extend the age of special concern to as late an age as ten. ${ }^{202}$ Because there are few studies of grade-school-age children moved from their primary caretakers, ${ }^{203}$ the fears about such a move are probably based on more general observations that psychosocial development can be affected by environmental changes at any stage of childhood ${ }^{204}$ and that the period from roughly five or six to ten or eleven, usually called "latency," is an important period of intellectual and social development for children. ${ }^{205}$

These are the arguments for primary caretakers that derive from attachment theory. Much about them is attractive. But the foundations of the case for primary caretakers prove wobbly when subjected to close scrutiny. A small part of the weakness is that the role of attachment bonds in child development has probably been overstated by Freud, Bowlby, and their other principal proponents. ${ }^{206}$ In their zeal to make certain that the importance of attachment was recog-

202. This concern has been expressed through endorsements of a presumption for mothers in custody disputes for children up to the age of ten. See, e.g., Watson, supra note 179, at 82; $c$. Garska v. McCoy, 278 S.E.2d 357 (W. Va. 1981) (applying a new preference for primary caretakers to children of "tender years," not defining the term but apparently including the children up to adolescence); Leonard \& Provence, The Development of Parent-Child Relationships and the Psychological Parent, 53 CoNN. B.J. 320 (1979) (custody should be given to the parent who had the primary nurturing role; the younger the child, the more likely the mother played that role, but individual examination is necessary).

203. Studies of children placed for adoption after reaching school age have been conducted but have included few children who had been living with a parent or single foster family up to that point. See, e.g., B. Tizard, Adoption: A SECond Chance 151-79 (1977).

204. See, e.g., Rutter, supra note 85, at 291; see also EARLY EXPERIENCE: MYTH AND EVIDENCE (A. Clarke \& A. Clarke eds. 1976) (claiming that stages beyond the early stages of development are just as important as the early stages).

205. See EARly EXPERIENCE: MYTH AND Evidence, supra note 204, at 273-76; E. ERIKson, supra note 192, at 258-61; $c f$. White, Some General Outlines of the Matrix of Developmental Changes Between Five and Seven Years, 26 BuLl. ORTON SOCY. 99, 101, 109 (1979) (between the ages of five and seven, children typically develop cognitive processes dominated by adult logic rather than juvenile logic, but both forms of logic always exist to varying degrees throughout the life of an individual).

206. For "revisionist" views of the centrality of the mother-infant attachment - not by any means claiming it unimportant to the child, but raising doubts about its irreplaceability and its dominance over other factors in the child's development - see Chess \& Thomas, supra note 196; Rutter, supra note 85 . More broadly, researchers have repeatedly found it difficult, even impossible, to predict the long-term outcomes from events occuring in early life. See A. SkolnICK, THE INTIMATE ENVIRONMENT: EXPLORING MARRIAGE AND THE FAMILY 378-79 (1973). 
nized, they ignored or undervalued the significance of other factors. ${ }^{207}$ Some recent research outside the context of divorce suggests that, even when a child moves permanently from her parents to caretakers she has not previously known at all, her long-term adjustment to separation "will be primarily determined by the quality of the relationship with the new caretakers, not by the experience of separation" from the previous attachment figure. ${ }^{208}$

For our purposes, however, the weakest part of the case for primary caretakers is not that it exaggerates the importance of attachment in general but that it exaggerates the importance of the bond to the primary-caretaker parent in comparison to the bond with the other parent. The claim for primary caretakers posits a minor position for secondary-caretaking parents in the development of children, or put more precisely, rests on observations of the mother-child relationship that have not included comparisons with any of the child's other relationships. ${ }^{209}$ Very few of those conducting the research with mothers have spent time observing the father-child relationship. They watched the miraculous bond that develops between primary-caretaking mothers and children and simply assumed that it was unique. ${ }^{210}$

Only within the last two decades has substantial research been conducted on the ties that children develop to their fathers in two-parent families. ${ }^{211}$ It indicates that although children have very different re-

207. See Wald, Thinking About Public Policy Toward Abuse and Neglect of Children: A Review of Before the Best Interests of the Child (Book Review), 78 MicH. L. REv. 645 (1980).

208. E. MAсCOBY, supra note 58, at 99. Yarrow, for example, found that children placed for adoption after developing attachments to a foster mother showed considerable distress at the time of being moved into the adoptive home, but eventually adjusted as well in their new homes as children placed for adoption nearer to birth. See Yarrow \& Goodwin, The Immediate Impact of Separation: Reaction of Infants to a Change in Mother Figures and Yarrow, Goodwin, Manheimer \& Milowe, Infancy Experiences and Cognitive and Personality Development at Ten Years, in The Competent INFANT: Research AND CommentaRy 1032, 1274 (L. Stone, H. Smith \& L. Murphy eds. 1973).

209. For example, one recent defense of a preference in custody disputes for primary-caretaker mothers traces the research on mothers and infants but overlooks the recent studies of the relationships children develop with their fathers. See Klaff, supra note 6, at 343-48.

210. As one study reviewing the literature on children commented, "A visitor from Mars might report that, as far as most psychologists on Earth are concerned, the only social object in the infant's life is its mother." Lewis \& Weinraub, The Father's Role in the Child's Social Network, in THe Role of THE FATHER IN CHILd Development 157 (M. Lamb ed. 1976).

211. One of the earliest studies of the father-infant relationship was H. SCHAFFER \& $P$. Emerson, The Development of Social AtTACHMENTS in INFANCY (Monograph of the Society for Research in Child Development, No. 29, 1964). See the especially helpful review of more recent literature by Thompson, supra note 83, at 64-77 (1983); see also Lamb, supra note 189; Fein, Research on Fathering: Social Policy and an Emergent Perspective, 34 J. Soc. IssUES, Winter 1978, at 122, 129-30. The research has taken many forms. Much of the work on attachment of fathers to infants and toddlers has been conducted using the "strange situation" procedure in which observers watch the interaction of parent and child in the presence of a stranger and upon reunion with the parent after being left alone with the stranger. For a recent description of the "strange situation" method and a general review of the literature, see Lamb, Thomp- 
lationships with their secondary-caretaker fathers than with their mothers, they typically form strong attachments to both.

An initial, uniform finding from interviews with parents is that, in general, fathers spend far less time with infants than mothers, even when mothers work outside the home. ${ }^{212}$ A high proportion of fathers report that they perform no regular caregiving functions at all. ${ }^{213}$

On the other hand, as early as eight months of age, and quite clearly by a year and a half, children differentiate both between their mothers and strangers and between their fathers and strangers, and their behavior toward their fathers is much more like their behavior toward their mothers than it is like their behavior toward strangers. ${ }^{214}$ Some studies have found that at about one year, children more commonly seek out their primary-caretaking mother in preference to fathers for relief when tired or anxious and both parents are present. ${ }^{215}$ But, at about the same age, when both are present, children more commonly turn to the father for social interaction. ${ }^{216}$ Forced to choose, many people would believe that the primary caretaker's relief-giving capacity is more important; yet, there is very little evidence to suggest that when only a secondary-caretaking parent is available, that parent is not fully adequate to provide the needed reassurance. ${ }^{217}$

The central message of this research is that by the time most children are toddlers, they have formed substantial emotional bonds with both parents. As children grow, primary-caretaking mothers continue

son, Gardner \& Charnow, supra note 26. Other research on fathers' ties to their children has involved interviewing or other forms of observation in laboratories or home settings. See Radin \& Russell, Increased Father Participation and Child Development Outcomes, in FATHERHOOD AND FAMILY Policy 191, 192-93 (M. Lamb \& A. Sagi eds. 1983) (describing research approaches).

212. See the review of studies in Thompson, supra note 83, at 64-65. One study found that fathers spent an average of only 15 to 20 minutes each day with infants. See Ban \& Lewis, Mothers and Fathers, Girls and Boys: Attachment Behavior in the One-Year Old, 20 MERRILL PALMER Q. 195 (1974).

213. Kotelchuck, The Infant's Relationship to the Father: Experimental Evidence, in THE Role of THE FATHER IN Child Development 329, 338 (M. Lamb ed. 1976) (reporting on a 1972 study by Kotelchuck, which found that in a middle-class Boston sample only $25 \%$ of fathers had "any regular daily caretaking responsibilities").

214. See Lamb, supra note 147, at 307-10 (describing study he conducted and reporting the research of others). Children typically engage in substantial amounts of attachment behavior and "affiliative behavior" such as smiling and laughing with both parents. See Thompson, supra note 83 , at $67-72$, for a thorough review of the "strange situation" literature as it bears on the father-infant relationship.

215. See, e.g., Cohen \& Campos, Father, Mother and Stranger as Elicitors of Attachment Behaviors in Infancy, 10 Developmental PsYchology 146 (1974).

216. See Thompson, supra note 83 , at 69.

217. I infer this from children's responses to fathers during "strange situation" experiments. See Thompson, supra note 83, at 67-72. Secondary-caretaking fathers, at least when observed in laboratory conditions, also seem as competent as primary-caretaking mothers in responding to their own newborns and infants. See Thompson, supra note 83, at 66-67. 
to devote more time than fathers to childcare, but fewer of the tasks require intimate physical interaction with the child. The amount of time that parents actually spend in social interaction with their children typically draws closer. ${ }^{218}$ During these years, secondary-caretaking fathers generally perform other important functions for children that seem to affect positively the strength of children's emotional ties to them. They help to establish and enforce rules of conduct; they provide models of appropriate behavior and express expectations for the children's conduct; they concern themselves with the child's physical safety; and they engage in various sorts of reciprocal behaviors such as "buddy" or "flirt." 19

To be sure, many of the functions the father performs are mediated by the role of the mother: what the child derives from the father is affected in part by the child's relationship with her mother and by the child's perception of each parent's relationship to the other. ${ }^{220}$ Nonetheless, whatever the mediating forces, fathers in the two-parent family typically hold a central position in children's daily lives and in their sense of well-being. As Ross Thompson has said in summarizing the literature:

[B]oth fathers and mothers are significant figures in the infant's world from a very early age. . . . [I]t is apparent that infants develop emotionally salient attachment relationships with each parent by the end of the first year. . . There is every reason to assume that the psychological salience of each parent persists as the child grows older. ${ }^{221}$

As Thompson and others recognize, however, the research with young children and each of their parents must be used with care. The attachment behavior observed by researchers toward secondary caretakers is not the same as the attachment itself. The frequency of any behavior, however suggestive, may not mirror the strength of the psychological bond of the child to either parent. ${ }^{222}$ It does not follow

218. See Pleck, Men's Family Work: Three Perspectives and Some New Data, 28 FAM. CoORDINATOR 481 (1979). Even for young children, the amount of time mothers actually interact with their infants (as opposed to being present in the room or home with them) is less than most people assume. See, e.g., K. Clarke-Stewart, InTERactions Between Mothers and Their Young ChildRen: Characteristics AND Consequences 32-33 (Monographs of the Society for Research in Child Development, Vol. 38, Nos. 6-7, 1973).

219. Radin \& Russell, supra note 211 , at 193-99 (1983).

220. See Clarke-Stewart, And Daddy Makes Three: The Father's Impact on Mother and Young Child, 49 CHILD DEV. 466 (1978) (discussing the effects of each parent on the other's relation with the child). Some of the functions secondary-caretaking parents perform, such as their role as participants in play, may be especially tied to their not having primary-caretaking responsibilities.

221. See Thompson, supra note 83 , at 90 (emphasis in original).

222. Under laboratory circumstances, for example, two-year-old children have been found to engage in attachment behavior toward a babysitter they have known only a few hours when a total stranger is introduced. Feldman \& Ingham, Attachment Behavior: A Validation Study in 
from the studies done, even if the researcher's observations are wholly accurate, that a child will suffer no more from long-term separation from a primary caretaker than from the same separation from a secondary caretaker. ${ }^{223}$

The ultimate point to be drawn from this brief review of the research is not that primary caretakers and other parents stand in precisely the same place in children's minds. Rather it is that the differences in the degree of significance of children's ties to their parents seem to be less than had been believed. In particular, there are, for our purposes, two complementary implications of the research, each supported by and supporting other information now available about divorced families with children. The first is that even though the primary-caretaking mother is typically associated in the child's mind with caregiving functions that we may believe are especially central to a child's well-being, it nonetheless may be the case that the trauma for children of losing daily contact with the primary caretaker will typically be no more severe or only marginally more severe than the trauma when they lose daily contact with the other parent. ${ }^{224}$ The studies of the close ties children typically develop with their fathers in ongoing families make more plausible the suggestions of Wallerstein and others that some children in the custody of their mothers who seem to have good relationships with their mothers have low self-esteem and high levels of depression due in significant part to the decreased contact with their father. ${ }^{225}$

The second implication is the converse: that there is less reason than in the past to fear that a secondary-caretaking father, if given custody, will meet his child's basic needs for continuity of attachment and nurturing less satisfactorily than primary-caretaking mothers. I described in an earlier section the many recent impressionistic studies

Two Age Groups, 46 CHILD DEv. 319 (1975). This research does not prove, of course, that the babysitter was as important a figure as the mother in the two-year-old's life.

223. While the research suggests that secondary-caretaking fathers serve many of the same functions for children in terms of their senses of security and well-being, it also leaves open the possibility that they they do not serve them to the same degree. Moreover, the same research suggests that fathers and primary-caretaking mothers serve somewhat different functions, functions that may or may not be of equal significance to the child.

224. Wallerstein and Kelly reported the grieving of children for their absent fathers and their sadness when he fails to visit (although it is impossible to determine how much of their grieving is for their broken family). J. WALLERSTEIN \& J. KELLY, supra note 92, at 132-46.

225. See J. WALlersteIN \& J. KelLY, supra note 92, at 170-72 (18 months after separation), 217-20 (five years after separation); Stress \& Coping, supra note 91; Hess \& Camara, PostDivorce Family Relationships as Mediating Factors in the Consequences of Divorce for Children, $\mathrm{J}$. Soc. Issues, Fall 1979, at 79. But cf., Nelson, Moderators of Women's and Children's Adjustment Following Parental Divorce, 4 J. DIvorCe 71 (1981) (mother's post-divorce relationship to her former spouse important to her own healthy adjustment, but pattern of visitation with child not reported by mothers as significant factor in child's adjustment). 
of fathers with custody after divorce, virtually all of which report that children in such settings are doing reasonably well. ${ }^{226}$ Because of their methodological shortcomings, these studies do not, standing alone, justify a conclusion that most children living with their fathers are doing as well as the nonrandom samples of children who have been studied, or even that the long-term outcomes for the very children observed would be as favorable as short-term appearances indicate. Taken together, however, with the recent studies of fathers' place in children's lives in two-parent families, the optimistic conclusions of the authors of the father-custody studies seem at least more plausible: when fathers assume custody, they may well typically begin with much more of a foundation than has been previously believed. ${ }^{227}$

Despite these encouraging suggestions from the research on fatherchild relationships, fears about the effects of secondary-caretaker custody may nonetheless persist for the youngest children, those up to four or five years of age. To be sure, there is little basis for such a fear in any of the studies actually observing mothers and fathers with their young children. On the other hand, these studies - typically brief observations in laboratories - cannot in themselves disprove the theories of Bowlby, Freud, and others who posit a unique bond between infants and primary-caretaking mothers that develops over the early years. At most, they raise doubts. There is still no methodologically rigorous research on children placed in the custody of secondary caretakers at an early age. Thus, where one comes out in the end with regard to custody decisions involving young children will depend in large part not on empirical research but on the persuasiveness of theory. I have shared earlier drafts of this Article with a substantial number of persons with training in psychology or psychiatry. 228 Nearly all acknowledge the absence of a firm empirical foundation for the conclusion that preserving the bond of children to primary caretakers is more critical than preserving the bond to secondary caretakers and yet nearly all believe that there is something special in that relationship worthy of weight in making decisions about placement.229

As to the next older group of children, those between roughly five

226. See notes 108-17 supra and accompanying text.

227. At a minimum, the research on children and fathers makes clear that nothing useful can be inferred about father-child relationships from the research on children in institutions or children adopted by strangers.

228. Some of them are listed in the acknowledgements in the opening footnote. Another of those who had a similar reaction to an earlier draft was Eleanor Maccoby, Department of Psychology, Stanford University.

229. In conversations, I am never fully certain whether the psychologists are reflecting an unspoken, and perhaps unconscious, concern for the primary caretaker as well. See Section II, supra, and Section III B, infra. 
and ten, theorists might still express some concerns, but their claims about the dangers that might accrue to children placed with a secondary caretaker whom they know well are almost certain to be more muted. Moreover, neither the research on single-parent fathers or single-parent mothers nor the research on single-parent families justifies a belief that secondary-caretaking parents who volunteer to care for children in this age group will perform less well because of their earlier secondary status.

In the end, developmental theory supports some sort of weight in the decisional process for primary caretakers of very young children. It also provides guidance toward a functional definition of "primary caretaker." It suggests that what is important is not simply tasks performed for the child but interactions with the child - direct contact in feeding, bathing, talking, snuggling, and so forth. ${ }^{230}$ If one parent performs many more of those interactions than the other parent, that parent should probably be considered the primary caretaker, even if he or she works part or full time outside the home and someone else provides the caregiving during work time. On the other hand, as the differences between the parents' roles decrease and the difference in time spent by them in these sorts of interactions becomes more nearly equal, theory and available evidence suggest little basis for drawing fine lines.

(c) A counterweight: the higher earnings of men and the relevance of resources in general. The preceding section argues that there may be certain advantages for a young child in placing her with the primary caretaker. In building this claim, however, I have overlooked a counterbalancing systematic advantage that secondary caretakers, particularly male secondary caretakers, are likely to offer the child: a higher income and greater resources. A large income disparity typi-

230. In Garska v. McCoy, 278 S.E.2d 357, 363 (W. Va. 1981), the West Virginia Supreme

Court endorsed a primary-caretaker preference, defining primary caretaker as follows:

In establishing which . . . parent is the primary caretaker, the trial court shall determine which parent has taken primary responsibility for, inter alia, the performance of the following caring and nurturing duties of a parent: (1) preparing and planning of meals; (2) bathing, grooming and dressing; (3) purchasing, cleaning, and care of clothes; (4) medical care, including nursing and trips to physicians; (5) arranging for social interaction among peers after school, i.e. transporting to friends' houses ... (6) arranging alternative care i.c. babysitting, day-care, etc.; (7) putting child to bed at night, attending to child in the middle of the night, waking child in the morning; (8) disciplining, i.e. teaching general manners and toilet training; (9) educating, i.e. religious, cultural, social, etc.; and (10) teaching elementary skills, i.e. reading, writing, and arithmetic.

Under the approach to defining "primary caretaker" that I would recommend, most, but not all, of the "duties of a parent" that the Garska court includes would be relevant. Tasks such as numbers (1) and (3) on the Garska list, the preparing and planning of meals or the purchasing, cleaning, and care of clothes, would not be of direct relevance unless they included close interaction with the child; on the other hand, a factor not included in the Garska list, the actual feeding of a small child, might be highly relevant under my definition. 
cally exists between divorcing parents. For example, within a sample of over four hundred divorcing families with minor children that I studied in Michigan, one parent earned at least fifty percent more than the other parent in over ninety percent of cases; in at least four out of five cases in which there was such a disparity, it was the father who had the higher income. ${ }^{231}$ And while child-support payments can be used to offset this disparity in part, a large income difference is likely to persist in a high proportion of cases. ${ }^{232}$

If, in general, secondary caretakers have substantially higher resources, are there advantages to children from access to such resources that neutralize the advantages of placing children with primary caretakers? Similarly, should the systematic higher earnings of men be considered as yet another reason for rejecting the arguments considered earlier for preferring women as caretakers for very young children?

At the extreme, of course, a child with no economic resources lacks the most basic necessities: food, clothing, and shelter. The risk of such privation, however, is rarely at issue in a custody dispute. In most cases, the child's most basic needs can be met in either setting. The disparity in income is, nonetheless, likely to make important differences in the quality of life available to the child in the two settings. Studies have shown that in successive income groups of the general population from low to high, the proportion of people who report themselves to be happy rises steadily. ${ }^{233}$ For the divorcing family, access to resources can determine whether or not the custodial parent can afford to remain in the home the couple lived in during the marriage and, as it does for all Americans, it can mean access to opportunity for the child - to a more expensive education, summer camp, or music lessons. ${ }^{234}$ Moreover, even when most basic needs can be met, a

231. The study was conducted in Genesee County, Michigan in the 1970's, using a random sample of about 400 divorced couples with minor children. Other findings from the study are reported in D. Chambers, Making Fathers Pay: The Enforcement of Child Support (1979).

232. Id. at 37-68.

233. See Easterlin, Does Economic Growth Improve the Human Lot? Some Empirical Evidence, in Nations AND Households in Economic Growth 89, 99-103 (P. David \& M. Reder eds. 1974); see also PRESIDENT's COMMISSION FOR A NATIONAL AGENDA FOR THE

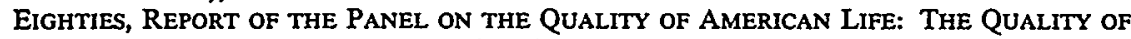
AMERICAN LIFE IN THE EIGHTIES 17 (1980). As many have pointed out, having sufficient resources within a culture is probably a necessary condition but not a sufficient condition for a sense of well-being. See A. CAMPBell, P. Converse \& W. Rodgers, THE QuALITY of AMERican life: Perceptions, Evaluations, ANd Satisfactions 380-84 (1976).

234. In fact, it is a belief that money makes a difference in children's well-being that explains, at least in substantial part, the recent calls for much more aggressive state enforcement of childsupport orders. 
parent accustomed to living at a higher standard is likely to worry a great deal about money, ${ }^{235}$ which in turn may produce stress for the child. ${ }^{236}$

At least in the abstract, it would thus appear wholly defensible for courts to give weight in custody decisions to the comparative financial positions of the parties. Some custody laws explicitly require considering the parents' resources, ${ }^{237}$ and some courts are reported to do so routinely under a best-interests standard. ${ }^{238}$ Similarly, legislatures might take these financial considerations into account in deciding whether or not to adopt an otherwise defensible preference for primary caretakers.

The problem with giving substantial weight to resources or income potential is that, in this country today, the effect of doing so is to disadvantage mothers in two ways that many people would consider unfair. ${ }^{239}$ First, women in general earn much less than men in general. ${ }^{240}$ This disparity in income is widely perceived to be the result of systematic discrimination against women in the labor market. Second, even in families in which the particular parent, usually a woman, could have earned as much as her spouse, a parent who has, with her spouse's concurrence, stayed at home or worked less than full time because of children is at a disadvantage as to resources for reasons that we should applaud, not count against her. For these reasons, it might well be argued that because of the effect it has on mothers, courts should ignore systematic income differences in forming rules.

If such an argument is to be accepted, the first ground of systematic discrimination against women is more compelling to me than the second. If there were no gender discrimination in wages, and the only disparity in earnings came from the fact that one parent had participated less in the labor market in order to care for her children, it would not be bothersome that parents who assume differing roles in

235. See A. CAmpbell, P. Converse \& W. Rodgers, supra note 233, at 398, 420.

236. Cf. Wallerstein \& Huntington, supra note 101, at 150-52 (good psychological adjustment of children significantly associated with adequate, stable child support, but poor psychological adjustment unrelated to issues of child support).

237. For example, Michigan's child custody act lists among factors for a court to consider in determining a child's best interests "the capacity . . . of competing parties involved to provide the child with food, clothing, medical care . . . and other material needs." MICH. CoMP. LAws M.C.L.A. § 722.23(3)(c) (1979).

238. See Polikoff, Exploding the Myths, supra note 69, at 190.

239. See Id.; Uviller, supra note 10.

240. See U.S. Bureau of the Census, Statistical Abstract of the United States, table 774, at 469 (1984). As of 1981, among year-round, full-time workers, women's median earnings were $\$ 12,457$, men's were $\$ 20,692$. In addition, more women than men work part time and earn even less than full-time working women. This disparity in income appears to apply to divorced men and women with children. See D. ChAMBERS, supra note 231, at 53. 
childcare should find their differing roles during marriage permitted them at separation to offer differing advantages to the child. ${ }^{241}$ On the other hand, the fact of gender discrimination in wages is genuinely troubling. It is not merely that women face a disadvantage for a reason outside their control (most qualities taken into account in custody matters are in some sense outside the individual's control) but rather that a male-dominated economic system has imposed this economic subjugation and now stands ready to take further advantage of it.

Expressly to offset this economic discrimination, some writers have proposed the return to a strong maternal preference that can be overcome only by a showing of unfitness. ${ }^{242}$ A milder approach would be to ignore systematic economic differences between men and women in considering a maternal or primary-caretaker preference, and to direct courts in individual cases to consider financial resources of the parties only if one parent is unlikely to be able to meet the child's most basic needs. Of the two approaches, I prefer the latter, even though I am uneasy about any special rule regarding resources. The source of my discomfort is that both ways of compensating for economic discrimination necessarily involve baldly placing some adult interest (here, the interest of women in equal treatment) ahead of the interests of the particular child involved in a custody dispute. Contrary to my stated goal in the section on the interests of the parent, ${ }^{243}$ an adult interest would be treated not as a secondary value to take into account only when the child's needs do not point to a placement with one parent over the other, but a primary interest being taken into account despite a potential cost to the child.

\section{B. What We Know About the Needs of the Parents.}

In Part II above, I argued that judges and legislators would be acting sensibly if, in framing rules for resolving custody disputes, they accorded some weight to the interests of parents, so long as they continued to give primary weight to the interests of children. ${ }^{244}$ I suggested in particular that a rule creating a rebuttable presumption for primary caretakers might justifiably rest in part on a finding, if one could be made, that primary caretakers typically suffered emotionally much more than secondary caretakers on the loss of the custody of

241. To be sure, women are socialized to remain in the home with children or to subordinate their careers to the careers of men, but men also are socialized not to remain at home and not to center their lives around children.

242. See, e.g., Uviller, supra note 10.

243. See text at notes 33,63 supra.

244. See notes 63-70 supra and accompanying text. 
their children. ${ }^{245}$ In this section I ask whether such a finding can in fact be made.

Unfortunately, just as there are no longitudinal studies comparing children in the custody of mothers (or primary caretakers) with children in the custody of fathers (or secondary caretakers), so there are no longitudinal studies comparing the experience of primary caretakers who are denied custody of children with that of secondary caretakers in the same position. Indeed, there appear to be only two published studies, of any kind, reporting on parents who had once been primary caretakers but later lived apart from their children. One is an exploratory, impressionistic study based on interviews with a small group of divorced, noncustodial mothers. ${ }^{246}$ The author describes many of the women she interviewed as feeling depressed, unworthy, unloved, and no longer in control of their world, but she was not in a position to compare these women's reactions with those of former secondary caretakers living apart from their children. The other study, very different in its scope, included a large sample of divorced parents, of whom around twenty-five were mothers living apart from their children. The study provides indirect support for a conclusion that primary caretakers have more at stake than secondary caretakers in continued contact with their child because the mothers living apart from their children were substantially more likely to maintain regular visitation with their children than were fathers living apart from their children. ${ }^{247}$

Despite the paucity of direct observations and comparisons, the hypothesis that primary caretakers generally will be more seriously affected emotionally by the loss of custody than secondary caretakers has substantial plausibility. Whenever one parent receives sole custody of a child, the other parent is necessarily shifted into being just a "visitor." The shift is likely to mark a much more dramatic change in the lives of most primary caretakers than it will for most secondary

245. An alternative hypothesis would be that even if primary caretakers without custody of their children are no more despondent than are secondary caretakers without custody of their children, it is possible nonetheless that having custody of their children will make primary caretakers substantially happier than having custody will make secondary caretakers.

246. See Fischer \& Cardea, Mother Child Relationships of Mothers Living Apart From Their Children, 5 ALTERNATIVE LIFESTYLES 42 (1982) (sample of 17 mothers, at least a few of whom had joint custodial arrangements in which children spent at least half their time with their fathers). There also have been a few journalistic pieces. See, e.g., Doudna, The Weekend Mother, N.Y. Times, Oct. 3, 1982, §6 (Magazine), at 72.

247. See Life Course, supra note 103, at 663 (In a sample of noncustodial mothers and fathers, $69 \%$ of the mothers, but only $33 \%$ of the fathers, had visited with their minor children at least once a month during the preceding year; in fact, $52 \%$ of the fathers, but only $14 \%$ of the mothers, had not seen their child in over a year. The sample included 336 fathers, but only 25 mothers.); see also Santrock, Warshak \& Elliott, Social Development and Parent-Child Interaction, supra note 117, at 294 (reporting similar finding in their study). 
caretakers. For primary caretakers, shifting to "visitor" status almost certainly leads to a substantial reduction in time spent with the child. ${ }^{248}$ While it is true that the primary caretaker who loses custody is freed from the petty drudgery of washing school clothes and packing lunches, for many caretakers the predictable rhythm of these very tasks had given structure to their lives. They are likely to experience the sudden freedom as a loss.

In addition, primary caretakers, whether female or male, may well be more dependent than secondary caretakers on the emotional support and stimulation they receive from the small interactions with the child, especially the young child - the cuddling, the seemingly aimless chatter, and so forth. ${ }^{249}$ Moreover, those primary caretakers, especially those who have been full-time homemakers, often have no identity other than their identity as spouse and parent to fall back upon. Divorced and without their children, they have nothing to make them feel valued. ${ }^{250}$ Most secondary caretakers, at least most secondary-caretaking men, have a second identity through their job. However much the parenting role has meant to them and however much they complain about their work, it seems likely that when they lose custody, they are less frequently left without any activity from which they derive a sense of worth and a sense of place. ${ }^{251}$

For all these reasons, one might suppose that, in general, primary caretakers, and especially those primary caretakers not employed outside the home, suffer emotionally more than secondary caretakers when deprived of the opportunity to live with their children.252

248. I have already alluded to the substantially greater number of hours that full-time primary caretakers typically spend with their children, especially when the children are young. See note 184 supra and accompanying text.

249. See Benedek, Parenthood as a Developmental Phase: A Contribution to the Libido Theory, 7 J. AM. PSYCHOANALYTIC A. 389 (1959) (referring to the intense "symbiotic" relation of mother and child during the period when child is nursing); Thompson, Normal Child Development, in SOcIal. WORK WITH ABUSED AND NEGLECTED ChILDREN: A MANUAL OF INTERDISCIPLINARY PRACTICE 219 (K. Faller ed. 1981) (primary-caretaking mother relives her own childhood experience through her child and the years of intense interaction with the child are critical to her sense of well-being and contribute to her own emotional growth); Pruett, supra note 149 , at 273 (reporting primary-caretaking fathers who developed an especially intense relationship with infants).

250. Cf. R. WEISS, supra note 98 , at 172 (reporting that mothers with custody of their children after divorce report that their children's need for them is critical to their sense of being a valuable person).

251. For a discussion of the central place of work to most working peoples' sense of selfworth, see WORK IN AMERICA: RePORT OF A SPECIAL TASK ForCE TO THE SECRETARY of Health, Education and Welfare 3-10 (1973).

252. Any attempt at assessing the probable differences between primary and secondary caretakers also needs to take into account an additional factor that probably affects the emotional responses of most primary-caretaking women, but not those of primary-caretaking men. In this country today, divorced women living apart from their children, particularly young children, are likely to be perceived by others as deserters or as unfit. They face a stigma not experienced by 
Luepnitz, in her interview study of parents after divorce, quoted one mother who, though speaking only about her own children and former husband, summarized well the case for primary caretakers: " $\mathrm{He}$ is an excellent parent, but they are the most important thing in my life, and I would not have survived without them. They would have been happy either way, but I wouldn't have pulled through if I had lost them."253

Unfortunately, the dearth of direct research on primary caretakers who have lost custody of children makes it impossible to prove or disprove any hypothesis about their suffering, even in the purest case of the full-time caretaker of the preschool child. Even less can be said about the probable emotional suffering of the primary caretaker who has been working full time for some period before the separation, 254 or the parent who served as full-time primary caretaker when the child was very young but whose child is now an adolescent.25s

A few suggestions about the probable harms to primary caretakers can be obtained from research in related areas, but this research can serve at most to refine hypotheses, not to prove or disprove them. Two sorts of analogous research are available. The first has examined adults' emotional responses to other life changes and stresses that might be comparable to loss of custody. The second is the research on the lives of primary-caretaking mothers with custody and the lives of secondary-caretaking fathers without custody, which may provide clues about what one might find if the situations were reversed.

With regard to other life stresses, research has repeatedly revealed

divorced men in general. Cf. Fischer, Mothers Living Apart from their Children, 32 FAM. REL. 351 (1983) (Faculty members and graduate students in West Texas were asked to appraise ten "lifestyles" in terms of being common or uncommon, socially approved or disapproved. The position of the noncustodial father was seen as common and approved; the position of noncustodial mother was seen as uncommon and disapproved. Only persons in homosexual cohabitation were seen as more disapproved than the woman who lived apart from her children.).

For our purposes, it is probably wise to try to separate out and disregard any additional emotional suffering caused by this stigma, because, if this were considered in the shaping of rules, states would simply be reinforcing old notions of proper responsibilities based on sex alone that they may no longer wish to endorse.

253. D. LUEPNITZ, supra note 108, at 23-24.

254. As of 1981, over half of American mothers with children three to five years old were in the labor force. See Bureau of the Census, U.S. Dept. OF Commerce, Statistical AbSTRACT OF THE UNITED STATES: 1982-83, at 142 (table 223) (103d ed. 1982). While it seems plausible that a job outside the home would give the primary caretaker a source of satisfaction and role to fall back upon, it is nonetheless equally plausible that, if the primary caretaker still has an intense attachment to his or her children, the loss of custody will deprive other life activities of their satisfaction. At least one study has suggested that employed mothers are far more likely to receive satisfaction from parenting than from their jobs. Hoffman, Social Change and its Effects on Parents and Children: Limitations to Knowledge, in WOMEN: A DEvelopmental Perspective 313, 319 (P. Berman \& E. Ramey eds. 1982).

255. Cf. note 264 infra (literature on the empty nest). 
that sudden, major changes of all sorts in people's lives trigger both emotional and physical problems. ${ }^{256}$ The more profound the change, the greater the likely reaction. Death of a spouse is the life event most likely to be followed by illness. ${ }^{257}$ Following it in frequency of health crises are marital separation and divorce, ${ }^{258}$ each of which is more closely comparable to the death of a spouse in the way it is experienced than has usually been recognized. ${ }^{259}$ Some research also suggests that the effects of sudden changes are additive: if several occur simultaneously the risks of illness or emotional problems increase correspondingly. ${ }^{260}$ Separation and divorce often produce multiple changes - not just the ending of a relationship but also movement to another home or town, changes in employment and income, and changes in daily living schedule, each an independently stressful occurrence. ${ }^{261}$ Loss of custody has not been studied in this context, but the research on these other events suggests that if loss of custody marks a more momentous further life change for primary caretakers than for secondary caretakers, then the emotional and health costs for the primary caretaker are likely to be greater.

One might hope to learn something about the comparative effects of loss of custody on primary and secondary caretakers from research on a few other life events that seem especially analogous to loss of custody. A small amount of research does exist, for example, on parents' reactions to the death of a child, ${ }^{262}$ to the placement of a child in foster care or in an institution, ${ }^{263}$ and to a child's growing up and

256. See, e.g., M. RILEY, M. JoHNSON \& A. FONER, AGING AND SOCIETY 184 (1972) (persons compelled to retire unhappy with their loss of a work role).

257. Holmes \& Rahe, The Social Readjustment Rating Scale, $11 \mathrm{~J}$. Psychosomatic RESEARCH 213 (1967). Some recent research suggests that divorce is even more likely to lead to physical and mental health problems than death of the spouse. See Divorce's Stress Exacts LongTerm Health Toll, N.Y. Times, Dec. 13, 1983, at Cl, col. 1; see also Rahe, Meyer, Smith, Kjaer \& Holmes, Social Stress and Illness Onset, 8 J. Psychosomatic Research 35 (1964).

258. See note 257 supra.

259. R. WEISS, supra note 98 , at $43-46$. Weiss believes that most married people, even those experiencing enormous tensions in the marriage, become intensely attached to their spouses and pass through something very similar to mourning upon separation.

260. See, eg., Hebert, Life Changes and Seriousness of Illness in Female College Students, 43 PsYCHOLOGICAL REP. 1297, 1298 (1978) (finding a significant relationship "between the number of life changes and the seriousness of illness"). But see Rabkin \& Struening, Life Events, Stress, and Ilness, 194 SCIENCE 1013, 1015 (1976) ("only cursory attention" has been devoted to "the size and practical significance of the correlation between number and nature of life events and subsequent illness episodes").

261. Changes in financial state, change to a different line of work, change of living conditions, revisions of personal habit, and changes of residence are all on the list of stressful events that, at least when coupled with other events, are frequently followed by illness. Holmes \& Rahe, supra note 257 , at 216.

262. See summary in J. BowlBX, Loss: SADNESS AND DEPRESSION 179 (1980).

263. See S. Jenkins \& E. Norman, Filial Deprivation and Foster Care 107, 225 
leaving home. ${ }^{264}$ Unfortunately, such research is inconclusive for our purposes, because almost none of it compares the reactions of primary and secondary caretakers.

Inconclusive also, unfortunately but inevitably, is the indirect evidence that can be adduced from the existing research on intact and divorced families. In stating at the beginning of this section the hypothesis that primary caretakers are likely to suffer more, I have already alluded to the principal supportive evidence: the substantially

(1972) (mothers and fathers report similiar sad feelings on day of placement); Mandelbaum, Parent-Child Separation: Its Significance to Parents, 7 Soc. WoRk, Oct. 1962, at 26 (parents of children entering residential treatment report feeling loneliness and inadequacy; no reported differences between mothers and fathers); Smith, Ricketts \& Smith, The Recommendation for Child Placement by a Psychiatric Clinic, 32 AM. J. ORTHOPSYCHIATRY 42 (1962) (parents report intense feelings of loneliness, emptiness, and guilt; no reported differences between mother and father).

264. There is somewhat more writing about parents' reactions to the child who leaves home on reaching adulthood. It has been long assumed that mothers reacted more severely than fathers to the suddenly "empty nest." See Harkins, Effects of the Empty Nest Transition on SelfReport of Psychological and Physical Well-Being, 40 J. MARRIAGE \& FAM. 549 (1978) (referring to both popular and clinical literature and pointing out recent full-page advertisements in medical journals recommending antidepressant medications for women to combat the empty-nest "syndrome").

Nearly all recent research concludes, however, that most women who have been primary caretakers either experience almost no sadness or, at most, a quickly passing period of sadness as their children leave. See, e.g., L. RUBIN, WOMEN OF A CERTAIN AGE 13-40 (1979) (interviews with 160 women aged 35-54, reporting periods of sadness but overall happiness and relief); Glenn, Psychological Well-Being in the Post-Parental Stage: Some Evidence from National Surveys, 37 J. MARRIAGE \& FAM. 105 (1975) (middle-aged women with children who have left home report somewhat greater happiness than middle-aged women with children still at home); Harkins, supra (study of 318 women with children recently graduating from high school or about to do so, children in varying stages of transition; found "empty nest" effects slight and quickly passing; transition produced positive effect on psychological well-being); Lewis, Freneau \& Roberts, Fathers and the Postparental Transition, 28 FAM. CoORdinator 514 (1979) (interviews with 118 fathers; $22 \%$ reported sadness at last child leaving home). But see Bart, Depression in Middle-Aged Women, in WOMEN IN SEXIST SocIETY 99 (V. Gorneck \& B. Moran eds. 1971) (depression in a sample of hospitalized women seemed to be related in part to empty nest and related loss of sense of performing important role); Birnbaum, Life Patterns and Self-Esteem in Gifted Family-Oriented and Career-Committed Women, in WOMEN AND ACHIEVEMENT 396 (M. Mednick, S. Tangri \& L. Hoffman eds. 1975). Few studies have compared mothers' responses with fathers' responses, and those that have do not report significant differences in self-reported reactions. See L. Saunders, Husband-Wife Consensus in Their Perceptions of Life Satisfaction in the Postparental Years (Aug. 1975) (unpublished paper presented at the meeting of the National Council on Family Relations), cited in Lewis, Freneau \& Roberts, supra, at 519. That primarycaretaking mothers do not seem to suffer especially severely, in absolute or comparative terms, as their children grow up and leave home might suggest that there would also be little suffering when custody of a younger child is placed in the other parent. Yet several reasons exist why a primary-caretaking mother who did not suffer when her teenager moved away might have suffered greatly if she had lost custody of the same child when the child was much younger. One reason is the greater intensity of the relationship with the child while the child is young. By the time children reach 18 or 19 , most mothers spend little time with them. A second difference is that the act of the older child leaving home is often experienced as a moment of success, as the capstone of successful parenting. By contrast, losing custody of a young child is unlikely to be experienced by a primary-caretaker mother as a fulfilling event. The low degree of distress reported by mothers whose teenagers leave home may, nonetheless, suggest that primary caretakers of adolescents will feel less distress than primary caretakers of younger children on losing custody disputes. 
greater time that the primary caretaker spends with the young child; the special nature of the emotional bond the primary caretaker may have with her child; the fewer sources of satisfaction other than parenting available to most primary caretakers; and the way that primary-caretaking mothers before and after divorce speak of their children as giving purpose to their lives. All of these suggest that the primary caretakers will suffer greater emotional harm than secondary caretakers from loss of custody.

Despite all this, other research on parents, separated and unseparated, suggests indirectly that the experience of being separated from their children may be nearly as traumatic for secondary caretakers as for primary caretakers. We have already discussed the growing evidence that children typically develop strong emotional ties to both parents. ${ }^{265}$ The reverse is also true: many secondary-caretaking fathers, perhaps most, also appear to develop strong emotional ties to their children. Some of the emotions that men feel toward their children are based on a sense of role fulfillment that has little to do with daily contact with the children. ${ }^{266}$ What it means to most men to be a parent may not be the same as what it means to most women. Yet, for many men, the relationships they build with their children around play and shared tasks are almost certainly central to their own emotional well-being and sense of self-worth, even if they spend much less time with their children than mothers. ${ }^{267}$

The ways that secondary-caretaking fathers respond to the loss of daily contact with their children is also revealing. A good deal of research, much of it anecdotal and descriptive rather than statistical, depicts the unhappy position of fathers living without their children in the period after divorce. The portrait of the divorced male as a carefree bachelor is greatly exaggerated. Divorced men, like divorced women, report lower degrees of life satisfaction than men and women who have never married, are currently married, or are widowed. ${ }^{268}$ Like divorced mothers, most divorced fathers report feeling anxious, depressed, angry, rejected, and incompetent during the first year or

265. See notes 211-21 supra and accompanying text.

266. See Fein, Men's Entrance to Parenthood, 25 FAM. Coordinator 341 (1976); Lewis, Freneau \& Roberts, supra note 264.

267. Both men and women report that parenthood and success at parenthood are important to their life satisfaction. For men, jobs and marriage vie with parenthood as sources of satisfaction. For women, parenthood appears somewhat more important than jobs and marriage. See Douvan \& Kulka, The American Family: A Twenty-Year View, in PsYchology AND WoMen: IN Transition 91-92 (J. Gullahorn ed. 1979).

268. See A. Campbell, P. Converse \& W. Rodgers, supra note 233, at 398; Douvan \& Kulka, supra note 267 , at 88. 
two after separation. ${ }^{269}$ They miss the sense of participating in a family. They report lacking a sense of structure in their lives and feelings of rootlessness. ${ }^{270}$

Of course, on this evidence alone, it is impossible to determine how much happier secondary-caretaker men would be if they had custody of their children. What is missing from their lives is not merely their children but their partner of many years and their status as head of an ongoing family. Yet the altered relationship with their children may well contribute significantly to many men's sense of unhappiness. Their new status as visitors to their children might at first blush seem little different from the relationship many of them had with their children while the family was intact. For many divorced men, however, the visiting proves too contrived, too formal, and too strained.271 It is different from the play at home at the end of a day's work while the family lived together. ${ }^{272}$

Moreover, even if more primary-caretaking mothers suffer more upon loss of custody than secondary caretakers do, the period of suffering may typically be of limited duration. Most human beings are resilient. The experience of a woman without her children is likely to be mixed rather than wholly bleak. During marriage, children are both a burden and a pleasure for the full-time caretaker. ${ }^{273}$ The same is true after divorce for women with custody. ${ }^{274}$ Without her children, the divorced primary caretaker loses an activity that has given structure to her life but is suddenly freed of obligations that can interfere with her efforts to establish a career, meet new people, and establish new sexual relationships. ${ }^{275}$ It is possible, though hardly certain, that

269. See Divorced Fathers, supra note 91 , at 426-27.

270. See The Aftermath of Divorce, supra note 91, at 158.

271. See J. WALlerstein \& J. KeLLY, supra note 92, at 123-26.

272. The alarming finding of one researcher shows that roughly half of the children living with their mothers after divorce have not seen their fathers in over a year. See Life Course, supra note 103, at 663 . While the finding suggests that most men care little about contact with their children, a closer look at the research, which also reports that visiting is much more common in the period immediately after separation and declines over time, leaves open the possibility that, for many men, it is largely the visiting relationship (which might be much the same for a former primary caretaker) and not a weakness in the preexisting relationship that leads to the infrequency of contact. On the other hand, the same study also found that noncustodial mothers visited their children more frequently than noncustodial fathers. See note 247 supra.

273. One should hardly need a footnote for this point, but research reveals much ambivalence among full-time caretakers about their lives. See, e.g., J. BERNARD, THE FUTURE of Marriage (2d ed. 1982); G. Gurin, J. Veroff \& S. Feld, Americans View Their Mental HEALTH 129 (1960) (women more likely than men to cite negative aspects of parenthood); Nye, Adjustment to Children, in THE EMPLOYED MOTHER IN AMERICA 356 (F. Nye ed. 1963) (In a study of over 2,000 working and nonworking mothers, $40 \%$ of homemakers and $28 \%$ of mothers employed outside the home agreed "children made them nervous.").

274. See text at notes 94-101 supra; see also Stress and Coping, supra note 91, at 111-25.

275. Cf. Bloom, Asher \& White, Marital Disruption as a Stressor: A Review and Analysis, 85 
the experience for most primary caretakers without custody of their children is little different from the experience of most secondary-caretaking men today - a year or two of loneliness, depression, and confusion, followed by a new and reasonably satisfying equilibrium.

It is also possible that those secondary-caretaking men who want custody of their children typically have more of an emotional stake in their relationship with their children than other secondary caretakers. For such secondary caretakers, even if they have full-time jobs outside the home from which they have derived satisfaction, the loss of their children may cast a pall over all other aspects of their lives, including their work, and leave them as bereft of a sense of identity and worth as the loss of the children would to the primary-caretaking parent without any outside employment.

On all the current evidence, it is thus plausible to hypothesize a trauma of comparable magnitude for both primary and secondary caretaker deprived of the custody of children. On the other hand, it is equally plausible, perhaps more plausible, to hypothesize that the trauma for the primary caretaker is typically substantially worse and of longer duration, especially for the primary caretaker who has young children and is not employed outside the home. We simply do not have enough evidence to reach a firm conclusion either way. My own hunch is that, in general, primary caretakers suffer more and for a longer period, but it is only a hunch.

\section{INFormation Bearing ON RULES FoR JoINT Physical CUSTODY}

When divorcing parents agree to cooperate in making important decisions about the child - decisions, for example, about major medical procedures or place of school attendance - they are agreeing to what is commonly called "joint legal custody." When parents go further and agree that the child will maintain a residence with each of them, they are agreeing to "joint physical custody." It is with joint physical custody that I am concerned in this Article. ${ }^{276}$ Joint physical custody takes many forms: most commonly the child spends half of

Psychology BULL. 867, 875-76 (1978) (reviews research suggesting that women without dependent children adjust more quickly after divorce than women with children; the women without children in these studies were not women who lost custody of their children, but were rather childless or mothers of grown children).

276. Joint physical custody is far less common than joint legal custody. See, e.g., W. Phear, J. Beck, B. Hauser, S. Clark \& R. Whitney, An Empirical Study of Custody Agreements: Joint versus Sole Legal Custody, 11 J. of L. \& PsychiaTRY 419, 425 (1983) [hereinafter cited as EMPIRICAL STUDY] (reporting a study of court records in Massachusetts' most populous county, finding joint-legal-custody arrangements in $22 \%$ of cases, but joint physical custody in only $2 \%$ of cases); Weitzman \& Dixon, supra note 29 , at 489,491 (reporting that, in 1972 , only $2.2 \%$ of 
each week or alternate weeks with each parent, but sometimes the child changes homes each month or even every six months. Sometimes the amount of time spent in the two homes is far from equal.277 In fact, the major difference between joint physical custody and singlecustody arrangements with provision for substantial visitation is a phrase in the divorce decree and a state of mind about where "home" is - a state of mind that seems to be meaningful to both adults and children.

Two principal questions need to be answered concerning joint physical custody. The first is whether or not childrens' (or adults') interests will be served when parents voluntarily enter into such arrangements. (The answer to this question might guide courts and legislatures in determining whether or not to encourage such voluntary arrangements either directly or through fostering procedures, such as mediation, that seem likely to lead to negotiated agreements for joint custody.) ${ }^{278}$ The second question is whether and under what circumstances the children's and adult's interests can be served when joint custody is imposed over the objections of either or both parents. Many states now expressly empower their courts to impose such arrangements. ${ }^{279}$

\section{A. What We Know About the Needs of Children}

Much of the research already reviewed in this Article provides a basis for hope that joint physical custody can serve the interests of children better than sole custody, at least when it is voluntarily entered into between the parents. We have seen that infants living with two parents typically form strong attachments to both and that both parents typically play important roles in their children's development. We have also seen that when parents divorce, children grieve for the absent parent and often find the visiting relationship unsatisfactory. ${ }^{280}$

all divorces in San Francisco ended in an award of joint physical custody (0.8\% in Los Angeles), while $16.3 \%$ ended in an award of joint legal custody (2.9\% in Los Angeles)).

It is not fully clear to me why so many parents with physical custody of a child are agreeing, apparently without major concessions from the other parent, to share legal custody of the child. Joint legal custody gives the noncustodial parent an effective veto over important decisions bearing on the child that the custodial parent alone is forced to live with. It is possible that custodial parents foresee, perhaps correctly, that noncustodial parents with joint legal custody will comply more readily with child-support obligations or maintain more regular visitation with the child.

277. The line between joint physical custody and a single-custody arrangement with generous visitation cannot be drawn by reference solely to the amount of time spent in the two homes: some children in single custody spend more time "visiting" with the noncustodial parent than some other children in joint custody spend "living" with one of their parents.

278. See Pearson \& Ring, supra note 129.

279. See Scott \& Derdyn, supra note 3 , at $471-74$.

280. See notes 95, 211-21 supra and accompanying text. 
Joint custody may thus have appeal because it promotes a continuing intimate relationship with both parents. The few studies of sole-custody fathers who had previously been secondary caretakers also suggest that fathers who volunteer for full-time custody are able to attend to the children's physical needs. ${ }^{281}$ They should be no less able to do so on a part-time basis.

On the other hand, some aspects of the same research point in the opposite direction. The fact that children are likely to fare reasonably well with either parent when there is visitation does not necessarily lead to a conclusion that the same children would fare as well living alternately with both parents. While the hope may be that joint custody will foster strong attachment bonds with both parents, the risk is that joint custody will undermine the child's sense of a secure tie to either parent. This fear seems most justified for the infant, who might experience each move from one parent's home to the other as an abandonment by the parent she is leaving. Even the older child may suffer from a more subtle anxiety about his security and his obligations of loyalty. ${ }^{282}$

Caution in endorsing joint custody seems justified. Throughout human history, families in many societies have been nomads, but in few have the children alone been the travellers moving between sets of principal caretakers and in even fewer, if any, have children moved between caretakers who were apart because they had proven unable to live together. Because of this anomalous quality of joint-custody arrangements, research appraising the effects of such arrangements on children should be held to particularly rigorous standards. Unfortunately the available research fails to meet such standards. As with children in the custody of fathers, there are no published studies that have followed children in joint custody over time beginning at the point of separation or divorce. ${ }^{283}$ Nor are there any studies of adults who spent their childhood in joint custody.

What does exist, again similar to the studies of father custody, are six studies, most of them impressionistic, of families in ongoing jointcustody arrangements. ${ }^{284}$ All six suffer from familiar problems. All

281. See note 114 supra and accompanying text.

282. It seems largely on the basis of these sorts of fears that Goldstein, Freud, and Solnit, without drawing on any research about joint custody, reject the idea of imposed joint custody and appear to have doubts about the wisdom of voluntary joint custody as well. See BEYOND THE BEST INTERESTS, supra note 82, at 37-39, 119-20.

283. One promising study is in progress that intends to follow representative samples of children in joint legal and joint physical custody (as well as in sole maternal and sole paternal custody). It is being conducted by Eleanor Maccoby, Robert Mnookin, and Charlene Depner at Stanford University.

284. The most thorough study by far is Steinman, The Experience of Children in a Joint 
drew small, nonrandom samples: the largest in which both parents and children were interviewed was twenty-four families; some had fewer than a dozen families. ${ }^{285}$ Only one included a matching sample of children in sole custody. ${ }^{286}$ Families were selected by means likely to bias the study sample toward contented families. ${ }^{287}$ Most included interviews with the parents only, and only one drew on more than one set of interviews. ${ }^{288}$ In nearly all, the interviews were conducted long after the arrangement had been established, providing few contemporaneous views of difficulties in a period of transition. And, of course, all were unavoidably limited to studying the sorts of joint-custody arrangements that currently exist. They were thus nearly all voluntary arrangements between parents willing to try something out of the ordinary; they involved couples more likely than the average divorcing

Custody Arrangement, 51 AM. J. ORTHOPSYCHIATRY 403 (1981) [hereinafter cited as Experience of Children]; S. Steinman, The Parental Experience of Joint Custody: A Report of a Study (1982) (unpublished manuscript) [hereinafter cited as Parental Experience]. Some of her findings are recounted in a recent law review article. See Steinman, Joint Custody: What We Know, What We Have Yet to Learn, and the Judicial and Legislative Implications, 16 U.C.D. L. REV. 739 (1983).

The others are D. LUEPNITZ, supra note 108 (18 parents with joint custody compared with 16 single-custody mothers and 16 single-custody fathers); Ahrons, The Coparental Divorce: Preliminary Research Findings and Policy Implications, in JoINT Custody: A HANDBOOK FOR Judges, LAwyers AND Counselors, C1 (Assn. of Family Conciliation Courts 1979) (41 parents with joint custody, unidentifiable proportion with joint legal custody only); Arbarbanel, Shared Parenting After Separation and Divorce: A Study of Joint Custody, 49 AM. J. ORTHOPSYCHIATRY 320 (1979) (only four families); Greif, Fathers, Children and Joint Custody, 49 AM. J. ORTHOPSYCHIATRY 311 (1979) (interviews with 40 divorced fathers, fewer than eight with jointcustody arrangements); $c f$. Keshet \& Rosenthal, Fathering After Marital Separation, 23 Soc. WORK 11 (1978) (study of 128 divorced men with children age seven or younger - although none of the men had sole custody, 10 who were interviewed at greater length took care of their children two or more days each week).

In addition there are several books that include anecdotal information about joint custody or more informal interviews, most of it strongly positive. See, e.g., M. GaLPER, Co-PARENTING: Sharing Your ChIld Equally (1978); M. MORgEnbesser \& N. Nehis, JoINT CuSTODY: AN Alternative for DIVORCINg Families (1981); M. RoMAN \& W. HADDAD, The DisPosable Parent (1978); C. Ware, Sharing Parenting After Divorce: AN Enlightened Custody GuIDE FOR MOTHERS, FATHERS, AND KIDS (1982).

Two studies of court records that include no interviews with parents or children also exist. One sought simply to learn whether or not parents in joint custody returned to court after divorce as frequently as parents in single custody, viewing returns to court as a sign of stress. See Ilfield, Ilfield \& Alexander, Does Joint Custody Work? A First Look at Outcome Data of Relitigation, 139 AM. J. PsYCHIATRY 62 (1983). The authors found that joint-custody parents returned only half as frequently. Unfortunately, the study mixes parents with joint legal custody with parents with joint physical custody, and thus its utility for our purposes is greatly reduced. In the other study, the children in joint custody were overwhelmingly in joint legal custody, not joint physical custody. See EMPIRICAL STuDY, supra note 276, at 425 . Unlike Ilfield, the Phear Study found that parents with joint legal custody returned to court as frequently as parents with sole custody. $I d$. at 432 .

285. E.g., the studies of Arbarbanel and Greif.

286. Luepnitz, supra note 284.

287. Families were found not through random sampling of court records but through other means, such as newspaper advertisements.

288. Experience of Children, supra note 284. 
couple to have only one child, and the one child was typically at least of nursery-school age when the arrangement was entered. Sadly, for our purposes, the available research provides almost no insights into families with joint custody imposed by a court, few glimpses of very young children, and few glimpses of families whose joint-custody arrangements have broken down in the first few years.

Despite these defects, there is a uniformity among the findings of these studies that makes them at least worth reporting, just as the father-custody studies seem worth reporting. For even the studies conducted by persons who do not seem biased in favor of joint custody are reporting that, at least in the short run, children in voluntary joint custody seem to be faring about as well as - and in some ways, probably better than - children in sole custody.

Of the six studies, the most thorough and balanced is that of Susan Steinman, who has been following twenty-four joint-custody families in California. ${ }^{289}$ In most respects it agrees with the finding of the other, more impressionistic, studies. She conducted two interviews each with the parents and children and then reinterviewed the families a year to eighteen months later. At the time of the first interview, the families had already shared their arrangements for two to nine years. Although Steinman's sample suffers from the same problem of nonrandomness of most other studies of families after divorce (her sample came from personal referrals and newspaper advertisements), she nonetheless provides valuable insights into the lives of a group of families who have been choosing joint physical custodial arrangements and sticking with them over an extended period.

Steinman found that the children she studied were attached to and strongly loyal to both their parents. She also found that the parents shared a strong ideological commitment to joint custody and were respectful of each other as parents and tolerant of their differences in childrearing practices, even though they typically did not get along well with each other as individuals. The children knew well and had generally adjusted comfortably to the differences between their parents. Steinman found none of the sort of grieving for an absent parent that Wallerstein and Kelly found in their study of children in the custody of their mothers. 290

289. See Experience of Children, supra note 284; Parental Experience, supra note 284. At the time of her first interviews in 1978, the combined incomes of the parents averaged about $\$ 16,000$. The 32 children in the 24 families ranged in age from 4 to 15 years. Three-quarters of her children either split their weeks or alternated weeks between the parents. See Experience of Children, supra note 284 , at $403,406-08$.

290. See discussion of Wallerstein and Kelly's research, beginning in the text at note 92 supra. 
On the other hand, the families were not without problems. Nearly all the children appreciated their access to both parents and the sense that both parents loved and wanted them, but many criticized the inconvenience of going back and forth. Some seemed also to feel a need to be "hyper-loyal" to both parents, to make certain that they treated them with absolute equality. In her conclusions on the basis of the first sets of interviews, she found that about one-third of the children suffered some unhappinesss and confusion and "felt overburdened by the demands and requirements of maintaining a strong presence in two homes."291 She concluded tentatively that the critical factors in the success of joint custody were the parents' shared commitment to make the arrangement work and their day-to-day behavior. ${ }^{292}$

When Steinman reinterviewed the same families later, 293 she found, to her surprise, that although the joint arrangements had all been in place for at least two years at the time of the first interview, by the second interview a year to eighteen months later, a third of the families had made major changes in their custodial arrangements. 294 The most frequent reason was a change in one of the parents' living situations - most commonly, remarriage or a move to a new city or both. Steinman does not report on whether or not children in families in which there had been a move or remarriage seemed adversely affected by the change; and, of course, she could not have determined, even if she had tried, whether any harms to the child that had occurred were greater than those that would have occurred if one of the parents had obtained sole custody at the point of the original separation.

Steinman's belief that some children in joint custody will suffer problems that are created or exacerbated by the joint custodial ar. rangements seems plausible. But we have already seen that children in sole-custody settings with their mothers also display recurrent problems that appear to relate to that form of custody. ${ }^{295}$ Wholly undetermined yet is whether certain children are simply likely to suffer more after divorce than other children regardless of the custodial ar-

291. Experience of Children, supra note 284, at 414.

292. See id.

293. See Parental Experience, supra note 284.

294. Compare a study of two-parent families in Australia in which parents shared caregiving, but in which half the families had changed their arrangements when the author followed up two years later. See Russell, Shared-Caregiving Families: An Australian Study, in NoNTRADITIONAL Families: Parenting and Childrearing 139 (M. Lamb ed. 1983).

295. E.g., mouming for the loss of one parent, disciplinary difficulties that may relate to not having two adults to back each other up, financial problems that cast a pall over much of their lives. See notes 92-105 supra and accompanying text. 
rangement, with the suffering simply manifesting itself in different ways depending on the custodial arrangement, or whether certain children, because of their family situation or personal characteristics, will encounter fewer problems in one form of custody than another. ${ }^{296}$

In a thorough review of the research bearing on joint custody, Clingempeel and Reppucci, ${ }^{297}$ writing shortly before Steinman, found the information on children actually in joint custody so thin that they relied largely on the sorts of indirect evidence from research on ongoing families that I used earlier to discuss fathers and primary caretakers. Clingempeel and Reppucci identified a wide range of factors including the remarriage of the parents, that they thought were likely to affect the success of joint custodial arrangements, none of which had been adequately studied. 298

For our purposes, there are two extremely serious gaps in the research on joint custody. The first is the absence of studies of children who have lived in joint custodial arrangements that have been terminated. Steinman's research suggests that the incidence of voluntary termination may be very high. The other gap, perhaps even more serious for those trying to frame recommendations for public policy, is the absence of studies of children in joint-custody arrangements that have been imposed by courts over the objections of one or both parents (or arrangements "voluntarily" entered into under pressure by a parent who wanted sole custody but feared that a court would award custody to the other parent or impose joint custody). ${ }^{299}$

296. Steinman believed that for the one-third of her subject children who seemed troubled, the joint "arrangement did not help them and may have added to their burden." See Experience of Children, supra note 284, at 414. Such a conclusion seems impossible to sustain in light of the sparse data directly comparing children in single and joint custody - as unsustainable as the conclusion that the other two-thirds of children were helped by the joint arrangement. See Kelly, Further Observations on Joint Custody, 16 U.C.D. L. REv. 762, 763-64 (1983) (pointing out that roughly one-third of the children in her study (with Wallerstein) of children with mothers were poorly adjusted at the five-year follow-up and that "either form of custody may create or consolidate adjustment problems"). Moreover, even if the same child is likely to encounter different problems in the two settings, the question remains whether or not the problems in one are likely to be as severe as the problems in the other.

297. Clingempeel \& Reppucci, supra note 25.

298. They grouped the factors into three sets. The first, centering around the divorced family itself, included the quality of the preexisting dyad relationships (mother-child, father-child, mother-father), the mechanics of the joint-custody plan, the similarity or dissimilarities of the two home environments, the characteristics of the child (age, temperament), and the socialdemographic characteristics of the family. Id. at 105-16. The second, centering around the family's social system, included jobs, schools, and informal social networks. Id. at 117-18. The third, which they call the "family life cycle," focuses on the recoupling or remarrying of the two parents. Id. at 118-23. Clingempeel and Reppucci were especially concerned about the potential impact on children in joint custody of the remarriages of their parents. Steinman's later reported finding of the frequent voluntary termination of joint-custody arrangements after remarriages suggests the need for pursuing this factor.

299. Of course, it is not surprising that there are no studies, because until recently courts 
There is good reason to fear for the experience of children in such compelled or pressured arrangements. Voluntary joint custody seems to work most satisfactorily to the parents and child when the parents are tolerant and resilient and when the children are not allowed to play one parent off against the other. ${ }^{300}$ The satisfying psychologicalparent relationship maintained by the child with each parent apparently experienced by many children today in voluntary joint-custody relationships is likely to be much less commonly experienced by children in court-compelled arrangements if the parents are hostile to each other and the court and try to undercut the child's relationship with the other parent. Research in other contexts suggests, not surprisingly, that stress can impair the apparent security of the attachment between a child and his parents even in a family with both parents living together. ${ }^{301}$ Furthermore, a principal difficulty in some voluntary joint-custody arrangements observed by Steinman - that even when parents cooperate, some children are anxious about treating each parent absolutely equally - seems likely to be even more frequently a problem in imposed joint-custody arrangements.

We must nonetheless be cautious in making apocalyptic predictions for imposed joint custody. Although published accounts of arrangements imposed by courts or entered into under pressure are not at all encouraging, ${ }^{302}$ we must remember the alternatives. In singlecustody arrangements, visitation will almost invariably be imposed, and visitation arrangements can lead to two different sets of problems for children, each potentially as upsetting to them as rancorous joint

rarely imposed joint custody. Two studies are being conducted now that include (or will include) families with imposed arrangements. One, by Steinman, draws on a sample referred to a clinic and is nearing completion. See S. Steinman, A Summary of Joint Custody Research: Some Preliminary Impressions from the Joint Custody Project (March 1984) (memorandum describing project prepared for a conference sponsored by the Women's Legal Defense Fund, Racine, Wisconsin). The other project, just getting started, is that of Robert Mnookin, Eleanor Maccoby, and Charlene Depner at Stanford University.

300. See Joint Custody, supra note 284, at 745-49; Experience of Children, supra note 284; see also Benedek \& Benedek, Joint Custody: Solution or Illusion?, 136 AM. J. PsYchiATRY 1540, 1543 (1979).

301. See Lamb, Thompson, Gardner, Charnov \& Estes, supra note 26, at 12-14.

302. In a very preliminary report of her newest study Steinman, supra note 299, reports on 10 families whose joint physical custodial arrangement had been imposed by the court or recommended by a court mediator prior to referral to her project for counselling and who were unable to work out their problems through her project. In all, the parents had been following a joint custodial plan but were unable to cooperate. Ten of the 15 children in these families were showing "major signs of emotional and behavioral problems," and the parents were unable to decide jointly, in most cases, how to help the child with these problems. Because the study is based on samples of families referred for counselling, there is no way of knowing how representative the families are among families with imposed joint custody. See also D. LEUPNITZ, supra note 108, at 49-51 (describing one case in which joint custody had been imposed by a court; the parents fought constantly and the children, who were 11 and 12 , showed "clear maladjustment" and yet both children said they preferred joint custody to either possible single-custody arrangement). 
custody. The first is that the parents often fight over the weekly details of visitation in much the same way that they might fight over the weekly arrangements of joint custody, so that the experience for the child would be closely similar in joint or sole custody. The other is that the incidence of visitation between the noncustodial parent and the child declines over time or even ceases; for the child, a rocky life in joint custody might be preferable to a lonely life in sole custody.

\section{B. What We Know About the Needs of Parents}

Will the total satisfaction for both parents in a joint-physical-custody arrangement commonly be greater than the total satisfaction of the two parents in either single-custody arrangement? ${ }^{303}$

As before, this question looks very different depending on whether the context is a voluntary or imposed arrangement. Looked at solely from the point of view of the parents' own satisfaction, it is plain that many adults are finding voluntary joint-custody arrangements satisfying. ${ }^{304}$ For the parent who would otherwise have had sole custody, joint custody permits time off for other activities and a sharing of the responsibilities for the child. Few parents with joint arrangements report that they have a less satisfying relationship with their child than they believe they would have had with single custody, though some do report that they regret missing out on events that occur at the other home. ${ }^{305}$

For the parent who would otherwise have had a visiting relationship, usually the father, the commonly reported benefits are even more substantial when compared to what the situation would have been in a visitor relationship. ${ }^{306}$ Indeed, many fathers report closer relationships with their children than they had as secondary caretakers before separation. To be sure, both parents report some difficulties and disadvantages: the logistics of joint custody can be annoying and the costs of maintaining full residences for the child in two homes can be

303. For earlier discussions of why the interests of parents can be relevant to the framing of rules, see notes 63-82 supra and accompanying text. Of course, the question posed in the text is unanswerable given the difficulties of defining and measuring satisfaction in this context.

304. With the two noted exceptions, see note 302 supra, all of the studies listed in note 284 supra included interviews with parents in voluntary joint-custody arrangements.

305. See Parental Experience, supra note 284; see also Joint Custody, supra note 284, at 74344 (describing the advantages and disadvantages for the parents).

306. We have already discussed the large number of fathers who experience a deep sense of loss when separated from their children by a traditional custodial arrangement and find the visiting relationship unsatisfying. They no longer feel part of a "family." Joint custody permits each parent to continue to experience participation in a "family" unit. See notes 268-72 supra and accompanying text. 
burdensome. ${ }^{307}$ But for large numbers of couples who have actually tried joint custody, the advantages seem substantial. That many choose to stick with the agreements for several years is some evidence that it works for them.

The problem with relying on all this enthusiasm reported in studies is again that none of the available research reports on voluntary joint custodial arrangements that have ended because of the dissatisfaction of the child or one or both parents. We do not have information on the proportion of voluntary arrangements that survive over time, let alone on what distinguishes those that survive from those that do not. We also do not know whether parents who terminate voluntary arrangements feel that their relationship with the child has been damaged and that the relationship would have been better if sole custody had been adopted from the outset.

Even if we assume that joint custody is likely to receive reasonably high marks from parents who embark on it voluntarily, it does not follow that parents will give even passing marks to joint custody imposed by a court. It seems likely that such coerced relationships will typically prove unsatisfying to all parties, even the parent who requested it. Joint custody offers even more opportunities than single custody for an angry parent to make life difficult for the other parent and for a parent who cannot accept the idea of the divorce to try fumblingly to get back together with a former spouse who is wholly uninterested in reconciling. Imposed joint custody might create a high level of tension between the parents, which might harm the relationship between one or both parents and the child. These discouraging guesses about compelled joint custody are plausible, but it is unfortunately the case that there are no available studies on the consequences of imposed joint custody for either parents or children.

\section{New SUbStantive Standards For the RESOlution of CUSTODY DISPUTES}

\section{A. Rules for Sole Custody}

The goal of the review of research was to determine whether an empirical foundation could be constructed for new rules of decision in custody disputes. Because of the difficulties posed for courts under the open best-interests standard used in most states today, my hope was to

307. Some women's groups, once supporters of joint custody, now oppose it, in part on these financial grounds and in part on the related ground of men's use of joint custodial arrangements to secure a reduction in the amount of child support that would otherwise be ordered. See Schulman, Who is Looking After the Children?, 5 FAM. ADvocATE, Fall 1982, at 31, 36. 
find some factor readily identifiable in all or most cases that could offer a solid basis for an evidentiary preference - a rule that the parent with that quality (or that relationship to the child) would receive custody unless the other parent demonstrated by evidence of some prescribed weight that the child's interests would be better served by a different placement. In order to merit recommendation, however, any such rule of decision ought to meet a fairly exacting standard. To be acceptable, it ought to help courts or parents reach, in the majority of cases, better results than are reached under the current case-by-case approach or results that are as often as good with fewer harmful transactional costs (such as protracted litigation or embittered litigants). A rule produces "better results" if it increases the probability that children will be placed with the parent who better serves their interests, in whatever manner the state defines children's interests. In the alternative, under the analysis of this Article, a rule also produces "better results" if it creates at least as high a probability of a placement that serves the child's interests coupled with a greater probability that placement will be with the parent more likely to suffer emotionally from separation from the child.

Because we do not, perhaps cannot, know how good the results are that are reached in contested cases under the current case-by-case system, it is in one sense impossible to know if some new preference would lead to better results. On the other hand, because of the many ways in which court determinations under the current rules are likely to be unreliable, ${ }^{308}$ if there is a sound basis for believing that any general rule will produce better outcomes than random assignment, such a rule has a plausible foundation.

Having completed the review, I now believe that no new or revived presumptions based on gender or primary-caretaker status can meet this standard on the basis of the existing empirical studies standing alone. There is simply not enough hard evidence that children in general are better off with women, primary caretakers, or the parent of the same sex than with the opposite parent. However, the state of evidence with regard to the three factors is not identical, and one of them, primary-caretaker status, may still warrant some sort of preference, when developmental theory and the practical values that a preference can serve are taken into account.

With regard to gender, my review has revealed that there is some evidence that men in general respond to children differently than women in general. On the other hand, there is no basis for concluding 
that women are substantially more likely than men to possess traits better suiting them for childcare, just because they are women, at least when the man and woman are parents of the child at issue and both have expressed a desire to care for the child. ${ }^{309}$

With regard to placing children with the parent of the same gender, psychological theory does suggest that children are likely to feel a special affinity with the parent of the same sex and one of the few studies ever conducted that sought to compare children in the custody of mothers with children in the custody of fathers, found that those with the same-sex parent were more secure, happier, and had higher self-esteem than those with the parent of the opposite sex. ${ }^{310}$ On the other hand, none of the other studies of children of divorce has reported comparable findings, and the study that did reach these conclusions used a small, nonrandom sample and can at most be regarded as exploratory and suggestive. Based on current knowledge, the most that a judge would be justified in doing is to look for an already existing bond between parent and child that appears to be related to their shared gender.

With regard to primary caretakers, the evidence is of a different order. As we have seen, there are few studies of children of divorce that include children in the custody of parents who were primary caretakers before separation together with children in the custody of parents who were not primary caretakers and no studies that conclude that children seem better off with the parent who had been the primary caretaker. And while there is an enormous body of research documenting the strong bond that develops between infants and primary-caretaking mothers, there is now a growing body of research that suggests that most children form a comparable, though probably not identical, bond with their secondary-caretaking fathers. On the basis of the current empirical research alone, there is thus no solid foundation for concluding that children, even young children, will be typically better off if placed with their primary caretaker. ${ }^{311}$ That is a surprising conclusion, but it is important to note that it is as much a conclusion about the rudimentary state of research on children of divorce as it is a conclusion about the actual quality of parent-child rela-

309. See notes 157-62 supra and accompanying text.

310. See the discussion of the research by Santrock and Warshak, text at note 117 supra.

311. J. Goldstein, A. Freud \& A. Solnit, in their celebrated book BEYOND THE BEST INTERESTS OF THE CHILD, supra note 82, have frequently been misread as suggesting that children can have only one adult to whom they will be strongly attached. That is not in fact the position they espouse. They believe a child typically forms a bond to both parents and would, for example, in divorce custody disputes create no presumption for the parent who has been the primary caretaker. See id. at 100 (Provisions for a Child Placement Statute, para. 30.3). 
tionships. It is equally correct to state that on the basis of current research, there is no solid foundation for concluding that children, and particularly young children, will not be better off if placed with the primary caretaker.

What policy recommendations one makes about primary caretakers may thus depend on what rule it is most reasonable to adopt in the absence of firm evidence either way. This Article has taken the position that the current open standard for resolving custody should not be altered to give weight to any particular factor unless evidence affirmatively suggests that giving such weight will produce better results in the generality of cases. In the absence of such evidence, we should simply call, as scholars often do, for more and better research. Yet a softer form of empirical data - developmental theory resting on nonsystematic clinical observation - may still suggest the wisdom of a preference for placing young children (those between roughly six months and five years) with their primary caretaker.

Although there are no studies focusing on such young children in the custody of parents who had previously been secondary caretakers, there is a large and widely accepted body of writing by developmental psychologists that concludes that there is typically a special attachment between a young child and a primary caretaker and that foresees subtle but significant harms from its breach. Research on the ties of children to secondary caretakers makes clear that such ties are typically stronger than once believed but leaves open the significant possibility that preserving the intimate interaction of the child with the primary caretaker is of greater importance to the child. In this context, in the absense of harder evidence to the contrary, it makes sense to listen to theory.

By much the same token, though there are again no studies measuring and comparing the emotional suffering of parents who are denied custody, my earlier review suggests the probability that primary caretakers will suffer more emotionally than secondary caretakers when shifted into a mere visitor's role. Standing alone, the evidence about the probable harm to primary caretakers is insufficient to justify a preference for them, but the plausibility of such harm and the absence of research suggesting the contrary, provides some reinforcement for legislatures to create an express preference for primary caretakers that is based primarily on the expected benefits to children and secondarily on the expected benefits to primary caretakers.

What form should such a preference take? Under existing legislation, judges would be wise to adopt as a starting point for their thinking about children's "best interests" the premise that children five or 
under should in general remain with their primary caretaker. ${ }^{312}$ Legislatures, drawing on both child's and adult's interests, should create a more formal preference for primary caretakers. They should define the primary caretaker as the parent, if there is one, who has performed a substantial majority of the caregiving tasks for the child that involve intimate interaction with the child. ${ }^{313}$ They could then endow the preference with any of at least three degrees of strength. The strongest rule would mirror the strongest form of the old maternal presumption: the primary caretaker of a young child receives custody unless demonstrated to be "unfit."314 Slightly less strong would be a rule that the primary caretaker receives custody, unless the other parent demonstrates by "clear and convincing evidence" that he or she is the more appropriate custodial parent. Least strong would be a rule that the primary caretaker receives custody, unless the other parent can show, by a preponderance of the evidence, that he or she is the more suitable placement.

The two stronger versions of the rule would probably discourage litigation by giving a clear signal to the parents about the probable outcome of going to court, but both may seem unacceptable on the ground that the empirical evidence supporting a primary-caretaker preference is simply too thin to justify tilting the decision so heavily toward primary caretakers. The evidence is indeed weak, but the degree of strength appropriately attached to a preference turns on more than just the evidence in its support. Once there is some basis for it, the strength of the preference appropriately turns in substantial part on the degree to which tribunals are capable of assessing the evidence in individual cases and reaching sensible decisions. I would reject the "unfit" parent form of the preference not because it is too strong but because it invites focusing on the wrong question - the moral and other qualities of one parent - and not on the parent-child relationship however difficult that relationship is to assess. ${ }^{315}$ On the other

312. A recent article points out that many state appellate courts are now using the term "primary caretaker" and giving weight to that parent in their decisions. See Atkinson, Criteria for Deciding Child Custody in the Trial and Appellate Courts, 18 FAM. L.Q. 1, 16-19 (1984).

313. See note 230 supra and accompanying text.

314. This is the standard that the Supreme Court of West Virginia has adopted in announcing a preference for "primary caretakers." See Garska v. McCoy, 278 S.E.2d 357 (W. Va. 1981).

315. The Supreme Court of West Virginia did define the term "unfit" in a way that appears to reflect concern with the parent's ability to provide the child with emotional support, nourishing food, and clean surroundings. Garska v. McCoy, 278 S.E.2d 357, 362 n.9 (W. Va. 1981). On the other hand, the notion of unfitness focused too frequently on the moral quality of the parent's conduct. Even in Garska, the "unfitness" test excludes any inquiry into the other parent's relationship with the child so long as the primary caretaker is not "unfit." I believe that there are cases in which a primary caretaker would meet the Supreme Court's definition of fitness but the secondary caretaker should not be excluded from consideration. 
hand, I believe that either of the other two standards - the "clearand-convincing evidence" test or the "preponderance" test - would be wholly justifiable.

The "preponderance" test would be more consistent with the modest empirical support for a preference, but it has a great disadvantage. Although it in theory ought to reduce the incidence of litigation by letting one side know it is less likely to win, there is some empirical evidence that in this weak form it is unlikely to have such a deterrent effect. ${ }^{316}$ For this reason, I would recommend to legislatures that they adopt the "clear-and-convincing evidence" test.

To be sure, under either the "preponderance" test or the "clearand-convincing evidence" test, the judge in cases that actually go to trial would still be burdened with making elusive measurements of current parent-child relationships and parenting capabilities in determining whether or not the secondary caretaker has met his or her burden of proof. Nonetheless, even if framed in the weakest form and clearly if framed in terms of "clear and convincing evidence," a new presumption, simply by placing the burden of proof on one party, should nonetheless resolve a large portion of disputes. Whoever bears the burden of proof will be denied custody in those cases, probably substantial in number, in which the judge concludes at the end of all the evidence that she has no strong basis for believing that the children will do better in one setting than the other. It is these cases, if the factual generalization underlying the presumption is sound, that should be resolved more wisely on average with the presumption than without.

There is another sense in which such a presumption may produce "better" results. If it is in fact the case that primary caretakers typically have more at stake than secondary caretakers in the relationships with their children, then primary caretakers, because they care more, are likely to be willing to make more concessions regarding property and financial matters in order to be certain of obtaining custody of their children. ${ }^{317}$ If we believe that the child (unlike a boat or cottage) is not an item that a parent ought to have to make financial concessions to receive, if indeed we want to protect the financial security of the child if the child ends up in the custody of the parent who wanted

316. Consider Weitzman and Dixon's surprising finding that the incidence of custody litigation did not rise in California after its legislature shifted from a weak maternal presumption to a wholly neutral best-interests test. See Weitzman \& Dixon, supra note 29, at 485-92.

317. See Mnookin \& Kornhauser, Bargaining in the Shadow of the Law: The Case of Divorce, 88 YALE L.J. 950, 977-78 (1979). The West Virginia Supreme Court in Garska was especially concerned about the sorts of concessions a primary caretaker might make to receive custody. Garska v. McCoy, 278 S.E.2d 357, 360, 362 (W. Va. 1981). 
her more, then creating a preference for primary caretakers may reduce at least slightly the use by secondary caretakers of the threat of a custody fight for tactical advantage.

The presumption argued for in this section applies only to disputes involving children up to about five years of age. What should courts do in cases of children above that age - or in the cases of families with children both over and under five? Our review found no empirical basis and a much flimsier theoretical basis for a statutory preference applying to such older children based on serving the interests of the child. States might conclude that there were values to children, especially young children, in not being separated from siblings, and expand the preference for placing young children with their primary caretakers to include cases of older children who have young siblings. ${ }^{318}$ For cases in which all the children are roughly between six and twelve, I have no suggestions for a new rule. Courts may simply have to make do with the unweighted "best-interests" test in its current form. ${ }^{319}$ For the oldest children, children twelve or so who have reached adolescence, states might adopt a rule permitting the children to choose for themselves. ${ }^{320}$ Whatever the age of the child, the evidence regarding attachment of children to both parents and of both parents to their children suggests the wisdom of continuing rules that create a strong presumption that noncustodial parents will be permit-

318. I can find no studies of "split custody" - families with more than one child in which at least one child was placed with each parent. Many judges, at least, believe that there is value in keeping siblings together. See Lowery, Child Custody Decisions in Divorce Proceedings: A Survey of Judges, 12 Prof. Psychology 492, 494 (1981).

319. For this group, the open best-interests test is, of course, not much less difficult to apply than it is for the younger group. If courts start approaching the question of children's best interests through the expected experience for the particular child, then the older the child the more the court should be able to learn about what makes the child feel happy or secure. See notes 52-58 supra and accompanying text.

Some would recommend the extension beyond age five of a primary-caretaker presumption as desirable for the interests of the child. See note 202 supra. To my reading, however, both theory and available evidence provide little persuasive support. Some might also extend beyond age five a preference for primary caretakers based on the interests of primary caretakers, but again my own review finds the evidence for comparatively greater emotional harm to primary caretakers denied custody too thin by itself to serve as the basis for a preference for children of any age. See text at notes $244-75$ supra. The most that could be said for extending a weak preference for primary caretakers up to the age of 11 or 12 would be that no better case can be made for any other presumption and that the benefits of creating some presumption (the benefits of reducing litigation and increasing certainty) might well outweigh the harms that would arise from cases in which a secondary caretaker who would better meet the child's needs either does not litigate or improperly loses because of the presumption.

320. See text at note 47 supra. Research on the capacity of children to make various sorts of decisions typically finds chronological age a poor predictor: many 10-year-olds make better decisions than many 12-year-olds. See Greenberg, supra note 47, at 140-44. On the other hand, there are values to both parents and children in clearly determinable general rules, and the only early determinable factor correlating even mildly with decisionmaking maturity is age. 
ted substantial visitation with their children. ${ }^{321}$

\section{B. Rules for Joint Custody}

Within the last few years, over half the states have adopted legislation dealing in some way with joint-custody awards in divorce. ${ }^{322}$ The new laws vary widely, but all were enacted in a context in which legislatures were trying to encourage or even compel the wider use of joint legal and joint physical custody.

The evidence reviewed in this Article suggests that much of the legislators' enthusiasm for joint physical custody is justified. In most unseparated families, children form strong emotional ties to both parents and both parents form ties to their children. Joint physical custody may thus help sustain the emotional ties that run both ways better than single custody even with generous visitation. Consistent with this hope, the few studies of families with voluntarily arranged joint custody report generally high levels of satisfaction both of children and of their parents.

This research, as reviewed earlier, has many methodological limits. Its lessons, to the extent that any lessons can be drawn from it, are clearer for voluntarily agreed joint physical custody than they are for court-imposed arrangements. In voluntary arrangements worked out by the parties, the satisfaction of many parents with joint-custody arrangements is sufficiently widespread that courts should refrain from setting aside parentally chosen joint custodial arrangements, just as they nearly always acquiesce in single-custody arrangements to which parents agree. In fact, legislatures should explicitly deprive courts of the power to disallow joint custodial arrangements voluntarily agreed upon by the parties. My recommendation for limiting court power in this manner does not flow from a belief that parents who choose joint custody will invariably be serving their children's needs, but rather from a belief that courts are rarely in a better position to determine that some other arrangement will be better for the child. ${ }^{323}$ It is only

321. See, e.g., UMDA, supra note 14 , at $\$ 407(a)$.

322. See summary of legislation in Scott \& Derdyn, supra note 3, at 456 n.5. Many legislatures have adopted laws that make it difficult for judges to disapprove voluntary joint-custody arrangements hammered out by the parties. Several legislatures have gone further by explicitly authorizing courts to enter orders of joint custody over the objection of either or both parties. A few have announced a state policy favoring joint custody that can be read as creating a formal legislative presumption for joint custody even in cases in which one or both parents object. Id. at 457 n.9, 471 n.73. Under state statutes that do not impose a preference for joint custody, state appellate units have often held that joint custody should rarely be imposed. See. e.g.. Braiman v. Braiman, 44 N.Y.2d 584, 378 N.E.2d 1019, 407 N.Y.S.2d 449 (1978); In re Marriage of Pool, 118 Ill. App. 1035, 455 N.E.2d 887 (1983).

323. As a general matter of principle (grounded only in part in beliefs about courts capacities), I believe that courts should stay out of decisions both parents make about their children 
as to infants still building attachment bonds with their parents that a joint physical arrangement would appear to pose risks of a sufficient degree that even cooperative parents should generally be discouraged, though not forbidden, from entering into them. ${ }^{324}$

The lessons of current research on the wisdom of permitting courts to impose joint physical custody are harder to draw. In one sense, there are no lessons because no studies have yet been published of imposed joint-custody relationships. Yet even without research that demonstrates how children fare under imposed joint custodial arrangements, I would recommend to legislatures that they act to deprive courts of the power to impose joint custody over the objections of one or both parents. Joint custody seems even more rife than single custody with opportunities for tension and anxiety for the child and for the parent on whom it is imposed, even conceding the difficulties of forced visitation in single-custody arrangements. Moreover, although there may be some cases where parents ordered to participate in a joint-custody arrangement would cooperate to make it succeed, even the best judges will have grave difficulty discerning which cases those are: in court, the parent who does not want joint custody may try nonetheless to appear reasonable in order to bolster his or her case for sole custody; the parent who wishes joint custody may try to seem more reasonable and cooperative than he or she would later be. In this context, judges may be misled about the probabilities of success. Worse, there is something insidiously attractive to judges about imposed joint custody. Because judges find custody disputes between parents painful, imposed joint custody may be too tempting a solution - a way of avoiding the appearance of labelling either parent inade-

except when a strong probability of serious harm to the child can be shown (the sort of standard we would set for intruding on a family on the grounds of abuse). In the context of joint custodial arrangements voluntarily agreed upon by the parties, the likelihood of such severe harms actually accruing is sufficiently slender that $I$ think it is sensible to cut off judicial inquiry altogether.

324. If legislatures wish to encourage voluntary joint-custody arrangements, the recommendation in the preceding section that legislatures create a preference for primary caretakers in disputes over sole custody might, if adopted, serve as a mild deterrent to voluntary joint-custody agreements. It might do so, because primary caretakers who prefer single custody to joint custody would then know more clearly than they do today that they are likely to receive single custody if they press for it and thus be somewhat less likely to agree to a request by the other party for joint custody.

Whether or not such deterrence is unfortunate is uncertain. On the one hand, if one parent in a couple prefers sole custody, that couple may not be as promising a candidate for a joint custodial arrangement as the couple with both parents agreeing on joint custody as their first choice. On the other hand, one of the reasons behind the suggestion of a preference for primary caretakers is to recognize the primary caretaker's emotional stake in the child, and voluntary joint custody might fully preserve the primary caretaker's ties, while preserving much better than a visiting arrangement the emotional ties of the secondary caretaker. 
quate - and judges will blind themselves to signs that the parents are unlikely to cooperate.

A final reason for depriving courts of the power to impose joint custody relates more to the negotiating process between the parties. A parent who is not really interested in having joint custody may use the threat of demanding it as a tool to induce the other parent to make concessions on issues of property division and child support. ${ }^{325}$ If there were good reasons to believe that imposed joint custody would work well for children, this impact on the negotiating process would be worth the risk. Because there are not, the risk is worth avoiding. ${ }^{326}$

Judges today, in states with legislation that appears to create an affirmative legislative preference for joint custody, may feel themselves without power to adopt a flat rule of never imposing joint custody. If they have doubts about imposed joint custody, they will sense an uncomfortable tension, indeed an inconsistency, between the legislature's expression of enthusiasm for joint custody and the legislature's more overarching injunction to resolve each case to serve the best interests of the child. For judges who believe that they must make case-by-case decisions on requests for joint custody, I would suggest that they impose joint custody only when they find that several conditions are met: (1) the child in question is not three years of age or younger; (2) both parents seem reasonably capable of meeting the child's needs for care and guidance; (3) both parents wish to continue their active involvement in raising the child; (4) the parents seem capable of making reasoned decisions together for the benefit of the child and seem reasonably likely to be able to do so even under the coerced circumstances; (5) joint custody would not impose substantial economic hardship on the parent who opposes it; and (6) joint custody would probably disrupt the parent-child relationships less than other custodial alternatives. ${ }^{327}$ I despair of the capacity of anyone, judge or any-

325. Compare the discussion above on the relationship between a preference for primary caretakers and the tactics of negotiation. See note 318 supra and accompanying text. Some critics of joint custody have been particularly concerned about requests for joint custody to obtain tactical advantage. See note 307 supra.

326. How, one might ask, can we ever learn whether imposed joint custody can work well for children if legislatures accept the advice to deny courts the power to impose it? The answer is simply that few states are likely to accept my advice, and researchers should be studying the children living in court-imposed or court-pressured arrangements.

327. I have borrowed most of these criteria from a thoughtful article by Jay Folberg and Marva Graham, who suggest that judges ought in fact to impose joint custody under the circumstances they prescribe. I agree with Folberg and Graham that if all their criteria can be met, the prospects for success in a particular case would be high (almost by definition, given factor (6)). Folberg \& Graham, Joint Custody of Children Following Divorce, 12 U.C.D. L. REV. 523 (1979). Folberg and Graham would have courts order joint custody if "(1) both parents are fit; (2) both parents wish to continue their active involvement in raising the child; (3) both parents are capa- 
one else, to make many of the findings in a reasonably accurate manner. I would thus recommend these criteria only for judges who believe they have no choice but to make case-by-case decisions, but I still recommend, for the several reasons stated above, that legislatures act to remove from judges the power to impose joint custody.

\section{CONCLUSION}

Sometimes you don't know whether to smile or to cry. The current approach states use for resolving custody disputes in divorce - a case-by-case inquiry into the best interests of the child - has many flaws. One has been that neither legislatures nor custom has provided judges with a coherent framework for thinking about what children's interests are. A second, equally serious, has been the inability of judges to make accurate determinations, under the circumstances prevailing in the context of litigation, of the quality of most individual children's relationships with their parents or of parents' skills at childrearing.

This Article has undertaken to define the goals that states should be seeking to serve when resolving custody disputes, arguing for viewing children's interests through the expected experience for the child as the child herself will view it and for expanding the state's goals to accord some subsidiary weight to the interests of parents. With these goals in mind, it then sought to identify some factors that might so regularly advance children's interests (or both children's and one parent's interests) that legislatures might wisely create new general presumptions and thus reduce to some degree the difficulties courts face in making case-by-case determinations. To this end, this Article reviewed available research to learn whether or not it supported judicial preferences for joint custody, for mothers, for parents of the same sex as the child, and for primary caretakers. Perhaps all of these should have been recognized as unpromising from the outset, but, with the exception of letting the children choose for themselves, they were about the only considerations that could provide the basis for rules that would apply in all or nearly all cases. In any event, the inquiry largely failed to unearth sturdy empirical support for new rules. At most it offers a weak but defensible basis for a preference for primary caretakers for children five and under and a basis for encouraging wholly voluntary joint-custody arrangements.

Yet our inquiry can still provide a basis for some wan smiles. One

ble of making reasoned decisions together in the best interests of the child; and (4) joint custody would disrupt the parent-child relationship less than other custodial alternatives." Id. at 579. 
reason why case-by-case inquiries are difficult and one reason why it is difficult to commend new preferences is that, as recent research has confirmed, in most families both parents develop strong ties to their children, ties important to the child and to the parents, and either parent seems likely to do a reasonably competent job of childrearing. Thus the urgency for new rules may be less than we suggested at the beginning. Courts may lack bases for principled choices but even their "bad" choices may still usually turn out reasonably well for children.

The smile is still a weak one. Litigation imposes heavy emotional and financial costs on families. Unlike most other forms of litigation the parties to this dispute generally continue to deal with each other after it is over: the "loser" is entitled to visitation over a long period of years. Parents who fight through an angry trial are likely to poison even the good aspects of their prior relationship. If parents viewed trial judges' decisions as the voice of the oracle - right merely because it was uttered by a sacred voice - it would make little difference if judges had principled bases for making choices. In this country, however, the losing parent is likely to condemn the judge's decision as stigmatizing, discriminatory, and arbitrary.

What this suggests in the end is the continuing need to search for alternatives to litigation, for ways to help parents resolve these cases for themselves. Encouraging forms of negotiation likely to lead to voluntary resolution rather than trial and providing mediation services are each attractive possibilities, though each has its own possible adverse costs. In the meantime, a preference for primary caretakers in cases of young children seems at least a modestly better rule for resolving disputed cases than the current open standard. 